https://helda.helsinki.fi

Counteracting age-related VEGF signaling insufficiency promotes healthy aging and extends life span

Grunewald, M.

2021-07-30

Grunewald, M , Kumar , S , Sharife , H , Volinsky , E , Gileles-Hillel , A , Licht , T , Permyakova , A , Hinden , L , Azar , S , Friedmann , Y, Kupetz , P , Tzuberi , R , Anisimov , A , Alitalo , K, Horwitz, M , Leebhoff , S, Khoma, O Z, Hlushchuk, R, Djonov, V G, Abramovitch , R , Tam , J \& Keshet, E 2021, ' Counteracting age-related VEGF signaling insufficiency promotes healthy aging and extends life span ', Science , vol. 373 , no. 6554 , pp. 533-+ . https://doi.org/10.1126/science.abc8479

http://hdl.handle.net/10138/336456

https://doi.org/10.1126/science.abc8479

acceptedVersion

Downloaded from Helda, University of Helsinki institutional repository.

This is an electronic reprint of the original article.

This reprint may differ from the original in pagination and typographic detail.

Please cite the original version. 


\section{Counteracting age-related VEGF signaling insufficiency promotes healthy aging and extends lifespan}

Authors: The author list should be one single paragraph (no breaks). Authors should be listed by given name or initial followed by family name and separated by commas. Use superscript numbers to link affiliations and symbols (e.g., $* \dagger+$ ) for author notes (see below).

M. Grunewald ${ }^{1 *}$, S. Kumar ${ }^{1 \dagger}$, H. Sharife ${ }^{1 \dagger}$, E. Volinski ${ }^{1 \dagger}$, A. Gileles-Hillel ${ }^{1,3,7}$, T. Licht ${ }^{1}$, A. Permyakova ${ }^{2}$, D. Maimon ${ }^{3}$, L. Hinden ${ }^{2}$, S. Azar ${ }^{2}$, Y. Friedman ${ }^{4}$, P. Kupetz ${ }^{1}$, R. Tsuberi ${ }^{1}$, T. Oliven ${ }^{1}$, A. Anisimov ${ }^{5}$, K. Alitalo ${ }^{5}$, M. Horwitz ${ }^{1}$, S. Leebhoff ${ }^{1}$, O.Z. Khoma ${ }^{6}$, R. Hlushchuk $^{6}$, V. Djonov ${ }^{6}$, R. Abramovitch ${ }^{3}$, J. Tam $^{2}$ and E. Keshet ${ }^{1 *}$.

\section{Affiliations:}

${ }^{1}$ Faculty of Medicine, The Hebrew University- Hadassah Medical School, Jerusalem, Israel.

${ }^{2}$ Obesity and Metabolism Laboratory, Institute for Drug Research, School of Pharmacy, Faculty of Medicine, The Hebrew University, Jerusalem, Israel.

${ }^{3}$ Wohl Institute for Translational Medicine and the Goldyne Savad Institute for Gene Therapy, Hadassah Hospital, Jerusalem, Israel.

${ }^{4}$ Bio-Imaging Unit, The Alexander Silberman Institute of Life Sciences, The Hebrew University, Jerusalem, Israel.

${ }^{5}$ Translational Cancer Biology Program, Research Programs Unit, Faculty of Medicine, University of Helsinki, Finland.

${ }^{6}$ Topographic and Clinical Anatomy, Institute of Anatomy, University of Bern, Switzerland.

${ }^{7}$ Pediatric Pulmonology and Sleep Unit, Department of Pediatrics, Hadassah Medical Center, Jerusalem, Israel.

*Corresponding authors: : myriamg@ekmd.huji.ac.il; elik@ekmd.huji.ac.il.

$\dagger$ Equal contribution 


\begin{abstract}
:
Aging is an established risk factor for vascular diseases but vascular aging contribution to progressive deterioration of organs function is underappreciated. Here we show that vascular endothelial growth factor (VEGF) signaling insufficiency in aged mice, due to increased production of decoy receptors, is a hierarchally high driver of physiological aging at large. Securing adequate VEGF signaling, via a compensatory increase of circulating VEGF levels, prevents age-associated capillary loss and improves organ perfusion and function, culminating in lifespan extension. Healthier aging was evidenced by favorable metabolism and body composition and amelioration of aging-associated pathologies including hepatic steatosis, sarcopenia, osteoporosis, inflammaging and increased tumor burden. These results place VEGF signaling insufficiency center-stage to organ aging and suggest its undoing as a yet uncharted modality for holistic geroprotection.
\end{abstract}

One Sentence Summary: Preventing age-associated deterioration of vascular function confers holistic geroprotection 


\section{Main Text:}

The vascular system is the largest bodily cellular network shared by all organs and, like other organ systems, blood vessels (BVs) undergo aging associated with reduced functionality (1). All cells in our body depend on BVs, not only for provision of oxygen and other blood-borne substances and for waste removal, but also for provision of paracrinicallyacting angiocrine factors elaborated by endothelial cells (ECs) and shown to be required for organ homeostasis (2). Correspondingly, age-related loss of vascular function is bound to greatly impact organ physiology, prompting the proposition that vascular aging is a hierarchally high driver of physiological aging at large. Yet, experimental proof for a 'vascular theory of aging' (3) is still limited.

Pathologies affecting macro-vessels, which include arterial stiffening, atherosclerosis and other vascular occlusive events, lead to a host of cardiovascular diseases (CVDs) whose prevalence increases with age (4). The most dramatic age-related process affecting microvessels in all organs and shown to accompany multiple age-associated pathologies is progressive failure to maintain adequate microvascular density (MVD), a phenomenon known as microvascular rarefaction $(1,5)$. Currently, alleviation of age-associated pathologies other than 'classical' CVDs by vascular manipulation in animal models has been reported in a limited number of studies. Notable cases are: improved osteogenesis via endothelium-specific Notch manipulation (6), amelioration of insulin resistance via endothelium-specific NF-kB blockade (7), improved muscular endurance and neurovascular function via boosting $\mathrm{NAD}^{+}$levels in the body $(8,9)$ and improved age- related brain endothelial cells changes by young plasma infusions (10). Conversely, premature induction of endothelial cells dysfunction in mice has been recently shown to impair systemic metabolic health (11). 
Vascular endothelial growth factor (VEGF) is a highly pleiotropic growth factor possessing both vascular and non-vascular functions (12). In addition to its acclaimed angiogenic activity, VEGF also plays essential roles in controlling vascular permeability (13), in sustaining survival of newly-formed blood BVs (14), in maintaining organ-specific vascular traits such as formation and maintenance of capillary fenestrations and other EC barrier functions $(15,16)$, as well as in induction of certain organ-specific angiocrine factors (2). Furthermore, cognate VEGF receptors are also expressed in non-vascular cells indicating responsiveness to VEGF signaling. VEGF is expressed in many adult tissues and its receptors are constitutively phosphorylated suggesting active signaling (17). Importantly, by virtue of its hypoxia-inducibility (18), VEGF constantly acts in matching microvascular density to changes in tissue needs and is, in fact, irreplaceable in this capacity (19). The proposition addressed herein that VEGF signaling impairment underlines age-associated organ dysfunction is also supported by our previous finding that age-dependent decline of hippocampal neurogenesis can be overridden by conditional brain-specific VEGF induction (20), and findings by others showing that age-dependent impairment of liver regeneration (21) and of skeletal muscle exercise capacity (8) can be alleviated by improved VEGF signaling.

\section{A mild increase in circulating VEGF levels rectifies age-related VEGF signaling insufficiency, prevents microvascular rarefaction and improves tissue perfusion and oxygenation.}

On the premise that apparent failure to maintain adequate MVD in aging is due to insufficient VEGF signaling (22-24), we examined whether securing a young-like level of VEGF signaling via compensatory, mild increase of systemic VEGF levels might prevent 
microvascular rarefaction and its adverse sequelae. To this end, a bi-transgenic mouse platform was used in which transgenic VEGF produced by hepatocytes is continuously released into the systemic circulation and is accessible to all peripheral tissues (see 'Methods' for description of the 'Tet-off' system used). Importantly, circulating VEGF levels in these mice (designated 'VEGF mice') were such that from early/mid adulthood and throughout their lifespan, they are only twofold higher than the physiological, homeostatic levels of circulatory VEGF (Fig.1A-males and Fig.S1-females). All measurements and phenotypes reported below are based on pairwise comparisons of VEGF mice and littermate controls maintained under identical conditions. Serving as controls were littermates who have inherited only one of the two transgenes (both the driver- and the VEGF responder transgenes are required for transgenic VEGF induction), thereby arguing against possible influences exerted by transgene integration sites. This concern was further ruled-out by using an Adeno Associated Virus mediated, non-transgenic platform, pre-tuned for production of comparable elevated levels of circulating VEGF (to be shown below).

In naïve mice, systemic VEGF levels, as well as VEGF levels in major peripheral organs (Fig. S2) did not appear to be significantly decreased with age (except for the kidney and brown adipose tissue). To examine the status of VEGF signaling in aging, we measured relative levels of VEGF receptor 2 (VEGFR2) phosphorylation on tyrosine 1175, a site shown to be essential for VEGF-promoted EC proliferation (25). VEGF signaling was found to be greatly compromised in old control mice but not in old VEGF mice who maintained a younglike level of VEGFR2 phosphorylation, not only in the liver (the organ from which transgenic VEGF emanates) but also in remote organs represented here by hind limb muscle (Fig.1B). In search for a mechanism that might explain the apparent discordance between VEGF levels and VEGF signaling levels in aging, we examined the proposition of VEGF trapping by 
natural decoy receptors, specifically its sequestration by soluble VEGF receptor 1 (sFlt1) (26). Longitudinal monitoring of sFlt1 indeed revealed its progressive buildup in plasma such that already by 1 year of age, levels of sFlt1 were 2 -fold higher than during early adulthood and were perceptually further increased towards reaching 2 years of age (Fig.1C). Ageassociated increase of sFlt1 expression in aorta, liver central veins and sinusoidal ECs and muscle capillaries were identified as the major, albeit not exclusive sources of circulatory sFlt1 (Fig. 1D). Examination of age-associated changes in tissue VEGFR1 mRNA (standardized to levels of the pan-endothelial marker VE-Cadherin (CDH5) mRNA) revealed no significant change in mRNA expression of the full length receptor (Fig. S3). Rather, there is a clear age-associated shift in alternative splicing towards increased sFlt1 mRNA production on the expense of mRNA encoding the full-length receptor (Fig. 1E).

To prove a causal relationship between excessive sFlt1 production and reduced VEGF signaling, sFlt1 was conditionally induced in a bi-transgenic 'Tet-off' system composed of a VE-Cadherin driver transgene and a sFlt1 responder transgene (mice designated as "sFlt1 mice"). Earlier accumulation of sFlt1 in adult mice to levels comparable to those detected naturally in older mice (Fig. S4) indeed resulted in further reduction of VEGF signaling in liver and hind limb muscle (Fig. 1F) and to premature development of the aging phenotypes to be described below.

Next, we compared microvascular densities in multiple organs of young, old, and old VEGF mice by direct visualization of immunostained blood vessels in tissue sections and, independently, by flow-cytometry-aided ECs quantification. Results confirmed a substantial microvascular rarefaction in all organs of 24 months old mice examined, including in liver, muscle, brown and white adipose tissues. In contrast, microvascular rarefaction was almost fully prevented in age-matched VEGF mice (Fig.1G and see Fig.S5 for representative 
immunostained tissue sections). Conversely, experimental VEGF blockade via conditional sFlt1 induction initiated at the age of 6 months led to accelerated capillary loss which was clearly evidenced already at the age of 16 months, thus reinforcing a requirement for ongoing VEGF signaling for microvascular maintenance (Fig. 1H).

Because physical regression of capillaries is often preceded by flow cessation due to adverse alterations taking place further upstream in the vascular tree, we wished to also follow ageassociated changes in perfusion. Luminal surfaces of perfused BVs were, therefore, selectively tagged by intravenous-injected fluorescently labeled VE-Cadherin antibodies and subsequently visualized in tissue sections. A marked perfusion deficit was already observed in 16 months old control mice but not in age-matched VEGF mice who maintained a younglike level of perfusion (Fig. 1I see Fig. S6 for representative images of muscle and liver perfusion). To determine whether, and to what extent compromised perfusion and its VEGFaided amelioration are functionally manifested by degree of tissue oxygenation, ultrasound measurements combined with photoacoustic imaging were used. Results revealed that the severe reduction in hind limb muscle oxygenation observed in 24 months old mice did not take place in age- matched VEGF mice (Fig. 1J).

\section{VEGF treated mice have an extended lifespan and favorable metabolism and body}

\section{composition.}

Lifespan measurements carried-out on multiple mice cohorts in the course of 4 years showed that VEGF mice of both genders have an extended median survival and a greater maximal lifespan as compared to their control littermates (Fig.2A) (see table $\mathbf{S 1}$ and $\mathbf{S 2}$ for a litter-by-litter account of mice used, including censored mice and tables S3 and S4 for

circulating VEGF levels in individual mice). Noteworthy, median lifespan of the control mice used (originating from BALB/cOlaHsd and C57BL/6J crossing, see Methods for details) was 
relatively shorter than other $\mathrm{C} 57 \mathrm{BL} / 6 \mathrm{~J}$-based strains. To rule-out that lifespan of control mice might have been affected by the presence of one or the other transgenes, survival curves were separately constructed for mice harboring either the driver transgene or the responder transgene. As seen in Fig. 2A, there was no difference in median lifespan between the two control subgroups.

Apparent variability in circulating VEGF levels among mice within the control group allowed examining whether a naturally higher VEGF level correlates with increased longevity. Retrospective comparison of circulating VEGF levels in control mice living up to 24 months and control mice living beyond 24 months (designated "short-lived" and "long-lived" mice) revealed that the latter group have had a slightly, but significantly higher levels of circulatory VEGF from early adulthood (Fig S7). Importantly, unlike in most of other lifespan prolonging interventions characterized by a rightward shift of a sigmoidal curve, VEGF mice (particularly females) presented an atypical survival curve distinguished by 'rectangularization' of the curve such that most VEGF mice were alive by the time that control littermates were all moribund or dead. Apparent compressed morbidity, a trait independent of lifespan, suggested by the shape of the survival curve, provided us with a first hint that, independent of longevity, VEGF mice may have increased healthspan, which is the primary goal of aging research (27).

Age-associated weight gain was significantly lower in VEGF mice and accelerated weight loss typifying moribund mice did not take place in VEGF mice who maintained a stable weight up to a few weeks before their death (Fig. 2B - males and Fig. S8 -females). EchoMRI-based analysis of fat-to-lean body mass ratio indicated that fat gain observed during the second year of life in control mice was reduced in age-matched VEGF mice of either gender (Fig. 2C and Fig. S9). 
The favorable body composition of old VEGF mice prompted a comparative analysis of the respective aging metabolism. Amounts of oxygen consumed and of carbon dioxide released by mice individually housed in metabolic cages were measured and the amounts of carbohydrates and fats oxidized were calculated by indirect calorimetry. Results showed that carbohydrate utilization by 16 months old male mice (which was significantly lower than in 4 months old control mice) was much higher in VEGF mice during resting and active periods resulting in a significantly higher respiratory quotient (Fig. 2D, for males and Fig. S10 for females, including ANCOVA analysis). Flexibility in fuel usage observed at old age correlates with a substrate preference towards lipids, reflecting an inability to adapt fuel oxidation to fuel availability (28). As seen, VEGF treatment significantly improved flexibility in fuel usage in old age. This was reflected in higher dynamic circadian changes in RQ, particularly significant in females (Fig. S11). Notably, metabolic changes observed in VEGF mice correlated with higher MVD in liver and muscle at 16 months of age (Fig. 1I).

VEGF-mediated metabolic alterations were also examined in an independent, non-transgenic VEGF gain-of-function system. Briefly, 2-months old wild-type mice were infected with a low titer of $\mathrm{VEGF}_{164}$-encoding adeno-associated virus (AAV-VEGF), resulting in long-term elevation of circulating VEGF to the targeted level of $150-200 \mathrm{pg} / \mathrm{ml}$ (i.e., a level comparable to the one attained in the transgenic platform) (see Fig S12 for actual VEGF levels) and mice were analyzed upon reaching 8 months of age. Again, VEGF-treated mice maintained a higher rate of carbohydrate oxidation and a significantly higher RQ than control mice treated with a control AAV vector (Fig. 2E).

Encouraged by the finding that, when initiated at the age of 8 months, a two months' duration of AAV-VEGF treatment was sufficient for a significant MVD increase (Fig. 4F), we wished to determine whether this relatively short time might also be sufficient for conferring a 
metabolic advantage. A similar metabolic analysis was, therefore, extended to 10 months old mice transduced with AAV-VEGF two months earlier. Results showed that, as previously, VEGF treated mice displayed a higher rate of carbohydrate oxidation and a higher RQ. This relatively short VEGF treatment had no significant effect on body mass and food intake (Fig. S13).

Considering the great impact of caloric consumption on metabolic health and lifespan, total daily food and water intakes were measured and total energy expenditure (TEE) was calculated by indirect calorimetry for 12 and 16 months old mice and their littermate controls. No significant difference was noted in total food and water intakes between age-matched mice. Noteworthy, aging control male mice significantly ate less than younger mice (Fig S14). While wheel running was not significantly different between control and VEGF mice, total distance covered reflecting both voluntary and non-voluntary activities was higher in male mice and lower in female mice compared to control littermates (see Fig S15). While there was no significant difference in total daily TEE at 12 months (Fig S16) and at16 months of age between control and VEGF males (Fig.2F), 12 and 16 months old female VEGF mice were found to have a significantly higher TEE than age-matched control females (Fig. S17). The basis for these apparent sexual dimorphisms in physical activity and daily TEE is unknown.

Next, we examined the potential for energy expenditure via thermogenesis, that is, i.e., heat production by uncoupling protein 1 (UCP1)-mediated mitochondrial uncoupling. Because thermogenesis mostly takes place in interscapular brown adipose tissue (BAT), we examined BAT histology in the respective old mice. BAT in $24 \mathrm{M}$ control mice, while of a larger mass (Fig. S18), was mostly composed of large white-like adipocytes that have undergone 'whitening', indicative of lost thermogenic capacity. In contrast, BAT in 24M old VEGF mice 
maintained a classic histology of activated BAT (Fig. 2G). Likewise, thermogenic UCP1expressing beige adipocytes (BeAT) interspersed in white adipose tissue (WAT) were frequently observed in 24M old VEGF mice but not in 24M old control mice (Fig. 2G).

\section{VEGF treatment ameliorates adverse age-associated alterations in adipose tissue and liver.}

Aging is usually accompanied by an increase in visceral fat deposition and by a decrease in subcutaneous fat. Both processes, known to be associated with negative health outcomes (29), were ameliorated in VEGF-treated mice. Progressive fat accumulation in the abdominal cavity of control mice and reduced aging-associated fat accumulation in VEGF mice were directly visualized using MRI (Fig.3A) and were further validated by weighing visceral WAT harvested at sacrifice (Fig. 3B). Protection from loss of subdermal fat was evidenced through counting more layers of subcutaneous adipocytes in skin sections of 2 years old VEGF mice as compared to control littermates (Fig. 3C).

A frequent accompaniment of aging is progressive accumulation of fat within liver hepatocytes (liver steatosis), a condition predisposing old people to hepatocytes injury and severe liver pathologies (30). Inspection of liver sections from 24 months old mice, highlighting lipid droplets by Oil-red-O staining, revealed that, in contrast to the highly steatotic liver of control littermates, lipid deposition in hepatocytes was greatly reduced in VEGF mice, where the degree of steatosis resembled more the one measured in 3 months old mice (Fig. 3D). Conversely, VEGF loss of function by premature sFlt1 induction led to aggravation of liver steatosis (Fig. 3E). Inspection of liver sections by electron microscopy (EM) corroborated reduced deposition of lipid droplets in old VEGF mice and revealed additional adverse alterations reduced by VEGF treatment, including alleviation of glycogen deprivation, presence of swollen and ribosomes-deprived rough endoplasmic reticulum and 
of large mitochondria displaying disorganized cristae (Fig. S19). A lessened degree of ageassociated liver injury in 24 months old VEGF mice was biochemically reflected in reduced serum levels of the liver enzymes alanine transaminase (ALT) and aspartate transaminase (AST) (Fig.3F).

Because liver steatosis has been linked to hepatic senescence (31), we examined liver sections stained for senescence-associated $\beta$-galactosidase activity (SA- $\beta$-gal). SA- $\beta$-gal activity in liver of old control mice was found to be mostly associated with sinusoidal blood vessels and only rarely with hepatocytes (Fig. 3G). Liver cell suspensions were, therefore, co-stained for SA- $\beta$-gal activity and for the endothelial marker CD31 and SA- $\beta-\mathrm{Gal}^{+} / \mathrm{CD} 31^{+}$double-positive cells were quantified by flow cytometry (following exclusion of non-endothelial CD31 ${ }^{+}$ cells). In agreement with recent studies $(32,33)$, results showed that senescent ECs indeed accumulate in the aged liver. Remarkably, VEGF reduced the fraction of senescent ECs such that by 2 years of age, VEGF mice had fewer senescent ECs compared to age-matched controls (3\% vs. $8 \%$ of ECs), comparable to the level of $\beta-\mathrm{Gal}^{+} \mathrm{ECs}$ detected in 6 months old control mice (Fig.3H). In addition to the use of SA- $\beta$-gal activity as a senescence readout, we also measured relative levels of hepatic p16 expression using RT-PCR. As shown in Fig. 3I, upregulated p16 expression in liver of 24 months old control mice was greatly reduced in liver of age-matched VEGF mice.

\section{VEGF treatment protects from age-related loss of muscle and bone}

Aging is associated with progressive loss of skeletal muscle mass and in reduced muscle force generating capacity (sarcopenia) (34). Because age-related loss of muscle mass in rodents is much lower than that in humans, with only $\sim 15 \%$ loss at mean lifespan (35), we examined other anatomical features typifying old muscle (36). Mis-positioned, centrally 
located nuclei reflecting a post-injury muscle response in aged and diseased muscles were frequently observed in hind limb muscles of 24 months old control mice but significantly less in muscles of VEGF-treated littermates (Fig. 4A). Other anatomical features frequently observed in muscle of 24 months old control mice but less frequently in muscle of 24 months old VEGF mice included ectopic multi-vesicular bodies, large tubular aggregates in the sarcoplasmic reticulum and swollen inter-myofibrillar mitochondria with damaged cristae (Fig.S20). Notably, sub-sarcolemma localized mitochondria, previously shown to contribute to exercise-induced muscular function improvement (37), were more abundant in muscle fibers of old VEGF mice (Fig.4B and see Fig. S20 for representative EM images).

To evaluate the functional significance of structural mitochondrial alterations in muscle, oxygen consumption rates (OCR) by young and old muscles were compared using a Seahorse ${ }^{\mathrm{TM}}$ platform. Results showed that myofibrils isolated from skeletal muscle of 24 months old VEGF mice have significantly higher basal- and maximal respiration rates and a higher rate of ATP production than myofibrils isolated from age-matched controls, approximating OCR measured in muscle of $3 \mathrm{M}$ old mice (Fig. 4C, upper panel). Conversely, myofibrils isolated from skeletal muscle of 16 months old sFlt-induced mice have significantly lower OCR than their control littermates (Fig.4C lower panel). To evaluate differences in force-generating capacity, mice at progressive ages were subjected to a Rotarod analysis. Results showed that aging VEGF mice stayed on a rotating rod significantly longer than age-matched controls, with 32 months old VEGF mice performing as good as control mice half their age (Fig. 4D). Improved Rotarod performance in VEGFmanipulated mice was also observed using AAV-mediated VEGF delivery to wild-type mice. Briefly, 8 months old mice were transduced with a low titer of AAV-VEGF and were subjected to a Rotarod performance test two months thereafter. As seen in Fig. 4E, VEGF- 
transduced mice could hold to a rotating rod $49 \%$ longer than mock-infected littermates. Improved Rotarod performance was also associated with increased microvascular density in the muscle of AAV-VEGF treated mice (Fig 4F).

Bone weakening due to bone tissue loss (osteoporosis) is the most common cause of bone breakage in old people of both genders, particularly affecting post-menopausal women (38). Imaging tibia of 24 months old female mice by micro-CT showed that the substantial bone thinning observed in old control mice was markedly prevented in old VEGF mice who had, on average, 33\% more bone than control littermates (Fig. 4G).

Age-related alterations in muscle and bone are often manifested in distorted vertebrae column curvature (kyphosis). Kyphosis indices measured from X-ray radiographic images revealed that by 24 months of age, old VEGF mice presented a 38\% higher kyphosis index (i.e., lower curvature) than control littermates (Fig. 4H).

\section{VEGF treatment reduces inflammaging and spontaneous tumor burden.}

Inflammaging, i.e. age-related chronic inflammation affecting multiple organs, is a fundamental hallmark of aging (39). Indicative of chronic inflammation is an elevated fraction of granulocytes amongst circulating leukocytes, which was observed in most old control mice examined but not in age-matched VEGF mice (Fig. 5A). Longitudinal measurements of the inflammation marker C-reactive protein (CRP) in blood serum showed that, unlike their age-matched controls, the majority of which presented elevated CRP levels, 24 month old VEGF mice presented CRP levels similar to those detected in 3 month old mice

(Fig. 5B). Monocyte Chemoattractant Protein-1 (MCP-1), also recognized as a frailty marker (40) and validated here to be upregulated in blood of old (24 months) control mice was barely elevated in age-matched VEGF mice (Fig. 5C, left). Conversely, sFlt1-mediated VEGF lossof-function led to premature MCP-1 accumulation in blood, already evidenced at the age of 
16 months (Fig. 5C, right). Reduced inflammaging in old VEGF mice was also evidenced in a lower number of histologically discernable perivascular inflammatory infiltrates, in fewer foci of necrotic inflammation, and in reduced number of infiltrated CD45-positive immune cells enumerated in single cell suspensions of liver and WAT (Fig. 5D).

Routine inspection at sacrifice of all mice used for lifespan studies for the presence of spontaneous tumors revealed that fewer VEGF mice presented at least one neoplastic lesion compared to age-matched control mice, with more than $40 \%$ of the longest lived VEGF mice remaining tumor-free at time of their natural death (Fig. 5E). Breakdown of spontaneous tumors by tumor type showed that most abundant tumors included lymphomas, lung adenocarcinoma, hepatocellular carcinomas, lipomas and fibromas (see organs presenting neoplastic lesions breakdown in Tables S1\&S2). This finding removed a concern that transgenic VEGF at the doses used herein may enhance tumorigenesis (which was anyway unlikely, considering that tumor neovascularization is promoted by much higher levels of intra-tumorally produced VEGF). Whether there is a causal relationship between reduced inflammaging, a trait recognized as a major tumor promoter (41), and reduced tumor burden in aging VEGF mice remains to be determined.

\section{Discussion}

Aging-associated processes take place at different levels of the biological hierarchy, i.e., not only at the cellular level but also at the level of the organ support systems where vascular aging appears to play a major role. Placing vascular aging in a hierarchally high position in organ aging as was previously suggested (3), is strongly supported by our findings that VEGF-assisted preservation of a young-like vascular homeostasis alleviates key cellular hallmarks of organ aging and associated pathologies and, conversely, that unscheduled 
premature VEGF neutralization accelerates, at least, the aging-associated phenotypes addressed herein. Our data suggest the following sequence of events: increased production of inhibitory VEGF decoy receptors leads to VEGF signaling insufficiency and a resultant failure to maintain adequate microvascular density. Microvascular deficit, in turn, leads to compromised perfusion, reduced tissue oxygenation, compromised mitochondrial activity and metabolic changes. Metabolically active organs, in particular, the adipose tissue, skeletal muscles and liver, then progressively lose function and, in the cases of bone and subcutaneous adipose tissue, this is also accompanied by a massive tissue loss. Findings presented herein that a small increase in circulating VEGF counteracts all these adverse processes implies that securing proper vascular homeostasis during aging might confer a comprehensive geroprotection, as indeed evidenced by apparent alleviation of major age-related pathologies, such as age-associated overweight gain, hepatic steatosis, osteoporosis, inflammaging, and increased tumor burden (see graphical summary of undone aging phenotypes in Fig.6). Further studies might reveal additional organ systems potentially benefitting from VEGF/vascular manipulations. An integrative reflection of VEGFs' beneficial effects is increased longevity of VEGF mice. It is however difficult to compare the magnitude of lifespan extension with that attained by other anti-aging manipulations, given the relatively short lifespan of the mixed mouse strain used in this study. In fact, it has been argued that lifespan-extending manipulations may remedy deficiencies in the genetic makeup or in the environment of one particular strain rather than altering the aging process (42). Extending similar analyses to other mouse strains is, therefore, required. A non-genetic, experimental factor that could have affected longevity was the presence of a low dose tetracycline included in the drinking water. 
While the angiogenic activity of VEGF clearly plays a critical role by virtue of securing adequate perfusion, it is possible that non-angiogenic functions of VEGF play additional geroprotective roles. For example, insufficient VEGF signals were shown to cause a reversible closure of EC fenestrations (16) that, when taking place for example in endocrine organs, is bound to impair systemic hormone distribution. To be considered is also VEGF activity as a vascular permeability factor, as well as VEGF actions on non-vascular cells (e.g. immune cells) expressing cognate VEGF receptors. As an example, monocytes have been shown to impair arteriogenesis in aged mice via sFlt1 production (22).

In search of possible cause(s) of reduced VEGF signaling in aging, we uncovered a previously unrecognized mechanism, namely, increased production of sVEGFR1 caused by age-related shift in alternative splicing of VEGFR1 mRNA. Alterations in splicing patterns occur frequently in aging (43) and it will be of interest to identify splicing factors responsible for the shift in VEGFR1 mRNA splicing. Additional mechanisms contributing to reduced VEGF signaling in aging might include impaired HIF1 activation and a blunted hypoxic VEGF responsiveness (44).

As increased levels of systemic VEGF were in effect from 8 months (corresponding to a human age of 40 years) and onwards, VEGF-induced anti-aging effects described should be viewed as preventive in nature. Whether VEGF/vascular treatments could be harnessed for reversing established aging phenotypes remains to be examined. A correlation between VEGF regulation and age-related human pathologies and longevity was also suggested by human studies of polymorphisms in the VEGF gene promoter region (45).

In conclusion, the study provides compelling evidence to the thesis that perturbation of vascular homeostasis is a critical driving force for multiorgan aging. Correspondingly, it 
suggests harnessing VEGF-aided restoration of vascular homeostasis as a yet uncharted modality for multifaceted healthspan increase. 


\section{References and Notes}

1. Z. Ungvari, S. Tarantini, T. Kiss, J. D. Wren, C. B. Giles, C. T. Griffin, W. L. Murfee, P. Pacher, A. Csiszar, Endothelial dysfunction and angiogenesis impairment in the ageing vasculature, Nat Rev Cardiol 15, 555-565 (2018).

2. S. Rafii, J. M. Butler, B. S. Ding, Angiocrine functions of organ-specific endothelial cells, Nature 529, 316-325 (2016).

3. D. G. Le Couteur, E. G. Lakatta, A vascular theory of aging, J Gerontol A Biol Sci Med Sci 65, 1025-1027 (2010).

4. B. J. North, D. A. Sinclair, The intersection between aging and cardiovascular disease, Circ Res 110, 1097-1108 (2012).

5. M. S. Goligorsky, Microvascular rarefaction: the decline and fall of blood vessels, Organogenesis 6, 1-10 (2010).

6. A. P. Kusumbe, S. K. Ramasamy, R. H. Adams, Coupling of angiogenesis and osteogenesis by a specific vessel subtype in bone, Nature 507, 323-328 (2014).

7. Y. Hasegawa, T. Saito, T. Ogihara, Y. Ishigaki, T. Yamada, J. Imai, K. Uno, J. Gao, K. Kaneko, T. Shimosawa, T. Asano, T. Fujita, Y. Oka, H. Katagiri, Blockade of the nuclear factor-kappaB pathway in the endothelium prevents insulin resistance and prolongs life spans, Circulation 125, 1122-1133 (2012).

8. A. Das, G. X. Huang, M. S. Bonkowski, A. Longchamp, C. Li, M. B. Schultz, L. J. Kim, B. Osborne, S. Joshi, Y. Lu, J. H. Trevino-Villarreal, M. J. Kang, T. T. Hung, B. Lee, E. O. Williams, M. Igarashi, J. R. Mitchell, L. E. Wu, N. Turner, Z. Arany, L. Guarente, D. A. Sinclair, Impairment of an Endothelial NAD(+)-H2S Signaling Network Is a Reversible Cause of Vascular Aging, Cell 173, 74-89 e20 (2018).

9. S. Tarantini, M. N. Valcarcel-Ares, P. Toth, A. Yabluchanskiy, Z. Tucsek, T. Kiss, P. Hertelendy, M. Kinter, P. Ballabh, Z. Sule, E. Farkas, J. A. Baur, D. A. Sinclair, A. Csiszar, Z. Ungvari, Nicotinamide mononucleotide (NMN) supplementation rescues cerebromicrovascular endothelial function and neurovascular coupling responses and improves cognitive function in aged mice, Redox Biol 24, 101192 (2019).

10. M. B. Chen, A. C. Yang, H. Yousef, D. Lee, W. Chen, N. Schaum, B. Lehallier, S. R. Quake, T. Wyss-Coray, Brain Endothelial Cells Are Exquisite Sensors of AgeRelated Circulatory Cues, Cell Rep 30, 4418-4432 e4414 (2020).

11. A. J. Barinda, K. Ikeda, D. B. Nugroho, D. A. Wardhana, N. Sasaki, S. Honda, R. Urata, S. Matoba, K. I. Hirata, N. Emoto, Endothelial progeria induces adipose tissue senescence and impairs insulin sensitivity through senescence associated secretory phenotype, Nat Commun 11, 481 (2020).

12. A. Lazarus, E. Keshet, Vascular endothelial growth factor and vascular homeostasis, Proc Am Thorac Soc 8, 508-511 (2011).

13. D. O. Bates, Vascular endothelial growth factors and vascular permeability, Cardiovasc Res 87, 262-271 (2010). 
14. L. E. Benjamin, I. Hemo, E. Keshet, A plasticity window for blood vessel remodelling is defined by pericyte coverage of the preformed endothelial network and is regulated by PDGF-B and VEGF, Development 125, 1591-1598 (1998).

15. S. C. Satchell, F. Braet, Glomerular endothelial cell fenestrations: an integral component of the glomerular filtration barrier, Am J Physiol Renal Physiol 296, F947-956 (2009).

16. D. May, V. Djonov, G. Zamir, M. Bala, R. Safadi, M. Sklair-Levy, E. Keshet, A transgenic model for conditional induction and rescue of portal hypertension reveals a role of VEGF-mediated regulation of sinusoidal fenestrations, PLoS One 6, e21478 (2011).

17. A. S. Maharaj, M. Saint-Geniez, A. E. Maldonado, P. A. D'Amore, Vascular endothelial growth factor localization in the adult, Am J Pathol 168, 639-648 (2006).

18. D. Shweiki, A. Itin, D. Soffer, E. Keshet, Vascular endothelial growth factor induced by hypoxia may mediate hypoxia-initiated angiogenesis, Nature 359, 843845 (1992).

19. D. May, D. Gilon, V. Djonov, A. Itin, A. Lazarus, O. Gordon, C. Rosenberger, E. Keshet, Transgenic system for conditional induction and rescue of chronic myocardial hibernation provides insights into genomic programs of hibernation, Proc Natl Acad Sci U S A 105, 282-287 (2008).

20. T. Licht, G. Rothe, T. Kreisel, B. Wolf, O. Benny, A. G. Rooney, C. FfrenchConstant, G. Enikolopov, E. Keshet, VEGF preconditioning leads to stem cell remodeling and attenuates age-related decay of adult hippocampal neurogenesis, Proc Natl Acad Sci U S A 113, E7828-E7836 (2016).

21. K. Furrer, A. Rickenbacher, Y. Tian, W. Jochum, A. G. Bittermann, A. Kach, B. Humar, R. Graf, W. Moritz, P. A. Clavien, Serotonin reverts age-related capillarization and failure of regeneration in the liver through a VEGF-dependent pathway, Proc Natl Acad Sci U S A 108, 2945-2950 (2011).

22. G. Zhao, X. W. Cheng, L. Piao, L. Hu, Y. Lei, G. Yang, A. Inoue, S. Ogasawara, H. Wu, C. N. Hao, K. Okumura, M. Kuzuya, The Soluble VEGF Receptor sFlt-1 Contributes to Impaired Neovascularization in Aged Mice, Aging Dis 8, 287-300 (2017).

23. A. Rivard, J. E. Fabre, M. Silver, D. Chen, T. Murohara, M. Kearney, M. Magner, T. Asahara, J. M. Isner, Age-dependent impairment of angiogenesis, Circulation 99, 111-120 (1999).

24. A. Ahluwalia, M. K. Jones, X. Deng, Z. Sandor, S. Szabo, A. S. Tarnawski, An imbalance between VEGF and endostatin underlies impaired angiogenesis in gastric mucosa of aging rats, Am J Physiol Gastrointest Liver Physiol 305, G325332 (2013).

25. T. Takahashi, S. Yamaguchi, K. Chida, M. Shibuya, A single autophosphorylation site on KDR/Flk-1 is essential for VEGF-A-dependent activation of PLC-gamma and DNA synthesis in vascular endothelial cells, EMBO J 20, 2768-2778 (2001).

26. R. L. Kendall, K. A. Thomas, Inhibition of vascular endothelial cell growth factor 
activity by an endogenously encoded soluble receptor, Proc Natl Acad Sci U S A 90, 10705-10709 (1993).

27. S. J. Olshansky, From Lifespan to Healthspan, JAMA 320, 1323-1324 (2018).

28. C. E. Riera, A. Dillin, Tipping the metabolic scales towards increased longevity in mammals, Nat Cell Biol 17, 196-203 (2015).

29. J. L. Kuk, T. J. Saunders, L. E. Davidson, R. Ross, Age-related changes in total and regional fat distribution, Ageing Res Rev 8, 339-348 (2009).

30. I. H. Kim, T. Kisseleva, D. A. Brenner, Aging and liver disease, Curr Opin Gastroenterol 31, 184-191 (2015).

31. M. Ogrodnik, S. Miwa, T. Tchkonia, D. Tiniakos, C. L. Wilson, A. Lahat, C. P. Day, A. Burt, A. Palmer, Q. M. Anstee, S. N. Grellscheid, J. H. J. Hoeijmakers, S. Barnhoorn, D. A. Mann, T. G. Bird, W. P. Vermeij, J. L. Kirkland, J. F. Passos, T. von Zglinicki, D. Jurk, Cellular senescence drives age-dependent hepatic steatosis, Nat Commun 8, 15691 (2017).

32. S. Omori, T. W. Wang, Y. Johmura, T. Kanai, Y. Nakano, T. Kido, E. A. Susaki, T. Nakajima, S. Shichino, S. Ueha, M. Ozawa, K. Yokote, S. Kumamoto, A. Nishiyama, T. Sakamoto, K. Yamaguchi, S. Hatakeyama, E. Shimizu, K. Katayama, Y. Yamada, S. Yamazaki, K. Iwasaki, C. Miyoshi, H. Funato, M. Yanagisawa, H. Ueno, S. Imoto, Y. Furukawa, N. Yoshida, K. Matsushima, H. R. Ueda, A. Miyajima, M. Nakanishi, Generation of a pl6 Reporter Mouse and Its Use to Characterize and Target p16(high) Cells In Vivo, Cell Metab 32, 814-828 e816 (2020).

33. L. Grosse, D. V. Bulavin, LSEC model of aging, Aging (Albany NY) 12, 1115211160 (2020).

34. I. Janssen, S. B. Heymsfield, R. Ross, Low relative skeletal muscle mass (sarcopenia) in older persons is associated with functional impairment and physical disability, J Am Geriatr Soc 50, 889-896 (2002).

35. S. B. Ballak, H. Degens, A. de Haan, R. T. Jaspers, Aging related changes in determinants of muscle force generating capacity: a comparison of muscle aging in men and male rodents, Ageing Res Rev 14, 43-55 (2014).

36. R. K. Sayed, E. C. de Leonardis, J. A. Guerrero-Martinez, I. Rahim, D. M. Mokhtar, A. M. Saleh, K. E. Abdalla, M. J. Pozo, G. Escames, L. C. Lopez, D. AcunaCastroviejo, Identification of morphological markers of sarcopenia at early stage of aging in skeletal muscle of mice, Exp Gerontol 83, 22-30 (2016).

37. E. V. Menshikova, V. B. Ritov, L. Fairfull, R. E. Ferrell, D. E. Kelley, B. H. Goodpaster, Effects of exercise on mitochondrial content and function in aging human skeletal muscle, J Gerontol A Biol Sci Med Sci 61, 534-540 (2006).

38. M. Almeida, L. Han, M. Martin-Millan, L. I. Plotkin, S. A. Stewart, P. K. Roberson, S. Kousteni, C. A. O'Brien, T. Bellido, A. M. Parfitt, R. S. Weinstein, R. L. Jilka, S. 
C. Manolagas, Skeletal involution by age-associated oxidative stress and its acceleration by loss of sex steroids, J Biol Chem 282, 27285-27297 (2007).

39. S. Salvioli, M. Capri, S. Valensin, P. Tieri, D. Monti, E. Ottaviani, C. Franceschi, Inflamm-aging, cytokines and aging: state of the art, new hypotheses on the role of mitochondria and new perspectives from systems biology, Curr Pharm Des 12, 3161-3171 (2006).

40. M. J. Yousefzadeh, M. J. Schafer, N. Noren Hooten, E. J. Atkinson, M. K. Evans, D. J. Baker, E. K. Quarles, P. D. Robbins, W. C. Ladiges, N. K. LeBrasseur, L. J. Niedernhofer, Circulating levels of monocyte chemoattractant protein-1 as a potential measure of biological age in mice and frailty in humans, Aging Cell 17, (2018).

41. G. C. Leonardi, G. Accardi, R. Monastero, F. Nicoletti, M. Libra, Ageing: from inflammation to cancer, Immun Ageing 15, 1 (2018).

42. B. G. Hughes, S. Hekimi, Different Mechanisms of Longevity in Long-Lived Mouse and Caenorhabditis elegans Mutants Revealed by Statistical Analysis of Mortality Rates, Genetics 204, 905-920 (2016).

43. K. Wang, D. Wu, H. Zhang, A. Das, M. Basu, J. Malin, K. Cao, S. Hannenhalli, Comprehensive map of age-associated splicing changes across human tissues and their contributions to age-associated diseases, Sci Rep 8, 10929 (2018).

44. S. Rey, G. L. Semenza, Hypoxia-inducible factor-1-dependent mechanisms of vascularization and vascular remodelling, Cardiovasc Res 86, 236-242 (2010).

45. R. Del Bo, S. Ghezzi, M. Scarlato, D. Albani, D. Galimberti, U. Lucca, M. Tettamanti, E. Scarpini, G. Forloni, N. Bresolin, G. P. Comi, Role of VEGF gene variability in longevity: a lesson from the Italian population, Neurobiol Aging 29, 1917-1922 (2008).

46. E. Zurita, M. Chagoyen, M. Cantero, R. Alonso, A. Gonzalez-Neira, A. LopezJimenez, J. A. Lopez-Moreno, C. P. Landel, J. Benitez, F. Pazos, L. Montoliu, Genetic polymorphisms among C57BL/6 mouse inbred strains, Transgenic Res 20, 481-489 (2011).

47. A. Kistner, M. Gossen, F. Zimmermann, J. Jerecic, C. Ullmer, H. Lubbert, H. Bujard, Doxycycline-mediated quantitative and tissue-specific control of gene expression in transgenic mice, Proc Natl Acad Sci U S A 93, 10933-10938 (1996).

48. Y. Dor, V. Djonov, R. Abramovitch, A. Itin, G. I. Fishman, P. Carmeliet, G. Goelman, E. Keshet, Conditional switching of VEGF provides new insights into adult neovascularization and pro-angiogenic therapy, EMBO J 21, 1939-1947 (2002).

49. J. F. Sun, T. Phung, I. Shiojima, T. Felske, J. N. Upalakalin, D. Feng, T. Kornaga, T. Dor, A. M. Dvorak, K. Walsh, L. E. Benjamin, Microvascular patterning is controlled by fine-tuning the Akt signal, Proc Natl Acad Sci U S A 102, 128-133 (2005).

50. A. Anisimov, A. Alitalo, P. Korpisalo, J. Soronen, S. Kaijalainen, V. M. Leppanen, M. Jeltsch, S. Yla-Herttuala, K. Alitalo, Activated forms of VEGF-C and VEGF-D 
provide improved vascular function in skeletal muscle, Circ Res 104, 1302-1312 (2009).

51. S. Udi, L. Hinden, B. Earley, A. Drori, N. Reuveni, R. Hadar, R. Cinar, A. Nemirovski, J. Tam, Proximal Tubular Cannabinoid-1 Receptor Regulates ObesityInduced CKD, J Am Soc Nephrol 28, 3518-3532 (2017).

52. M. H. Tschop, J. R. Speakman, J. R. Arch, J. Auwerx, J. C. Bruning, L. Chan, R. H. Eckel, R. V. Farese, Jr., J. E. Galgani, C. Hambly, M. A. Herman, T. L. Horvath, B. B. Kahn, S. C. Kozma, E. Maratos-Flier, T. D. Muller, H. Munzberg, P. T. Pfluger, L. Plum, M. L. Reitman, K. Rahmouni, G. I. Shulman, G. Thomas, C. R. Kahn, E. Ravussin, A guide to analysis of mouse energy metabolism, Nat Methods 9, 57-63 (2011).

53. D. C. Simonson, R. A. DeFronzo, Indirect calorimetry: methodological and interpretative problems, Am J Physiol 258, E399-412 (1990).

54. J. Tam, V. K. Vemuri, J. Liu, S. Batkai, B. Mukhopadhyay, G. Godlewski, D. OseiHyiaman, S. Ohnuma, S. V. Ambudkar, J. Pickel, A. Makriyannis, G. Kunos, Peripheral CB1 cannabinoid receptor blockade improves cardiometabolic risk in mouse models of obesity, J Clin Invest 120, 2953-2966 (2010).

55. K. W. Cho, D. L. Morris, C. N. Lumeng, Flow cytometry analyses of adipose tissue macrophages, Methods Enzymol 537, 297-314 (2014).

56. Y. Ovadya, T. Landsberger, H. Leins, E. Vadai, H. Gal, A. Biran, R. Yosef, A. Sagiv, A. Agrawal, A. Shapira, J. Windheim, M. Tsoory, R. Schirmbeck, I. Amit, H. Geiger, V. Krizhanovsky, Impaired immune surveillance accelerates accumulation of senescent cells and aging, Nat Commun 9, 5435 (2018).

57. W. Yang, L. Chen, Y. Ding, X. Zhuang, U. J. Kang, Paraquat induces dopaminergic dysfunction and proteasome impairment in DJ-1-deficient mice, Hum Mol Genet 16, 2900-2910 (2007).

58. N. Laws, A. Hoey, Progression of kyphosis in mdx mice, J Appl Physiol (1985) 97, 1970-1977 (2004).

Acknowledgments: We thank Dr. Rachel Hertz, Prof. Jacob Bar-Tana, Prof. Shmuel BenSasson and Prof. Yuval Dor for helpful discussions. We thank Dr Amit Agrawal and Prof. Valery Krizhanovsky for technical help with the SA- $\beta$ gal assay, David Kushnir (Surgical Innovation and Technology Center, Hadassah Medical Center) for his help with the radiography imaging, Dr. Tzuri Lifschytz and Prof. Bernard Lerer from the National 
Knowledge Center for Research on Brain Disorders (Hadassah- Medical Center) for their help with the Rotarod performance assay. We also thank Amos Grunewald for art work.

Fundings: The study was funded in part by research grants from

- the Britain Israel Research and Academic Exchange partnership (BIRAX grant No 2779/19)

- the Israel Science Foundation (grants No. 783/20 and 158/18).

Author contributions: MG, SK, HS, EV, AGH, TL, MH, SL performed experiments. AP, LH, SA, JT performed metabolic analyses, DM and RA performed MRI and EchoUS experiments. YF performed Electron microscopy imaging, AA and KA provided AAVVEGF and AAV-control viruses. OZK, R H, VD performed part of bone density analysis. RT, TO and PK provided technical assistance. MG and EK conceptualized the study, designed experiments, interpreted data, wrote the manuscript and supervised the study.

Competing interests: MG and EK are inventors on a patent entitled "ANTI- AGING COMPOSITIONS AND METHODS OF USE" (US provisional application No. 62/656,471). The remaining authors declare no competing interests.

Data and materials availability: All data is available in the main text or the supplementary materials.

\section{Supplementary Materials:}

Materials and Methods

Figures S1-S20

Tables S1-S4 
References (46-58) 

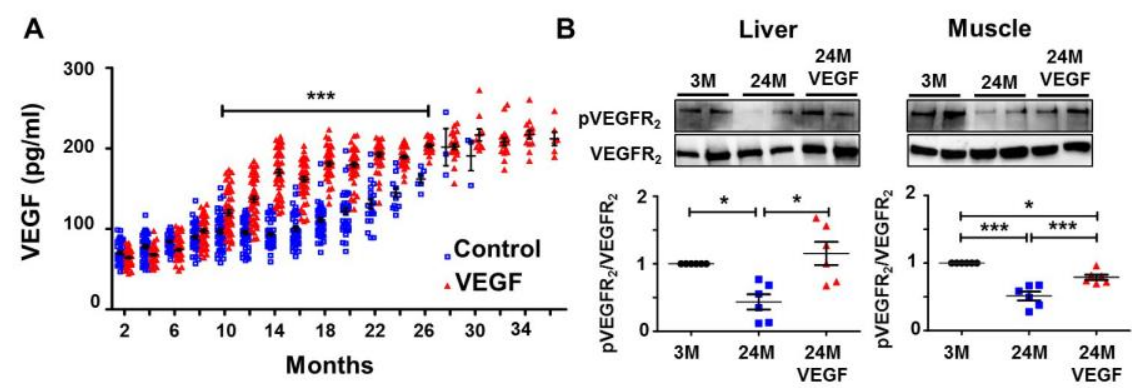

C

D

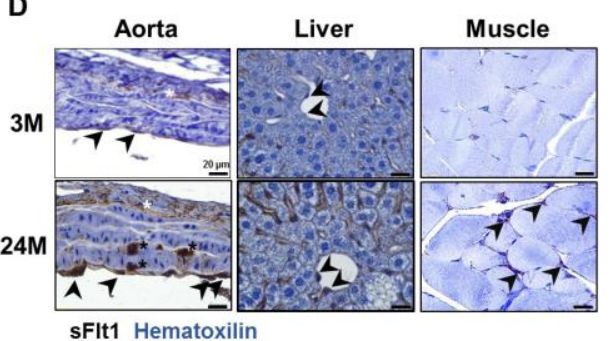

$\mathbf{E}$

$\mathbf{F}$
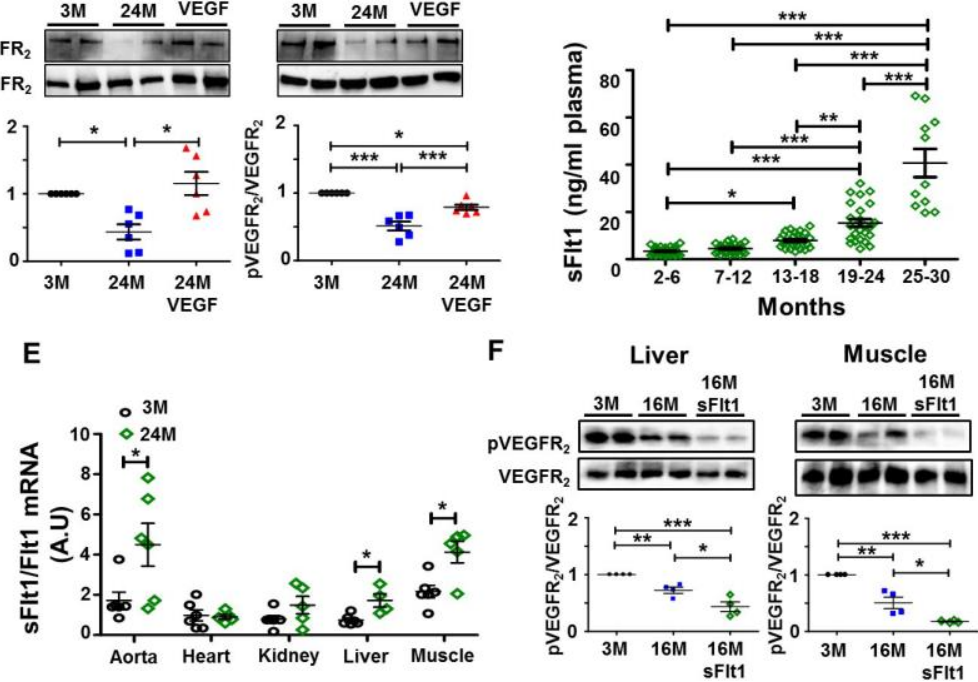

G
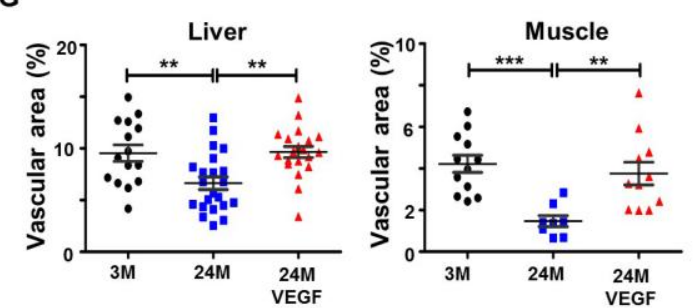

H
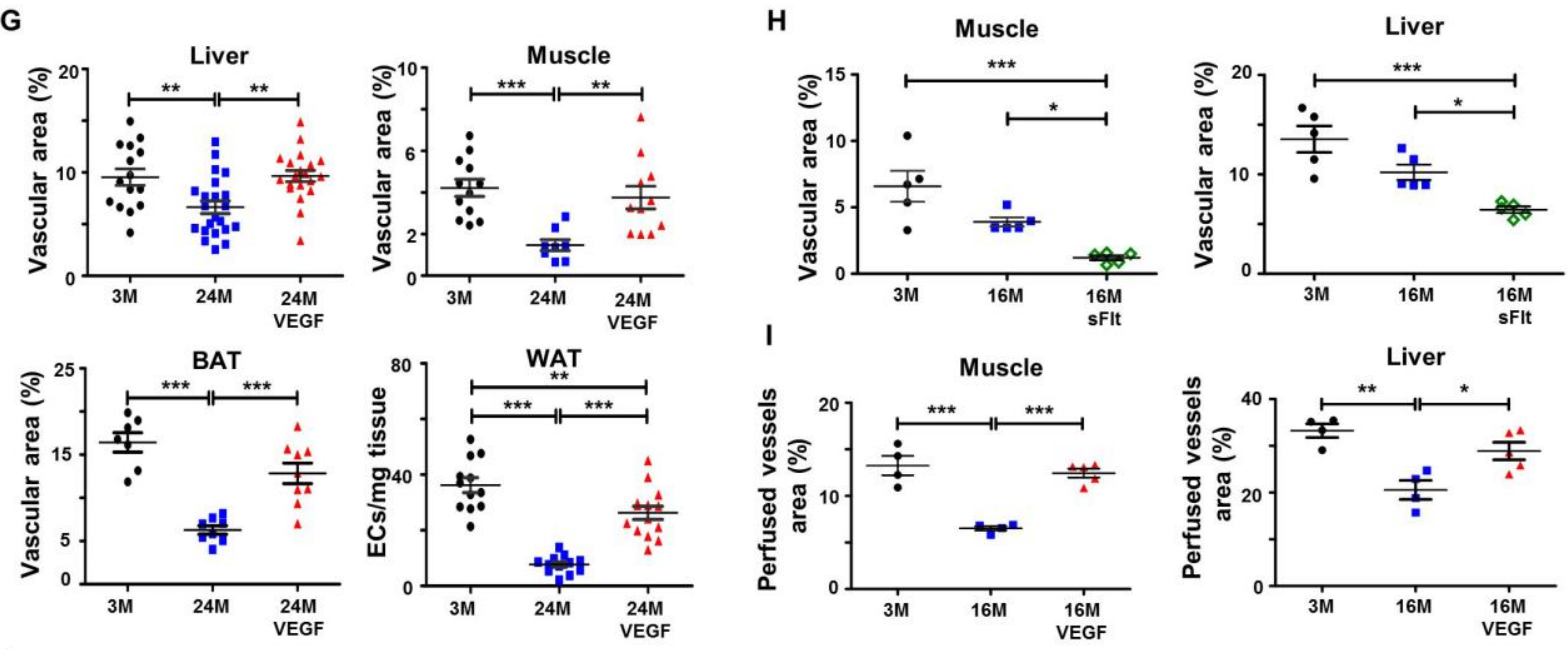

$\mathbf{J}$
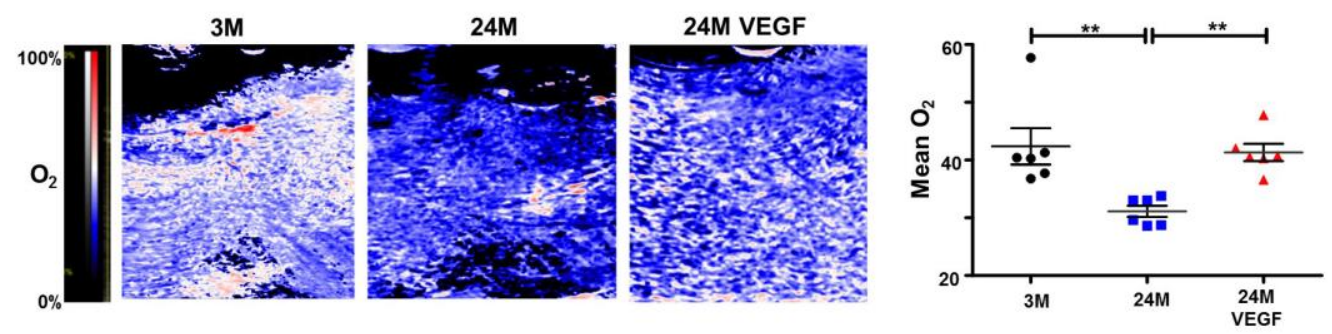

Fig. 1. VEGF rectifies age-related VEGF signaling insufficiency, prevents microvascular rarefaction and improves tissue oxygenation whereas earlier sFlt1 induction produces the opposite. (A) Plasma VEGF protein levels in Control and VEGF male mice determined longitudinally with VEGF ELISA. ( $n=50$ mice per group). Note a significant difference in systemic VEGF levels between Control and VEGF male mice at each time point from 10 to 26 months of age. (B) Quantification of the phosphorylated fraction (pVEGFR2: position Y1175) relative to total VEGFR2 in liver and muscle lysates obtained from male mice of indicated age. Representative immunoblots are shown on top and calculated pVEGFR2/VEGFR2 ratio on bottom (with the young mice ratio assigned as 
1). (C) sFlt1 protein levels in plasma of Control mice (pooled males and females) determined using a Flt1-specific Elisa. For presentation, mice were divided in indicated age groups. (D) Representative tissue sections of control male mice immunostained with sFlt1specific antibody and counterstained with hematoxylin. Arrowheads highlights sFlt1positive endothelial cells and white and black asterisks highlight sFlt1-positive medial and adventitial cells, respectively (Bars $=20 \mu \mathrm{m})$. (E) sFlt1/Flt1 mRNA ratio in the indicated organs and age indicative of an alternative splicing shift. (F) VEGFR2 phosphorylation in liver and muscle of 16 months old mice (pooled males and females) in which sFlt 1 was induced 8 months earlier. Note markedly reduced VEGFR2 phosphorylation compared to age-matched controls. Representative immunoblots are shown on top and calculated pVEGFR2/VEGFR2 ratio on bottom (with the young mice ratio assigned as 1). (G) Microvascular densities in organs retrieved from male and female mice at indicated ages, expressed as the relative area covered by capillaries highlighted in CD31-stained sections of liver, muscle and brown adipose tissue (BAT). For white adipose tissue (WAT), relative MVDs were expressed as the number of $\mathrm{CD} 31^{+} \mathrm{ECs}$ in $\mathrm{mg}$ tissue enumerated by flow cytometry. ( $n>8$ male and female mice per group). (H) Microvascular densities in muscle (left) and liver (right) isolated from the sFlt1-induced mice used in Fig.1F and quantified as in Fig. 1G. (I) Densities of perfused vessels marked by uptake of intravenously injected fluorescent VE-Cadherin antibodies calculated as the relative area covered by stained capillaries. Each dot represents the average of 10 tissue sections analyzed per mouse. (J) Blood oxygen saturation levels $\left(\mathrm{sO}_{2}\right)$ in the hind limb of young ( 3 months old) and 24 months old control and VEGF male and female mice determined by US-photoacoustics. Left: representative images. Right: quantification of $\mathrm{sO}_{2}$ in 6 mice per group.

Statistical analysis. Each dot represents a mouse. $p$ values are derived from (A) Two-way ANOVA with Bonferroni post-tests. (B, C, F, G, H, I, J) One-way ANOVA with Tukey post-tests. (E) two-tailed Student's t test. Values are mean +/-SEM. p values indicated as * $<0.05$; $* *<0.01$; $* * *<0.001$. p values $>0.05$ are not indicated. 

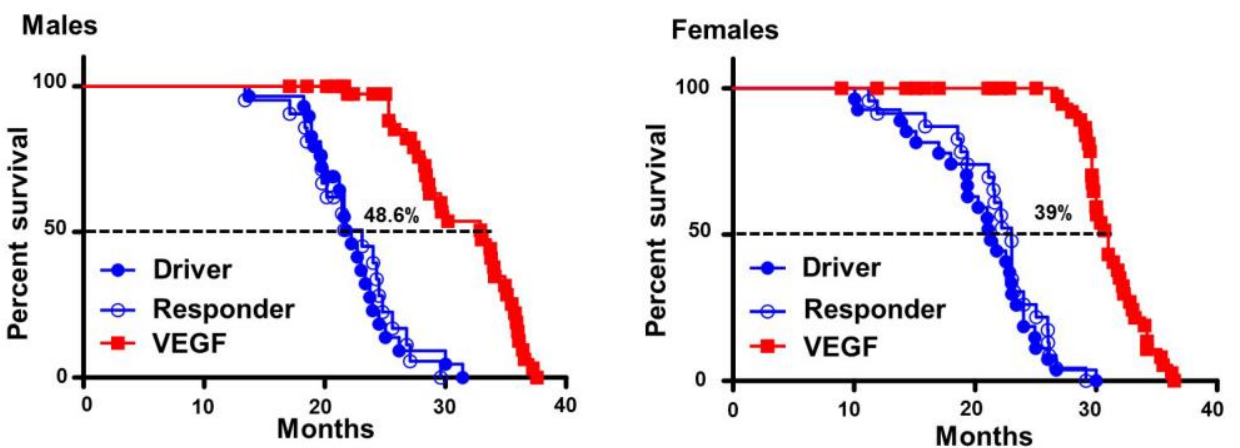

B

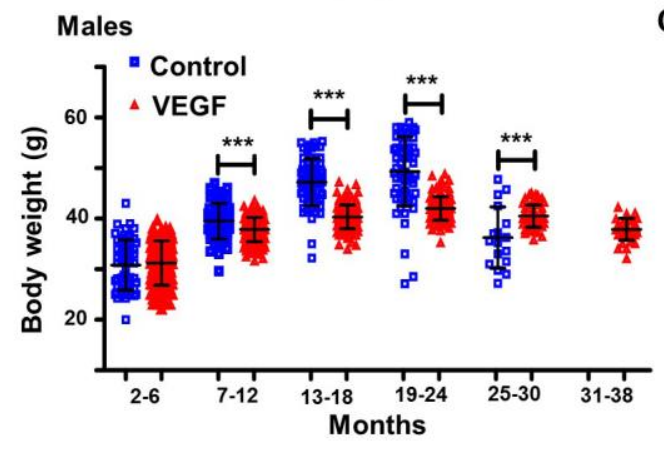

C

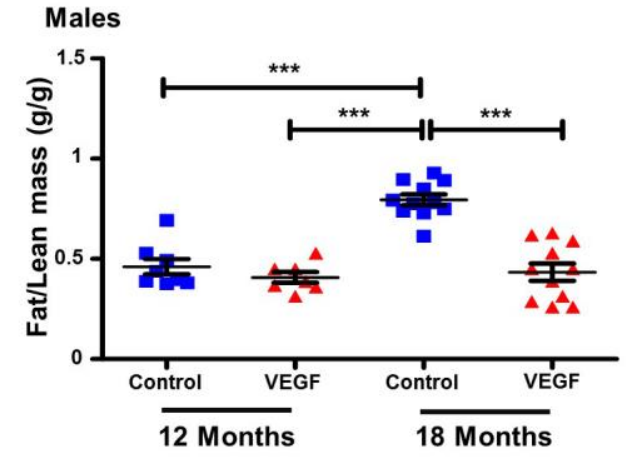

Dales
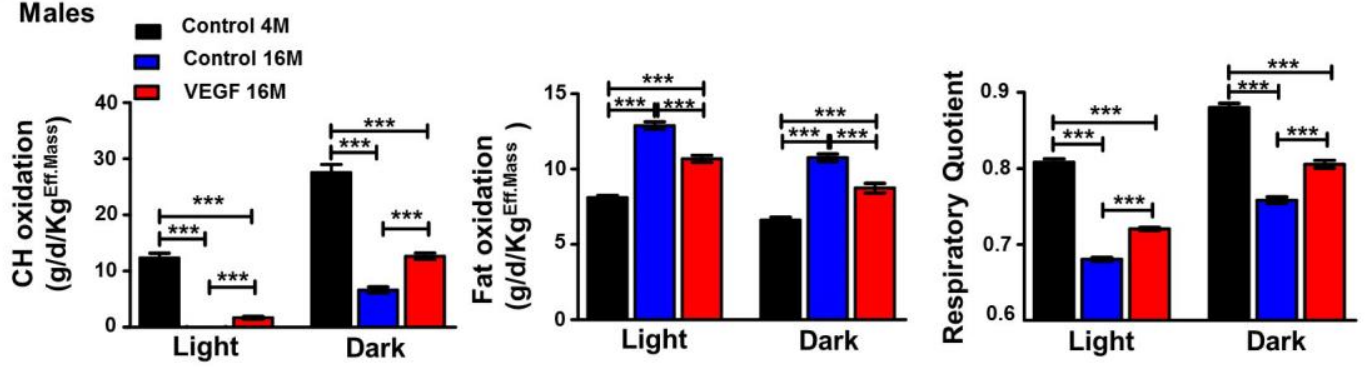

E
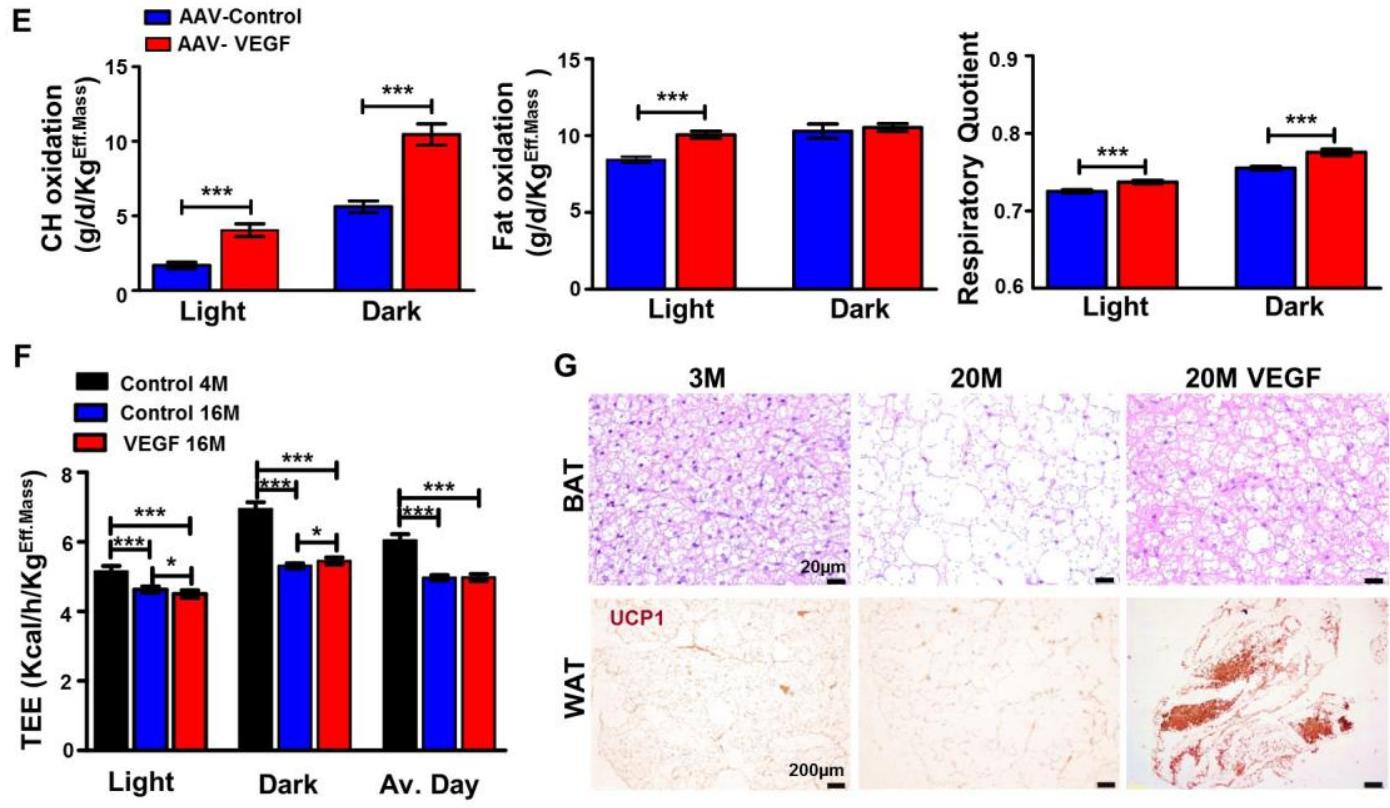

$20 \mathrm{M}$

20M VEGF

$20 \mathrm{M}$

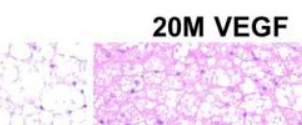

Fig. 2. Increased lifespan and improved body composition and metabolism of aged VEGF-treated mice. (A) Kaplan-Meier survival curves of male and female mice. 100 mice 
per gender were used, of which half were control mice and the other half VEGF mice. The control group was subdivided into mice harboring only the driver transgene and mice harboring only the responder transgene. Curves shown also included mice censored for reasons outlined in Tables S1 and S2. Percent indicated is of increased median survival of VEGF mice. $\mathrm{p}<0.0001$ for both males and females (derived from log-rank (Mantel-Cox) tests). (B) Body weights of male mice ( $n=50$ mice per group). For presentations, monthly weighed mice were divided in age groups of 5 to 6 months each. (C) Lean-to-fat body mass ratio calculated on the basis of Echo-MRI measurements in male mice. $(11>n>6)$. (D) Circadian changes in carbohydrate $(\mathrm{CH})$ and fat oxidation individually measured in 4 and 16 months old male mice (10>n>6 for each group). Respiratory Quotient (RQ) was calculated based on gas exchange measurements. Note significantly higher RQ in old VEGF mice indicative of improved Carbohydrate use $(\mathrm{RQ}=0.7$ signifies fat oxidation only and $\mathrm{RQ}=1.0$ signifies carbohydrate oxidation only). (E) Circadian changes in carbohydrate and fat oxidation and in RQ in 8 months old mice infected 6 months earlier with a low titer of AAV-VEGF ${ }_{164}$. Control mice were injected with the same titer of AAV-control ( $n=5$ for each group of mice). (F) Total energy expenditure (TEE) by 4 months old control mice and 16 months old male control and VEGF mice (normalized to effective body mass) measured by indirect calorimetry. (10>n>6 for each group). (G) Thermogenic brown and beige adipocytes in BAT and WAT. Top: Representative H\&E-stained BAT sections resected from young (3 mo) and old (20 mo) mice showing alleviation of BAT whitening in old VEGF mice. Bottom: Representative UCP1-immunostained sections of abdominal WAT. Note abundant UCP1-expressing beige adipocytes in old VEGF mice but not in control littermate. (Bars are $20 \mu \mathrm{m}$ and $200 \mu \mathrm{m}$ ).

Statistical analysis: Each dot represents a mouse. p values derived from (A) log-rank (Mantel-Cox) tests. (B, D, E, F) two-tailed unpaired Student's t test. (C) One-way ANOVA with Tukey post-tests. Values are mean +/-SEM. p values indicated as $*<0.05$; $* *<0.01$; $* * *<0.001 . \mathrm{p}$ values $>0.05$ are not indicated. 
A
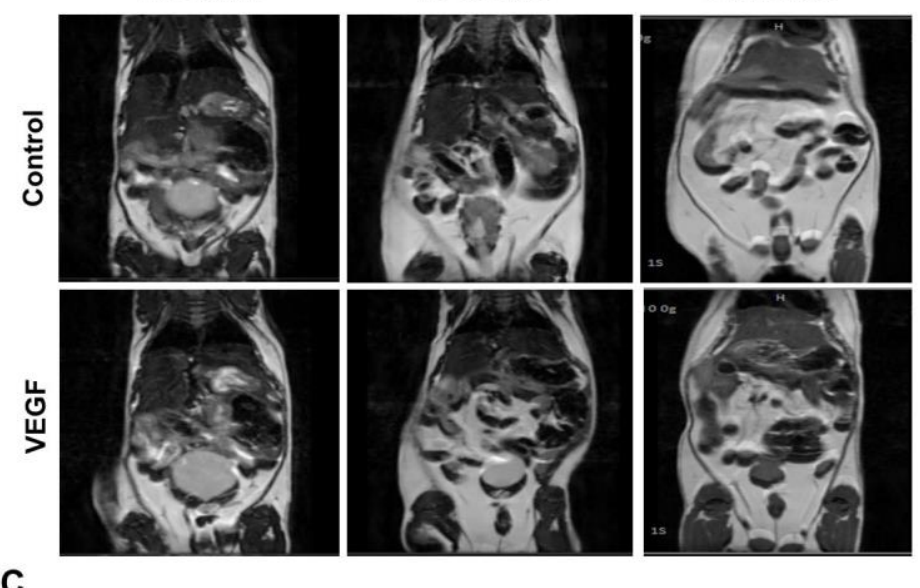

B

C

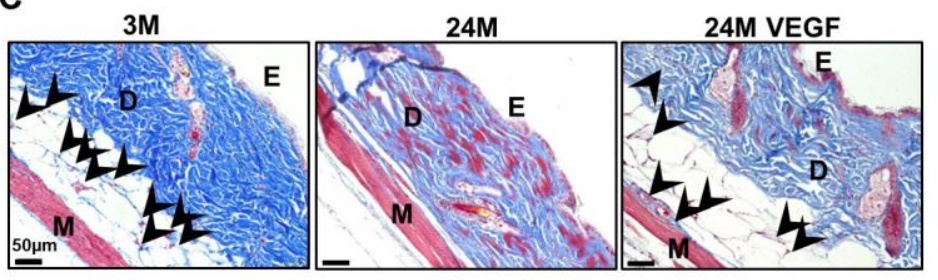

D

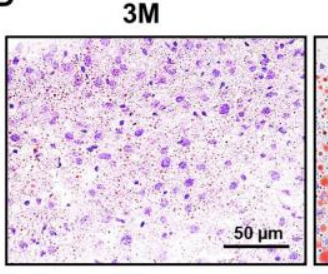

E

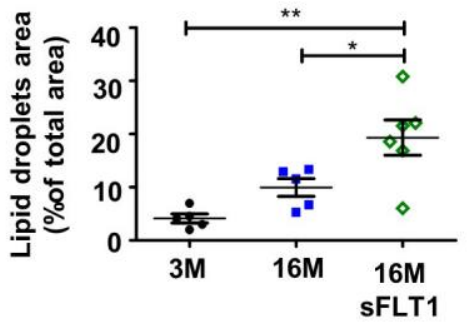

G

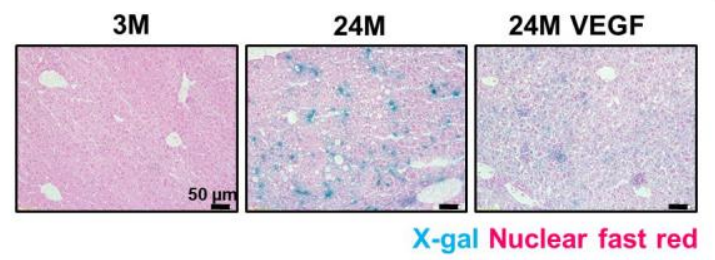

24M VEGF

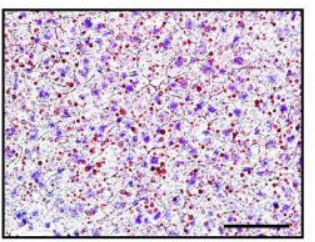

Oil Red O Hematoxilin

F

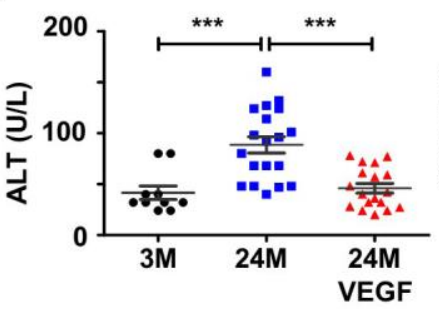

H

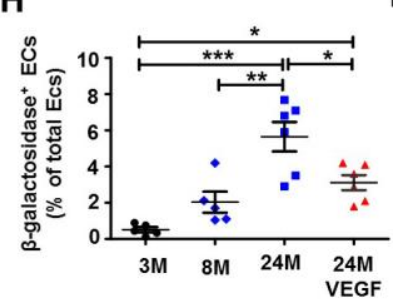

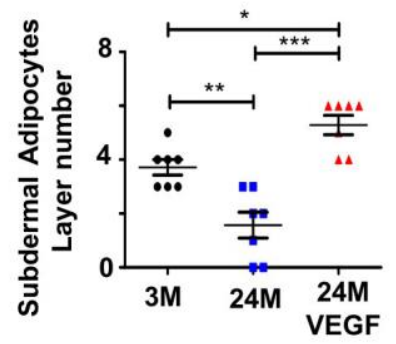
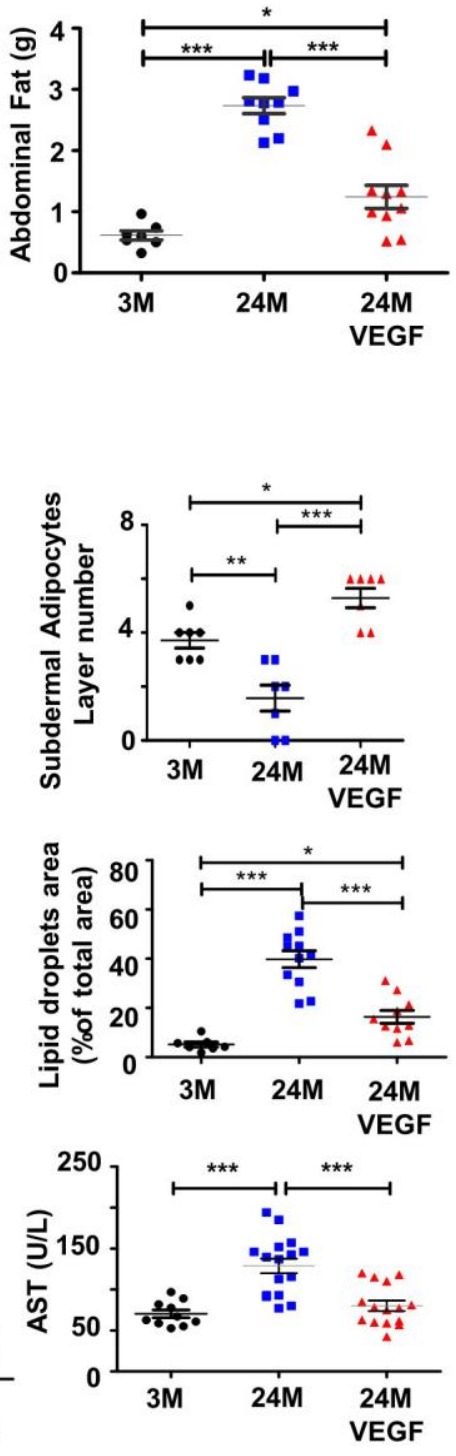

I

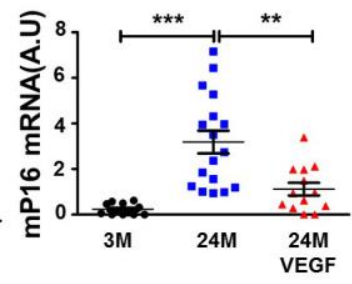

Fig. 3. Age-related alterations in fat distribution and liver pathology negated by VEGF. (A) Progressive accumulation of abdominal fat in a representative pair of control and VEGF male mice littermates visualized by MRI (fat appears white) ( $n=4$ for each group of mice) (B) Combined weights of epididymal and inguinal fat resected from young and old male mice. (10>n>6 for each group of mice) (C) Left: Representative Masson- 
Trichrome stained skin sections from young (3M) and old (24M) male mice. Arrowheads highlight subdermal capillaries detectable in young and old VEGF mice but not in the greatly diminished subdermal fat observed in old mice. $\mathbf{E}$ epidermis, $\mathbf{D}$ dermis, $\mathbf{M}$ muscle. Right: Number of subdermal adipocytes layers $n=5$ mice per group. (D) Representative liver sections from young $(3 \mathrm{M})$ and old $(24 \mathrm{M})$ mice stained with Oil-red-O and

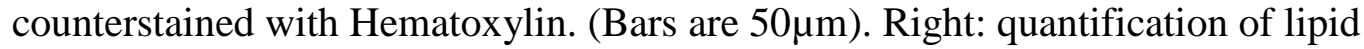
accumulation in hepatocytes. Each dot represents the relative average area covered by Oilre-O staining in 3 to 6 different sections per mouse, $11>n>7$ mice per group. (E) Quantification of lipid accumulation in hepatocytes in livers isolated from young (3M), adult (16 M) and age-matched adult sFlt mice, done as in (D), $n=5$ mice per group. $(\mathbf{F})$ Serum levels of the liver enzymes ALT and AST indicative of hepatocytes injury. (19>n>10 mice per group). (G) Representative liver cryosections stained for SA- $\beta g a l$ activity in young $(3 \mathrm{M})$ and old $(24 \mathrm{M})$ mice, showing age-related increase in senescent cells accumulation, mostly in BVs, and their reduced accumulation in old VEGF mice. $(\mathrm{Bar}=50 \mu \mathrm{m})$. (H) The fraction of senescent ECs $\left(\mathrm{Cd} 45^{-}\right.$Ter119- CD31 ${ }^{+} \mathrm{SA}-\beta-\mathrm{gal}^{+}$cells) from total ECs $\left(\mathrm{Cd} 45^{-}\right.$Ter119- $\left.{ }^{-} \mathrm{CD} 31^{+} \mathrm{SA}-\beta-\mathrm{gal}^{-}\right)$enumerated by FACS analysis. $(6>n>5$ mice per group of mice of the indicated age). (I) Relative levels of p16 mRNA expression in liver measured by RT-PCR.

Statistical analysis: Each dot represents a mouse. p derived from (B, C, D, E, F, H, I) Oneway ANOVA with Tukey post-tests. Values are mean +/-SEM. p values indicated as * $<0.05 ; * *<0.01 ; * * *<0.001$. p values $>0.05$ are not indicated. 
A

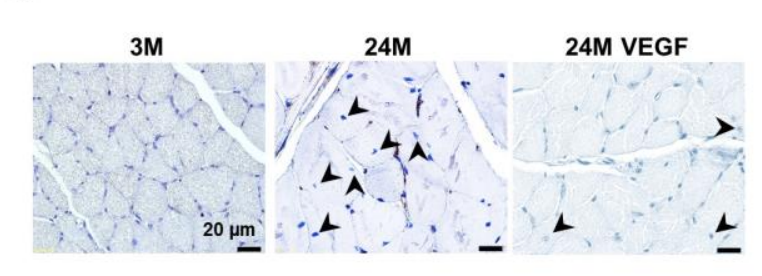

C
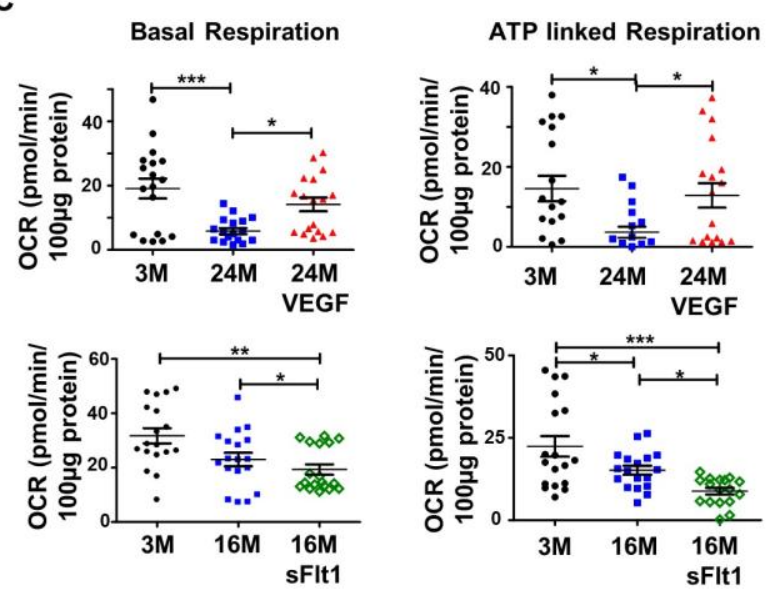

D

D

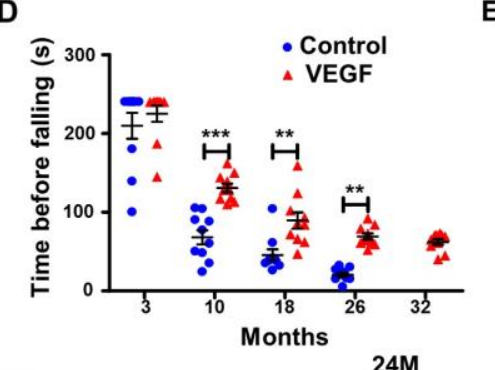

G

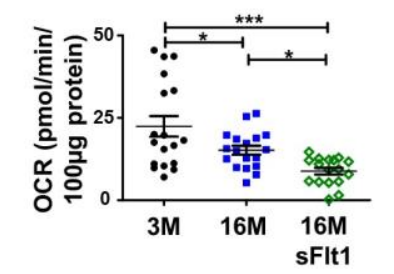

E

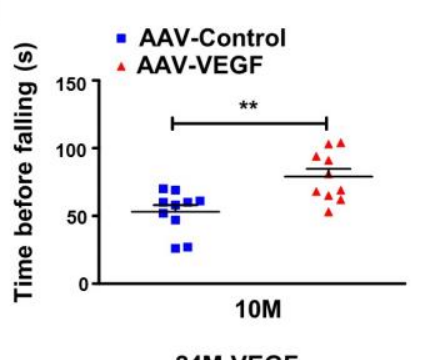

24M
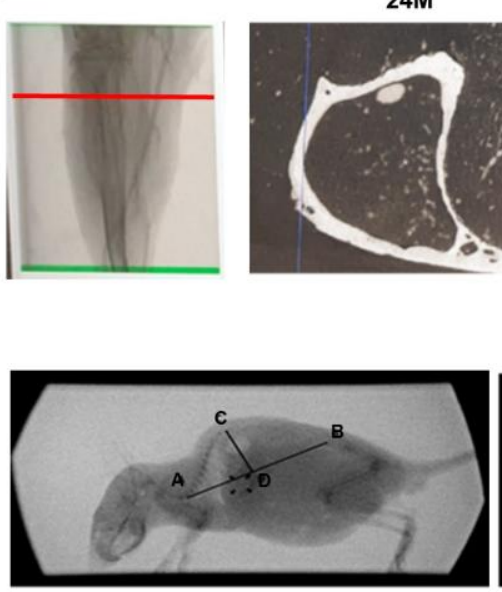

$24 M$

24M VEGF

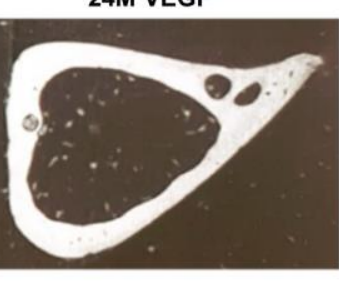

H

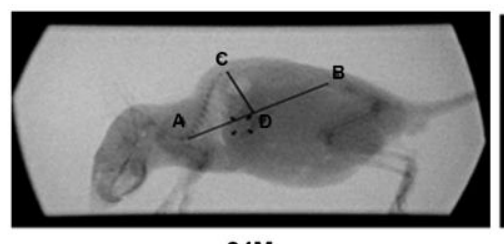

24M VEGF

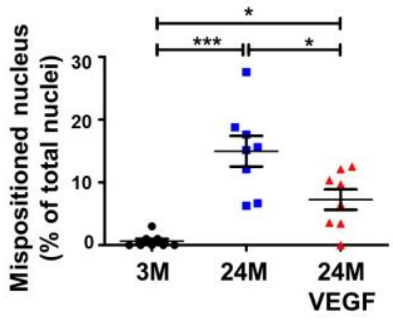

Maximal Respiration
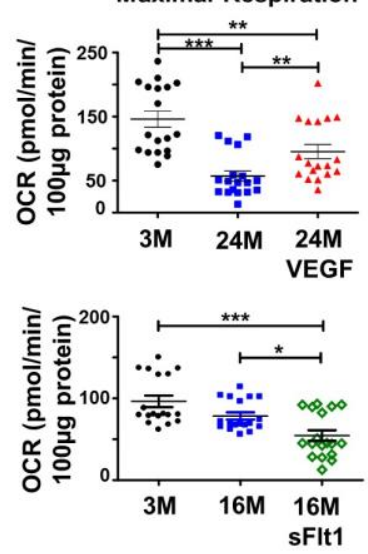

F
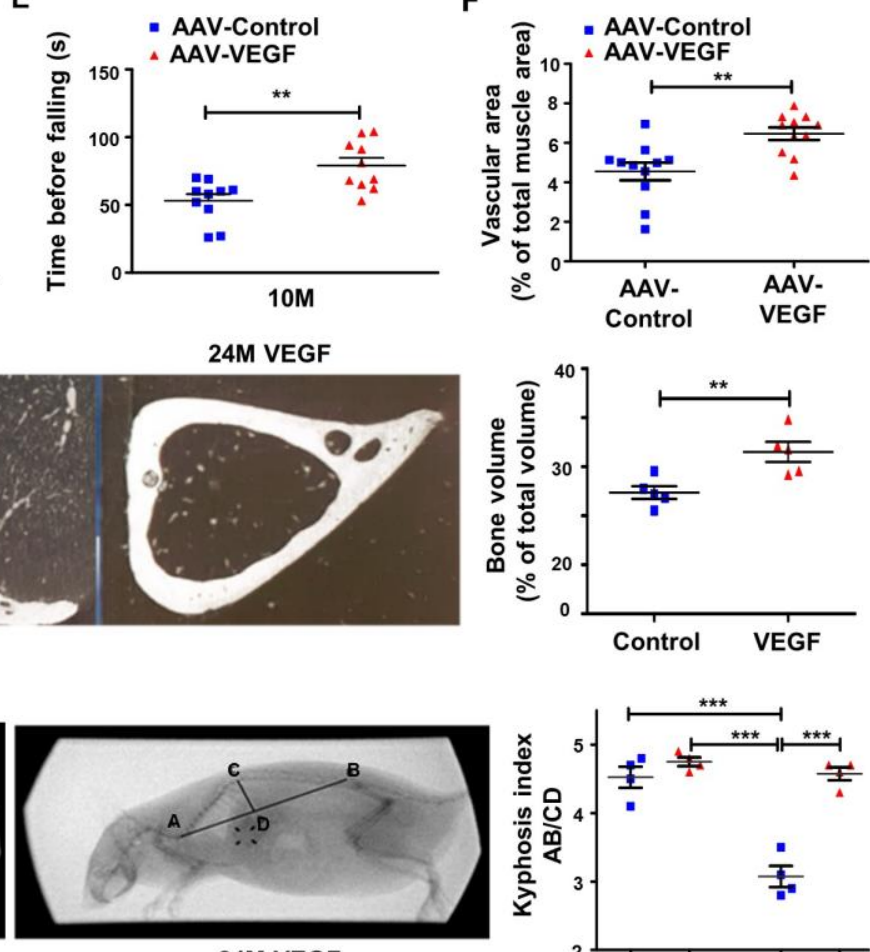
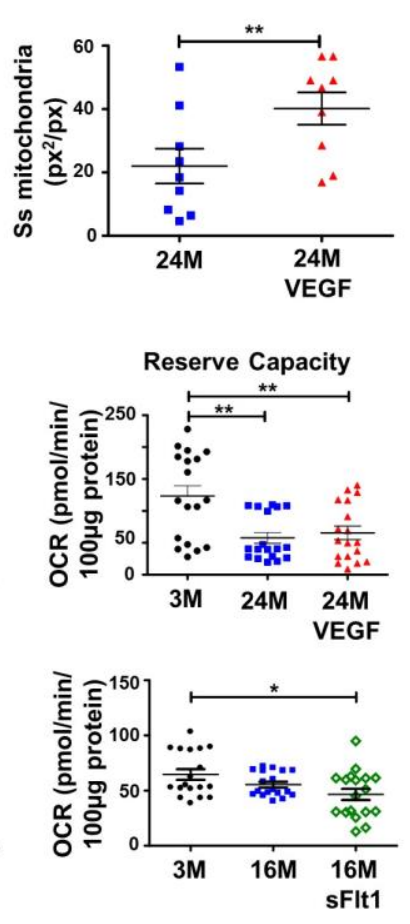

EGF
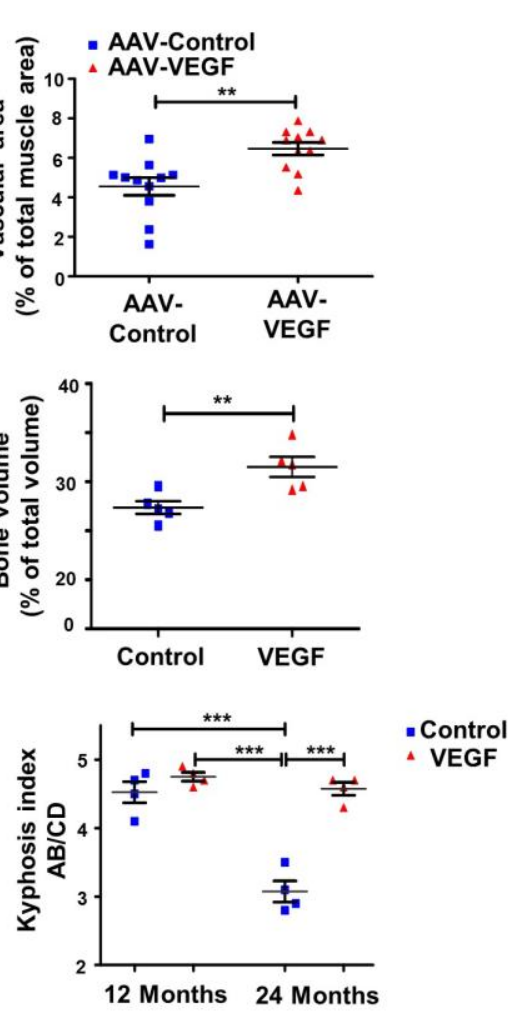

Fig. 4. Alleviation of sarcopenia and osteoporosis in old VEGF-treated mice. (A) (left) Representative hematoxylin-stained sections of hind limb muscle showing mispositioned, centrally located nuclei in muscle fibers of old (24M) control mice (arrowheads) but rarely in young $(3 \mathrm{M})$ or old $(24 \mathrm{M})$ VEGF mice. (Bars=20 $\mu \mathrm{m})$. Right: Fraction of centrally located 
nuclei measured in three sections each from 8 mice per group. (B) Density of

Subsarcolemmal (Ss) mitochondria: each dot represents the relative area in a sarcolemma segment occupied by Ss mitochondria. For each fiber, the entire sarcolemma was analyzed. $n=3$ mice per group and 3 fibers per mouse. (C) Oxygen consumption rate (OCR) in myofibrils isolated from hind limb muscle of the indicated mice measured ex vivo using a Seahorse $^{\mathrm{TM}}$ platform. Data were compiled from three different experiments with each dot representing pooled fibers isolated from the muscle of a different mouse. OCR values are normalized to total protein content. $n=4$ mice per group. (D) Mice of the indicated ages were tested for the time they can stay on a rotating rod. $n=10$ mice per group (E) Wild type mice were infected with AAV-VEGF (or with control virus) at the age of eight months and subjected to a rotarod test two months later. $n=10$ mice in each group. (F) Microvascular densities in muscle of the same mice used in (E). (G) Left: Representative micro-CT bone images of hind limb tibiae of 24 months old female control and VEGF littermates. Images shown are a transverse view at the level marked on the left with a redline. Right: Bone volume calculated on the basis of micro-CT images and expressed as the percentage of total area occupied by bone. $n=5$ mice in each group $(\mathbf{H})$ Representative images of whole body X-rays radiography of 24 months old male control and VEGF littermates. Kyphosis indices were measured as previously described $(\underline{58})$ from X-ray radiography-generated images in mice of the indicated ages. $n=4$ mice in each group

Statistical analysis: $\mathrm{p}$ values derived from (A, B, C, H) One-way ANOVA with Tukey post-tests. (D, E, F, G) two-tailed unpaired Student's t test. Values are mean+/-SEM p values indicated as $*<0.05 ; * *<0.01 ; * * *<0.001$. $\mathrm{p}$ values $>0.05$ are not indicated. 
A

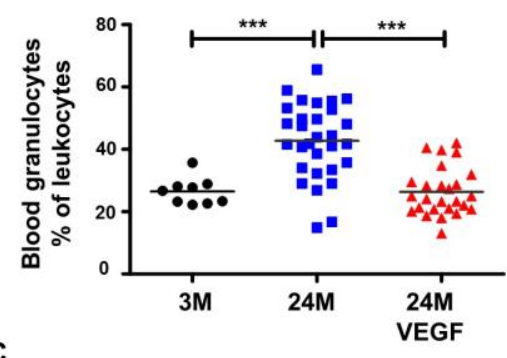

C

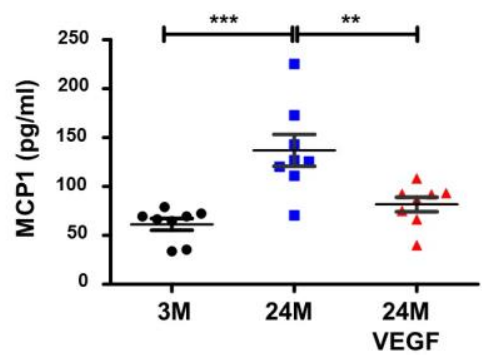

D
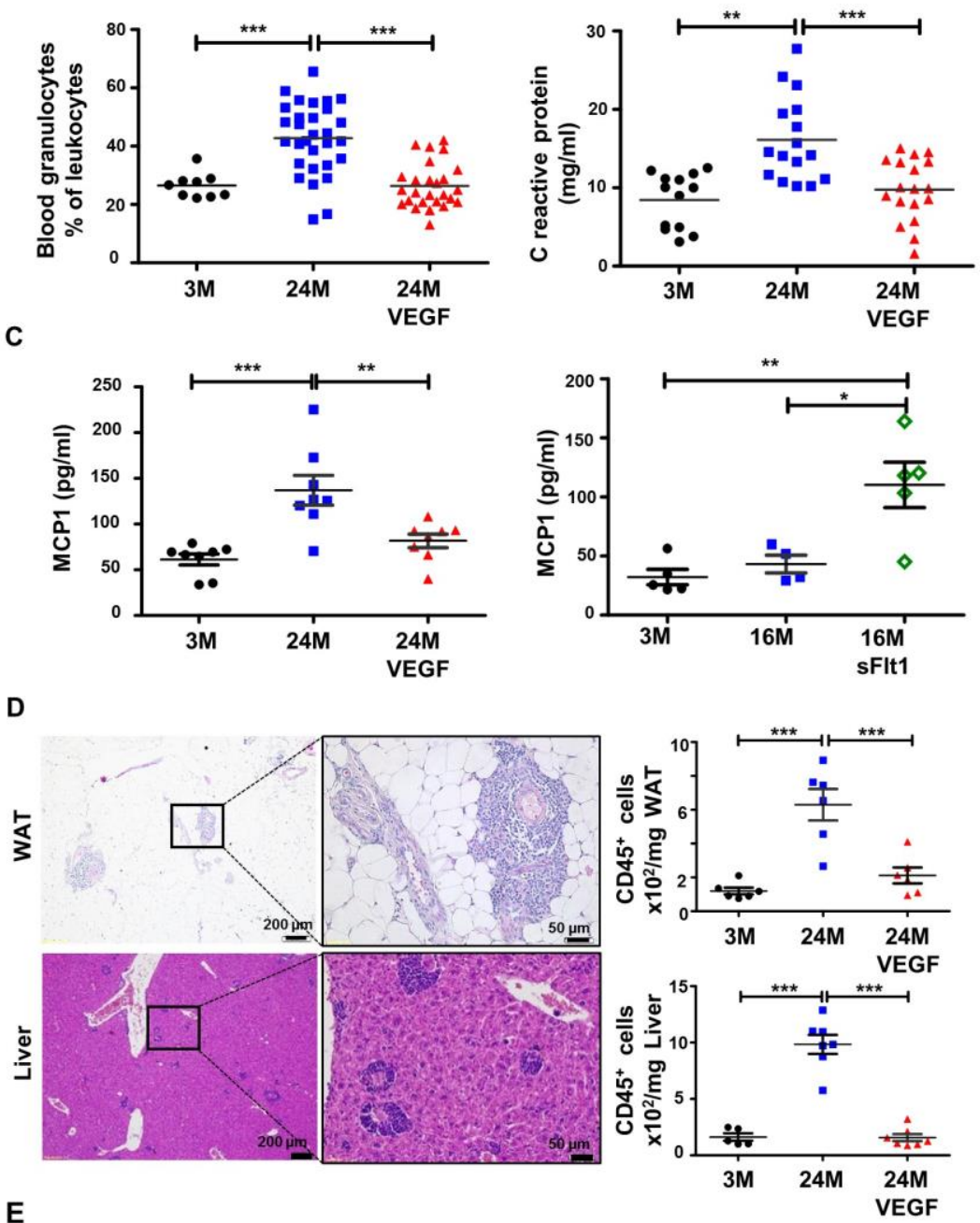

E

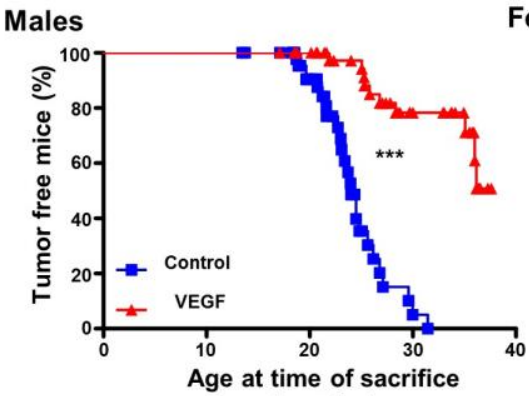

(months) 
liver sections from $18 \mathrm{M}$ old control mice. Note multiple foci of perivascular and perinecrotic immune cells infiltrates (boxed areas enlarged) indicative of inflammaging. Significantly fewer foci of inflammatory infiltrates were detected in age-matched VEGF mice (not shown). Right: CD45 immune cells in WAT and liver of the indicated age and genotype. $n=5$ mice per group. (E) Spontaneous tumors detected at sacrifice in control and VEGF mice. Tumors were routinely recorded at time of sacrifice and percent of animals remaining tumor-free was determined separately for males and females. The survey included 50 mice of each group (200 in total) Statistical analysis: Each dot represents a mouse. $\mathrm{p}$ values derived from (A, B, C, D) One-way ANOVA with Tukey post-tests. (E) log-rank (Mantel-Cox) tests. Values are median $+/$ - SEM. p values indicated as $*<0.05$; $* *<0.01 ; * * *<0.001$. $\mathrm{p}$ values $>0.05$ are not indicated. 


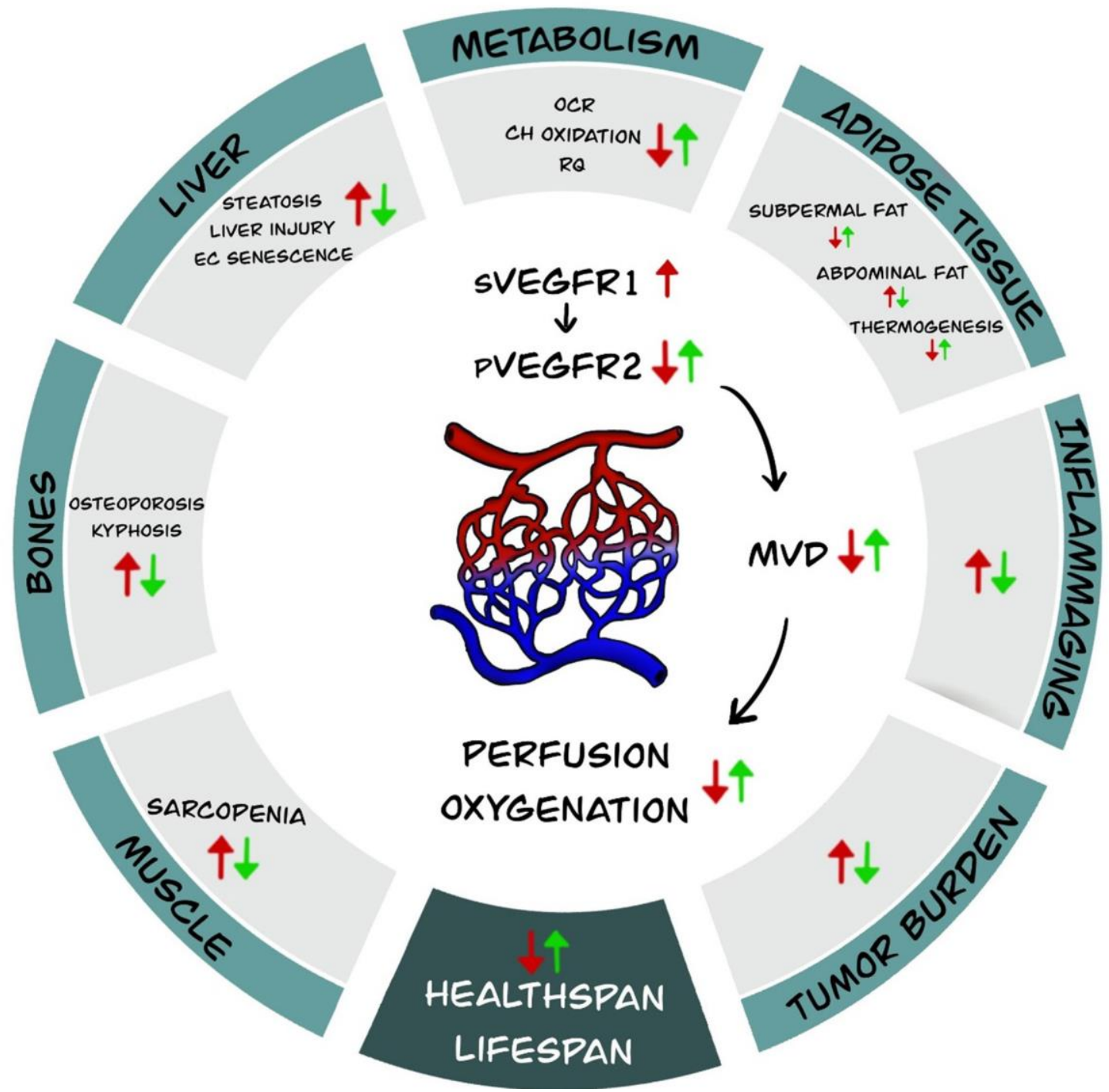

Fig. 6. Centrality of VEGF and vascular alterations in age-related phenotypes. A graphic representation of age-associated alteration in organ physiology and function (red arrows) alleviated by VEGF manipulation (green arrows). s VEGFR1=soluble VEGF receptor 1, pVEGFR2= phosphorylated VEGF receptor 2, MVD= microvascular density, $\mathrm{EC}=$ endothelial cell, $\mathrm{OCR}=$ oxygen consumption rate, $\mathrm{CH}=$ carbohydrate, $\mathrm{RQ}=$ respiratory quotient. 


\section{Science \\ МlAAAS}

\section{Supplementary Materials for}

\section{Counteracting age-related VEGF signaling insufficiency promotes healthy aging and extends lifespan}

M. Grunewald ${ }^{1 *}$, S. Kumar ${ }^{1 \dagger}$, H. Sharife ${ }^{1 \dagger}$, E. Volinski ${ }^{1 \dagger}$, A. Gileles-Hillel ${ }^{1,3,7}$, T. Licht $^{1}$, A. Permyakova ${ }^{2}$, D. Maimon ${ }^{3}$, L. Hinden ${ }^{2}$, S. Azar ${ }^{2}$, Y. Friedman ${ }^{4}$, P. Kupetz ${ }^{1}$, R. Tsuberi ${ }^{1}$, T. Oliven ${ }^{1}$, A. Anisimov ${ }^{5}$, K. Alitalo ${ }^{5}$, M. Horwitz ${ }^{1}$, S. Leebhoff ${ }^{1}$, O.Z. Khoma ${ }^{6}$, R. Hlushchuk ${ }^{6}$, V. Djonov ${ }^{6}$, R. Abramovitch ${ }^{3}$, J. Tam ${ }^{2}$ and E. Keshet ${ }^{1 *}$.

Correspondence to: myriamg@ekmd.huji.ac.il; elik@ekmd.huji.ac.il

This PDF file includes:

Materials and Methods

Figs. S1 to S20

Tables S1 to S4

Captions for Data S1 to S20 


\section{Materials and Methods}

Mice strains

Transgenic VEGF and control mice originated from transgenic BALB/cOlaHsd mice, which were backcrossed into C57BL/6J background for more than 10 generations. Transgenic mice were maintained as heterozygous and colonies were refreshed by backcrossing to C57BL/6JRccHsd new breeders (see (46) for details on this specific strain obtained from Envigo RMS Israel). The genetic background of parents and littermates used in this study was retrospectively verified by single nucleotide polymorphism (SNP) analysis (performed at the Jackson laboratory) and was found to contain 0.7 to $1.4 \%$ Balb/cJ into C57BL6 background (19.26 to 25\% C57BL6/NJ and 75 to $80.74 \%$ C57BL6/J).

Transgenic VEGF production by hepatocytes was induced in a bi-transgenic 'Tet-off' system composed of a 'driver' line in which a tetracycline-regulated transactivator (tTA) protein is driven by a C/EBP $\beta$ (also known as liver-activator protein (LAP) promoter (47) and a 'responder' tetracycline-responsive promoter element (TRE) -VEGF-A164 line (48). To keep the system in the 'off' mode $500 \mu \mathrm{g} / \mathrm{ml}$ tetracycline (tetracycline hydrochloride TB0504, Biobasic) is usually added to the drinking water in breeding cages and from weaning onwards and transgenic VEGF is induced by removal of tetracycline. We found that during adulthood, the system is somewhat leaky and low levels of VEGF are also released to the circulation in the intended 'off' mode in some litters. With the aim of reproducibly attain a low level of circulating transgenic VEGF, we used a limited level of tetracycline $(320 \mu \mathrm{g} / \mathrm{ml})$, from weaning onwards. Levels of circulating VEGF were measured bimonthly using a mouse specific VEGF ELISA (R\&D) and were found to be in the range of $80-250 \mathrm{pg} / \mathrm{ml}$. Littermates resulting from a [heterozygous driver: heterozygous responder] mating who have inherited only one of the transgenes, and grown in the same cage, served as controls. To obtain sufficiently large number of doubletransgenic VEGF mice, each male mouse was housed together with 2-3 female mice and offspring's born in the same day were considered as a single litter. The genetic composition of each individual mouse used for survival studies, arranged by litter, is indicated in tables S1 and S2.

Transgenic sFlt1 and control mice are on a BALB/cOlaHsd background. A soluble form of the human VEGFR1 (sFlt1) consisting of the extracellular part of the receptor, acting as a decoy receptor for VEGF, was conditionally induced in endothelial cells using a bitransgenic 'Tet-off' system with Cdh5 promoter-tTA (49) serving as the driving transgene and a TRE-sFlt1 as the responder transgene (19). Double-transgenic mice were kept in the 'off' mode by inclusion of $500 \mu \mathrm{g} / \mathrm{ml}$ Tetracycline (TB0504, Biobasic in 3\% sucrose) in the drinking water and sFlt1 was induced at the indicated ages by Tetracycline withdrawal. Levels of hsFlt1 induced were determined periodically using a human specific VEGFR1 ELISA (R\&D).

Adeno-Associated Virus (AAV)- mediated VEGF delivery: Recombinant AdenoAssociated Viral vectors (AAV, serotype 9) encoding mouse VEGF164 (AAV-VEGF) or scrambled control sequence (AAV-Control) were constructed and amplified as described previously (50) but using the Open Reading Frame of VEGF-A 164 (Genbank sequence NM_009505). Low titers of virus were injected intraperitoneally at a titer of $5.107 \mathrm{vp}$ in $150 \mu \mathrm{l}$ sterile saline onto C57BL/6JRccHsd (Envigo RMS Israel). Infection efficiency was verified by measuring VEGF circulating levels using VEGF ELISA (R\&), from two weeks following the injection and monthly thereafter. Infection efficiency was verified by 
measuring VEGF circulating levels using ELISA, two weeks following the injection and monthly thereafter.

General mouse procedures

All animal procedures were performed in accordance with the Hebrew University of Jerusalem Institutional Animal Care and Use Committee guidelines under animal ethics protocols MD-15513-5.

Mice were housed in a SPF facility with controlled temperature and humidity on $12 \mathrm{~h}$ light/dark cycles and fed Ad-libitum with regular rodent's chow.

The number of animals shown in each figure is indicated in the legends as $n=x$ mice per group.

Mice used for lifespan measurements were maintained until near end of life and were euthanized when clinical signs suggested death within 24 hours (except for censored mice). A complete necropsy was performed on all mice and discernable tumors were recorded.

For complete blood counts, blood was drawn from the tail vein and at the time of sacrifice, by cardiac puncture. Blood was collected into EDTA-coated collection tubes (BD, K2E microtainers) and analyzed by a Mindray BC-2800 Vet hematology analyzer. Plasma was separated by centrifugation for $20 \mathrm{mn}$ at $2000 \mathrm{~g}$.

\section{ELISA}

The following commercially available ELISA kits were used to measure protein levels in plasma and tissue lysates: mouse VEGF- Quantikine ELISA kit (R\&D Systems; MV00), mouse VEGF Receptor 1- Quantikine ELISA kit (R\&D Systems; MVR100), human VEGF Receptor 1 -Quantikine ELISA kit (R\&D Systems; DVR100B), mouse C- reactive Protein - Quantikine Elisa kit (R\&D Systems MCRP00) and mouse MCP1- Quantikine Elisa kit (R\&D systems MJE00B). Tissue lysates for ELISA were homogenized in PBS using a Next Advance Bullet Blender homogenizer, stored overnight at $-20^{\circ} \mathrm{C}$, and lysed by two freeze-thaw cycles followed by centrifugation for $5 \mathrm{~min}$ at 5,000 $\mathrm{g}$ and supernatant collection. Bradford assay was used to standardize tissue lysate concentrations according to the manufacturer's instructions (Bio-Rad Protein Assay Dye Reagent Concentrate; 5000006). ELISAs were read at $450 \mathrm{~nm}$ with a reference value of $540 \mathrm{~nm}$ using a Tecan Infinite f200 Pro 96-well plate reader.

\section{Liver enzymes level measurement in serum}

Serum alanine aminotransferase (ALT) and aspartate aminotransferase (AST) levels were determined using COBAS C-111 chemistry analyzer (Roche, Switzerland)

\section{Immunoprecipitation and Western Blot}

Indicated organs, harvested at the specified ages, were homogenized in lysis buffer (20mM Tris $\mathrm{HCl}$ [pH 8], $137 \mathrm{mM} \mathrm{NaCl}, 1 \%$ Nonidet P-40 and 2mM EDTA) supplemented with protease inhibitor cocktail (SIGMAFAST, Merck) and phosphatase inhibitor cocktail (PhosSTOP, Merck). For immunoprecipitation, $1 \mathrm{mg}$ of total protein was diluted to a volume of $1 \mathrm{ml}$ and incubated overnight at $4{ }^{\circ} \mathrm{C}$ with $10 \mu \mathrm{l}$ VEGFR2 antibody (Cell Signaling \#2479) bound to $100 \mu$ l of Protein A-agarose beads (Santa Cruz Biotechnology, \#sc-2001). The next day, beads were washed 3 times in lysis buffer and 
were further boiled in $100 \mu \mathrm{l}$ of $1 \mathrm{X}$ SDS buffer (50 mM Tris $\mathrm{HCl}$ [pH 6.8], 2\% SDS, 6\% Glycerol, $0.004 \%$ Bromophenol blue and 1\% $\beta$-Mercaptoethanol). Immunoprecipitates were resolved by 4-20\% SDS-PAGE gel (Bio-rad, \#4568094) and transferred onto nitrocellulose membrane using Trans-Blot Turbo transfer system (Bio-rad, \#1704159). The membranes were then incubated in blocking buffer (3\% BSA in 1X Tris buffered saline with $0.1 \%$ Tween 20 [TBST]) for $2 \mathrm{~h}$ at room temperature followed by overnight incubation with the following antibodies: p-VEGFR2 (Cell Signaling \#2478, 1:500) or VEGFR2 (Cell Signaling \#2479, 1:500) at $4{ }^{\circ} \mathrm{C}$. The following day, the membranes were washed $3 \mathrm{X}$ with washing buffer (1X TBST) and incubated with appropriate HRPconjugated secondary antibody (Cell Signaling \#7074, 1:1000) for $2 \mathrm{~h}$ at room temperature. Signal was detected using chemiluminescent HRP substrates (Supersignal West Pico/Femto, Thermo Fisher Scientific, Millipore). Imaging and quantification of signal was done using ChemiDocTMXRS+ imager.

$\underline{\text { RNA isolation and cDNA preparation }}$

Tissues were homogenized using a Next Advance Bullet Blender homogenizer and RNA was isolated using TriReagant (Sigma) according to the manufacturer's instructions. RNA was quantified using a Nanodrop spectrophotometer. cDNA was prepared using a high-capacity cDNA reverse transcription kit (iScript cDNA synthesis kit (Biorad) with RNase inhibitor according to the manufacturer's instructions.

Quantitative PCR

FAST SYBR Green Master Mix (Applied Biosystems) was used for qPCR according to the manufacturer's instructions. Real-time PCR was performed on an Applied Biosystems StepOne Plus qPCR machine. An extra dissociation step was added. qPCR results were analyzed using StepOne Plus Software v2.3 (Applied Biosystems).

Expression of all genes was normalized to GAPDH except for $\mathrm{mP16}$ that was normalized to HPRT.

Primers were designed by using Nucleotide database (NCBI). Primers were synthesized by Integrated DNA Technologies. The sequences for the primers used were as follows:

m-Flt-F: GGGTGTCTATAGGTGCCGAG

m-Flt-R: AGCCAAAAGAGGGTCGCA

m-sFlt1-F: TCTAGAAGACTCGGGCACCTATG

m-sFlt1-R: CGCAGTGCTCACCTCTAACG

mCDH5-F: TCCTCTGCATCCTCACTATCA

mCDH5-R: GTAAGTGACCAACTGCTCGTG

mGAPDH-F: CCTGGAGAAACCTGCCAAG

mGAPDH-R: CAACCTGGTCCTCAGTGTAGC

mP16INK4a expression analysis was performed using Taqman Master Mix (Applied

Biosystems) according to manufacturer's instructions, using the following primers

mP16-F:CGGTCGTACCCCGATTCAG

mP16-R: GCACCGTAGTTGAGCAGAAGAG.

Relative gene expression was normalized to HPRT with commercially provided primers (Thermo Fisher- 4331182). 
Tissue section staining

$5-\mu \mathrm{m}$ paraffin sections were cut from indicated organs at specified ages as indicated in the figure legends. Paraffin-embedded tissue sections were stained with hematoxylin and eosin (H\&E) for routine examination.

For analysis of skin sections, $5-\mu \mathrm{m}$ paraffin sections from dorsal skin flaps were stained with Masson-Trichome (Diagnostic Biosystems \#KT034) highlighting muscle and intercellular fibers in red, nuclei in black and collagen in blue.

For Oil-red-O staining, non-fixed tissue was embedded in OCT (Tissue-Tek) and frozen in liquid nitrogen. $10 \mu \mathrm{m}$-thick slices were prepared using a Leica CM1950 cryostat and stored at $-80^{\circ} \mathrm{C}$ until used. Sections were then immersed in Oil Red O working solution ( $0.5 \%$ Oil red O (Sigma o0625) in isopropanol) for 30min and counterstained with Hematoxylin. The relative area covered by red-stained oil droplets was calculated using an ImageJ software.

For SA- $\beta$-gal activity cryosection staining, freshly prepared liver cryosections (Leica CM1950 cryostat) were fixed with $0.5 \%$ glutaraldehyde in PBS for 15 min, washed with PBS supplemented with $1 \mathrm{mM} \mathrm{MgCl}$, and stained for 6-8 h in X-Gal staining solution (PBS/MgCl2, 0.2M K3Fe(CN)6, 0.2M K4Fe(CN)6 3H20, X-Gal) and counterstained with Nuclear Fast Red (Sigma).

For immunostaining, antigen retrieval was performed by citrate buffer ( $\mathrm{pH}$ 6; Zymed Laboratories) in a pressure cooker. Sections were then blocked in 1\% BSA and 0.5\% Triton X-100. Primary antibodies used were: anti-mouse sFlt1 (INVITROGEN \#361100), anti-mouse CD31 (ABCAM \#ab28364), anti-mouse UCP1 (ABCAM \#ab10983). Sections were incubated overnight in primary antibody diluted in 1\% BSA and $0.5 \%$ Triton X-100 at $4^{\circ} \mathrm{C}$. Universal anti mouse and rabbit Ig was used as a secondary antibody according to the manufacturer's instruction (ImmPress Reagent Kit peroxidase \#MP7500- Vector). Peroxidase activity was detected using AEC staining kit according to the manufacturer (Sigma \#AEC101-1KT). Sections were counterstained by standard Hematoxylin (Meyer's hematoxilin (Sigma)).

Fluorescent lectin (Vector \# DL-1207) was used to detect capillaries in brown adipose tissues. Sections were mounted with Permafluor mounting medium containing DAPI (Thermo Fisher Scientific). Confocal images were taken using an Olympus FV-1000 Confocal and images were analyzed with FV10-ASW 3.0 Viewer and ImageJ software.

Microvascular density (MVD) and perfusion mapping

MVD was calculated from CD31- or lectin- stained tissue sections using ImageJ software and expressed as the relative area covered by stained capillaries. Each dot in the graphs represents the average of measures obtained from 7 to 10 fields in 2 different tissue sections per mouse.

For perfusion mapping, perfused vessels were selectively labelled by tail vein injection of a solution containing $0.16 \mu \mathrm{g}$ of Alexa-Fluor 647 conjugated CD144 antibody (Biolegend, BV13) per gram of body weight, 10 minutes before mice were euthanized by overdose of anesthetics Ketanest $(100 \mathrm{mg} / \mathrm{kg})$ and Rompun $(10 \mathrm{mg} / \mathrm{kg})$. Mice were perfused through the left ventricle with $20 \mathrm{ml}$ of PBS and then with $60 \mathrm{ml}$ of ice-cold fixing solution (4\% buffered Paraformaldehyde, $\mathrm{pH}-7.36$ ). Fixed tissues were harvested and left in $30 \%$ sucrose in $4 \%$ PFA solution for 24 hours at $4^{\circ} \mathrm{C}$. Tissues were 
then embedded in OCT, snap frozen in liquid nitrogen and cryosectioned. 50 $\mu$ m-thick Zstacked images were captured using a Zeiss LSM 710 confocal microscope and the relative area covered by stained capillaries was calculated using Image Pro-Plus analysis software (Media Cybernetics).

\section{Ultrasound and Photoacoustic imaging}

High-resolution ultrasound imaging was performed using a Vevo3100- LAZRX small animal US combined with photoacoustic (PA) imaging system (Visualsonics, Toronto, Canada), with a MX-550D linear-array transducer (40-MHz center frequency) used to acquire all images. A tunable laser supplied 10-20 mJ per pulse over the 680-970-nm wavelength range, with a pulse repetition frequency of $20 \mathrm{~Hz}$. Once initialized, the system was switched to the oxy/hemo mode to measure $\mathrm{sO} 2$ using the following parameters: depth, $10.00 \mathrm{~mm}$; width, $14.08 \mathrm{~mm}$; wavelength, 750 and $850 \mathrm{~nm}$ for the total hemoglobin concentration threshold ( $\mathrm{Hbt}$ ), and $\mathrm{sO} 2$, respectively. For presentation, hind limb $\mathrm{sO} 2$ maps were pseudo-colored. Mice analyzed were anesthetized with isoflurane $(2.0 \%)$ and placed in a supine position on a heated platform, with body temperature, heart rate, and respiration rate monitored. All images were acquired by placing the probe directly over the right hind limb. Before $\mathrm{sO} 2$ measurement, B-mode and Doppler US images were acquired to evaluate femoral artery blood flow and identify the region of interest in the hind limb muscle. The peak systolic velocity (Vs) and the minimal end diastolic velocity $(\mathrm{Vd})$ were calculated over an average of three cardiac cycles using Vevo Lab software.

Body composition analysis

Total body fat and lean masses were determined by EchoMRI-100H TM (Echo Medical Systems LLC, Houston, TX, USA).

Multi-parameter metabolic assessment

Metabolic and activity profiles of the mice were assessed by using the Promethion HighDefinition Behavioral Phenotyping System (Sable Instruments, Inc., Las Vegas, NV, USA) as described previously (51). Briefly, mice with free access to food and water were subjected to a standard $12 \mathrm{~h}$ light/12 h dark cycle, which consisted of a $48 \mathrm{~h}$ acclimation period followed by $24 \mathrm{~h}$ of sampling. Respiratory gases were measured by using the GA-3 gas analyzer (Sable Systems, Inc., Las Vegas, NV, USA) using a pull- mode, negativepressure system. Air flow was measured and controlled by FR-8 (Sable Systems, Inc., Las Vegas, NV, USA), with a set flow rate of $2000 \mathrm{~mL} / \mathrm{min}$. Water vapor was continuously measured and its dilution effect on $\mathrm{O} 2$ and $\mathrm{CO} 2$ was mathematically compensated. Effective body mass was calculated by ANCOVA analysis as described previously (52). Respiratory quotient (RQ) was calculated as the ratio of $\mathrm{VCO} 2 / \mathrm{VO} 2$, and total energy expenditure (TEE) was calculated as VO2 x $(3.815+1.232 \times \mathrm{RQ})$, normalized to effective body mass, and expressed as $\mathrm{kcal} / \mathrm{h} / \mathrm{kgEff}$.Mass. Fat oxidation (FO) and carbohydrate oxidation $(\mathrm{CHO})$ were calculated as $\mathrm{FO}=1.69 \times \mathrm{VO} 2-1.69 \times \mathrm{VCO} 2$ and $\mathrm{CHO}=4.57 \times$ $\mathrm{VCO} 2-3.23 \times \mathrm{VO} 2$ and expressed as $\mathrm{g} / \mathrm{d} / \mathrm{kg}$ Eff.Mass . References for the equations used can be found in $(53,54)$.

Activity and position were monitored simultaneously with the collection of the calorimetry data using XYZ beam arrays with a beam spacing of $0.25 \mathrm{~cm}$. Food and water intakes were measured while calorimetric data were sampled. 
Flow cytometry

For WAT endothelial cells enumeration, a single-cell suspension containing the stromal cell fraction was prepared from WAT as previously described (55) and washed in staining buffer $(0.2 \%$ BSA and $5 \mathrm{mM}$ glucose in PBS). Hematopoietic cells were excluded using Pacific-blue rat anti-mouse CD45 (BioLegend; clone 30-F11) and rat anti-mouse Ter119 (BioLegend; clone TER-119). Endothelial cells were then identified with PE-rat anti-mouse CD31 (BioLegend clone 390) and biotin rat anti-mouse Panendothelial cell Antigen (BioLegend clone MECA-32) with APC/cy7 Streptavidin (BioLegend \#405208).

Immune cells infiltrates in WAT and Liver were identified by exclusion of erythrocytes (using Pacific blue rat anti-mouse Ter119 (BioLegend; clone TER-119)) and marking of leukocytes using PE-rat anti-mouse CD45 (BD Bioscience clone 30-F11).

Liver Senescent endothelial cells were quantified using a protocol adapted from (56). A liver sample was homogenized to a single cell suspension and CD146+ endothelial cells were captured on CD146 (LSEC) microbeads (Miltenyi Biotec) according to the manufacturer instructions. Cells were pretreated with $300 \mu \mathrm{M}$ chloroquine for $20 \mathrm{~min}$ in fresh cell culture medium at $37 \mathrm{C}^{\circ}, 5 \% \mathrm{CO} 2$. The SA- $\beta$-gal substrate $\mathrm{C} 12 \mathrm{FDG}$ (Thermofisher \#D2893) was then added to a final concentration of $33 \mu \mathrm{M}$ and samples were incubated for $40 \mathrm{~min}$ at $37 \mathrm{C}^{\circ}, 5 \% \mathrm{CO} 2$. Cells were centrifuged at $1500 \mathrm{RPM}$, washed twice with PBS and resuspended in $100 \mu \mathrm{l}$ of staining solution containing Pacific-blue rat anti-mouse CD45 (BioLegend; clone 30-F11) and rat anti- mouse Ter119 (BioLegend; clone TER-119), PE-rat anti-mouse CD31 (BioLegend clone 390). Samples were incubated for $30 \mathrm{~min}$, washed and processed for flow cytometry.

Flow cytometry was performed on a MACS Quant Analyzer (Miltenyi), and data analyzed using FlowJo version 10.

\section{Oxygen consumption assay}

Mitochondrial oxygen consumption rates by isolated skeletal muscle fibers were measured ex-vivo using Agilent Seahorse XF24 Analyzer. Skeletal muscles (Tibialis Anterior and Extensor Digitorum Longus) were ressected from the specified experimental groups of mice. Myofibers were isolated by first, incubating the muscle tissue in $0.2 \%$ Collagenase type I in DMEM (Dulbecco's modified Eagle's mediums, high glucose, supplemented with L-glutamine and Sodium pyruvate- Biological Industries, \#01-055-1A) for $10 \mathrm{~min}$ at $37{ }^{\circ} \mathrm{C}$. Myofibers were then released through gentle flushing of the muscle using a $1 \mathrm{ml}$ pipette with a large bore to limit damage to the fibers. Single myofibers were then seeded on to a XF24 cell culture microplate pre-coated with $3 \mu 1$ of Matrigel (Corning, \#354230) in DMEM medium and incubated at $37{ }^{\circ} \mathrm{C}$ for $1 \mathrm{~h}$ at $5 \% \mathrm{CO} 2$. Medium was replaced with pre-warmed assay medium (Agilent Technologies, \#103334-100) and equilibrated for $1 \mathrm{hr}$ at $37{ }^{\circ} \mathrm{C}$. Meanwhile, Agilent Seahorse XF Assay Cartridge was loaded with Oligomycin $(1 \mu \mathrm{M})$, FCCP $(1 \mu \mathrm{M})$ and Rotenone/AntimycinA (5 $\mu \mathrm{M})$ in Ports A, B and C respectively. During the equilibration period, the compound loaded cartridge was calibrated as recommended by the manufacturer. Following 
calibration, the calibration plate was replaced with the plate containing the fibers and readings were recorded to calculate OCR. OCR was normalized to the total protein content of muscle fibers that was measured using Bradford assay (BioRad)

$\underline{\text { Rotarod assay }}$

Rotarod assay was performed as previously described (57). Mice were individually placed on a horizontal rod, which rotates with an acceleration rate of 5 rounds per minute (rpm) to achieve a maximum of $40 \mathrm{rpm}$ in 99 seconds. Time before falling from the rod is recorded (with a cut-off time of $4 \mathrm{~min}$ ). Each mouse underwent 3 consecutive trials separated by a 20 $\mathrm{mn}$ resting interval. Measures from the last 2 trials are averaged to determine time before falling.

\section{$\underline{\mu C T}$ imaging and bone morphometry}

Bones were harvested and immersion-fixed in $2 \%$ paraformaldehyde solution until scanning. To prevent their eventual displacement during the scan, the samples were wrapped into moisturized melamine foam and placed into a cylindrical sample holder. Bones were scanned in Bruker® Skyscan 1172 X-ray microCT system with 50kV acceleration voltage and $200 \mu \mathrm{A}$ current on the X-ray source. No filter was applied. The scanning was done for 360 degrees' rotation with rotation step of 0.1 degree resulting in 3600 projections. Each projection was $4000 \times 2672$ pixels with resolution of each pixel of $2.98 \mu \mathrm{m}$. Reconstruction was done with Bruker® reconstruction software NRecon. Prior to reconstruction, each dataset was corrected for thermal shifts as well as misalignment according to the manufacturer's protocol (Bruker microCT).

Each dataset was realigned and correspondingly resliced in ImageJ software in order to achieve same orientation of the tibia. Afterwards, the tibia segment of 200 virtual sections was delineated as volume of interest (VOI) for further bone morphometry analysis. The proximal limit of the VOI was located approximately $0.5 \mathrm{~cm}(\approx 170$ layers $)$ below the most distal ossified part of the tibias epiphyseal plate. Bone morphometry analysis was conducted using CTAn Software (Bruker microCT) according to the manufacturer's instructionsX-ray micrograph.

\section{Transmission electron microscopy}

Muscle and liver tissue were cut into $3 \mathrm{~mm}$ slices and fixed in $2 \%$ paraformaldehyde, $2.5 \%$ Glutaraldeyde in $0.1 \mathrm{M}$ Cacodylate buffer $(\mathrm{pH} 7.4)$ overnight at room temperature. Tissues were then rinsed 4 times, 10 minutes each, in cacodylate buffer and post fixed and stained with $1 \%$ osmium tetroxide, $1.5 \%$ potassium ferricyanide in $0.1 \mathrm{M}$ cacodylate buffer for 1 hour. Tissues were then washed 4 times in cacodylate buffer followed by dehydration in increasing concentrations of ethanol $(30 \%, 50 \%, 70 \%, 80 \%, 90 \%, 95 \%)$ for 10 minutes each step followed by $100 \%$ anhydrous ethanol 3 times, 20 minutes each, and propylene oxide 2 times, 10 minutes each. Following dehydration, tissues were infiltrated with increasing concentrations of Agar 100 resin in propylene oxide, consisting of 25, 50, 75, and $100 \%$ resin for 16 hours each step. The tissues were then embedded in fresh resin and let polymerize in an oven at $600 \mathrm{C}$ for 48 hours.

Embedded tissues in blocks were sectioned with a diamond knife on a Leica Reichert Ultracut S microtome and ultrathin sections (80nm) were collected onto $200 \mathrm{Mesh}$, thin bar copper grids. The sections on grids were sequentially stained with Uranyl acetate for 
5 minutes and Lead citrate for 2 minutes and viewed with Jeol, TEM 1400Plus, Japan with charge-coupled device camera (Gatan Orius SC600). Multiple sections derived from 3 mice of each group were examined. The most representative images are included in Supplemental figures S18 and S19.

Measurements of Kyphosis Index:

Radiography imaging of sedated mice immobilized on a radiographic table was done using OEC 9900 Elite (General Electric) in Roentgen mode. Mice were radiographed at the age of $12 \mathrm{mo}$ and, again, at the age of 24 mo. Kyphosis index (KI) was calculated as the distance between the caudal margin of the last cervical vertebra to the caudal margin of the sixth lumbar vertebra (usually corresponding to the cranial border of the wing of the ilium) divided by a line perpendicular to this from the dorsal edge of the vertebra at the point of greatest curvature, as previously described (58). Care was taken to avoid overextension or flexion of limbs.

$\underline{\text { Statistical analysis }}$

For the statistical analysis of survival and tumor incidence, Chi square log-rank (Mantel-Cox) test was used. For comparison between two groups, Student's t test was used. Comparisons between multiple groups with one variable were calculated by one- way ANOVA with Tukey post-test. Comparisons between multiple groups with two variables were calculated by two-way ANOVA with Bonferonni posttests. Comparisons between multiple groups with not normal distribution were calculated by ANOVA nonparametric test (Kruskal-Wallis test and Dunn's Multiple Comparison post-Test). $\mathrm{p}$ values assumed twotailed distribution and unequal variances $(*, \mathrm{P}<0.05$; **, $\mathrm{P}<0.01$; ***, $\mathrm{P}<0.001)$. Statistical information relevant to individual experiments is detailed in the figure legends. GraphPad Prism 7 software was used for statistical analysis. The investigators were not blinded during group allocation, the experiment, or when assessing the outcome. 


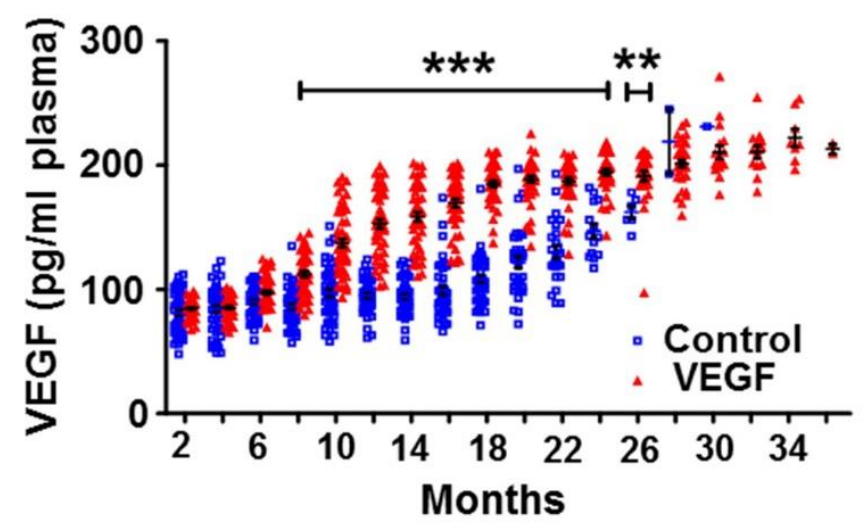

Fig. S1.

Plasma VEGF protein levels in female control and VEGF mice. VEGF levels were determined at progressive ages with a VEGF-A-specific ELISA. $n=50$ mice per group. Values measured in Control and VEGF male mice were significantly different between 8 to 26 months of age.

Statistical analysis. Each dot represents a mouse. $p$ values derived from Two-way ANOVA with Bonferroni post-tests. Values are mean +/-SEM.

$\mathrm{p}$ values indicated as $*<0.05 ; * *<0.01 ; * * *<0.001 . \mathrm{p}$ values $>0.05$ are not indicated 


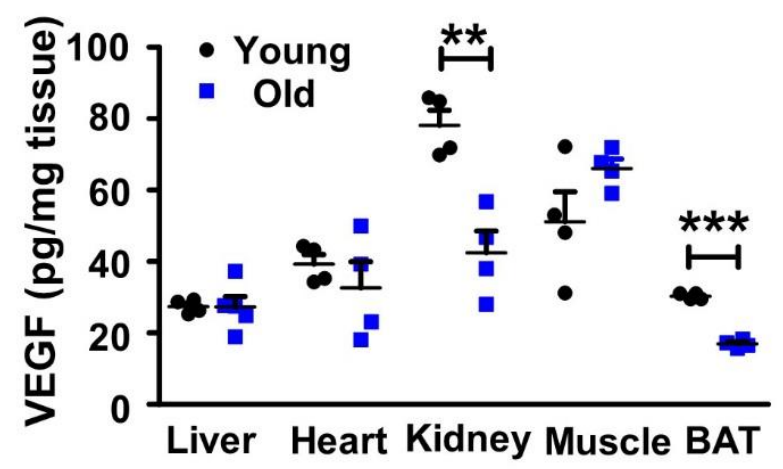

Fig. S2.

VEGF levels in peripheral organs of naïve mice. VEGF in lysates of the indicated organs prepared from young (2-4 months old) and old (20-24 months old) mice were determined with a VEGF ELISA. $n=4$ mice per organ.

Statistical analysis. Each dot represents a mouse. $\mathrm{p}$ values are derived from two-tailed Student's t test. Values are mean $+/-$ SEM.

$\mathrm{p}$ values indicated as $*<0.05 ; * *<0.01 ; * * *<0.001 . \mathrm{p}$ values $>0.05$ are not indicated 


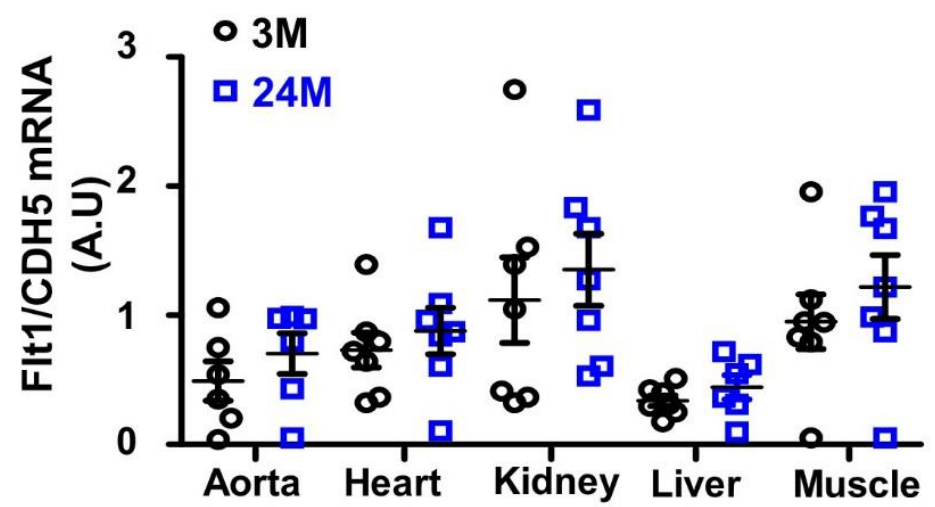

Fig. S3.

Age-related VEGFR1 (Flt1) expression. Relative levels of Flt1 expression in the indicated organs and ages, as determined by qPCR with primers detecting mRNAs encoding the fulllength receptor. Levels were standardized to the level of mRNAs encoding the pan-endothelial marker CDH5. $n=7$ mice per group

Statistical analysis. Each dot represents a mouse. $\mathrm{p}$ values are derived from two-tailed Student's t test. Values are mean $+/-$ SEM.

$\mathrm{p}$ values indicated as $*<0.05 ; * *<0.01 ; * * *<0.001 . \mathrm{p}$ values $>0.05$ are not indicated 


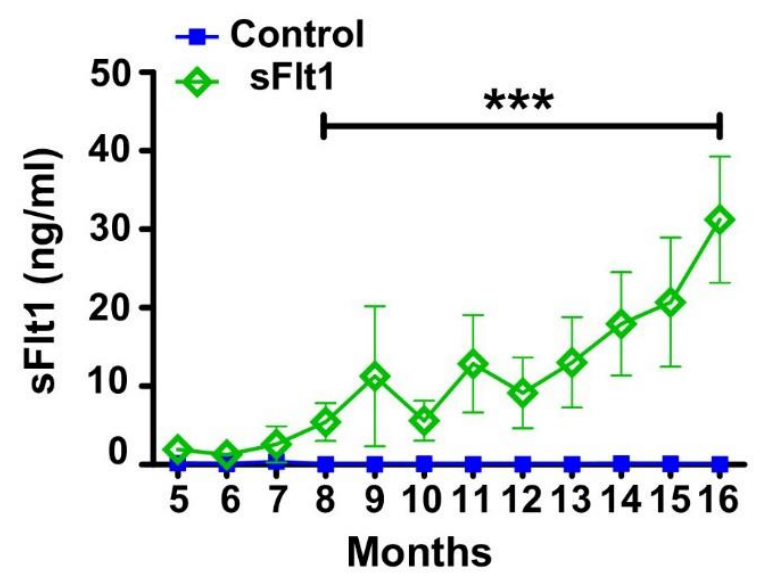

Fig. S4.

Circulating levels of transgenic sFlt1 induced in a VE-Cadherin::sFlt1 bi-transgenic system. Monthly monitoring with a human sFlt1 ELISA of plasma sFlt1 levels induced in the sFlt1 inducible system (see 'Methods' for details). Significantly higher levels of sFlt1 are measured from 8 months and onwards at each time point.

Statistical analysis: Each dot represents the mean concentration measured in the blood of 5 mice per group. $\mathrm{p}$ values are derived from Two-way ANOVA with Bonferroni post- tests. Values are mean +/-SEM. p values indicated as $*<0.05 ; * *<0.01 ; * * *<0.001$. p values $>$ 0.05 are not indicated 


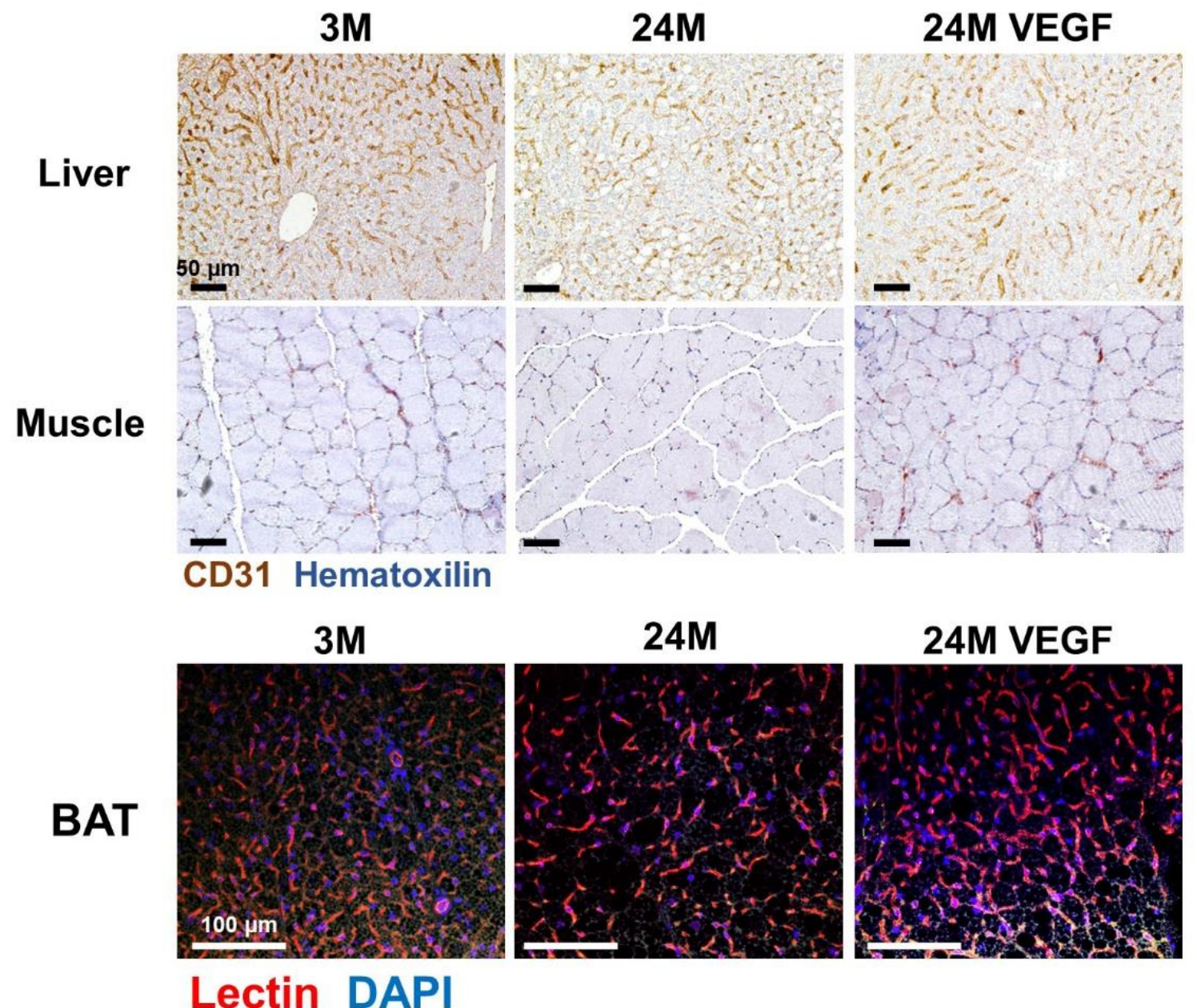

Fig. S5.

Representative images of sections immunostained for blood vessels. Sections of the indicated organs obtained from young (2-4 months old) and old (20-24 months old) mice were stained for the EC-specific marker CD31 or lectin. 
$3 M$
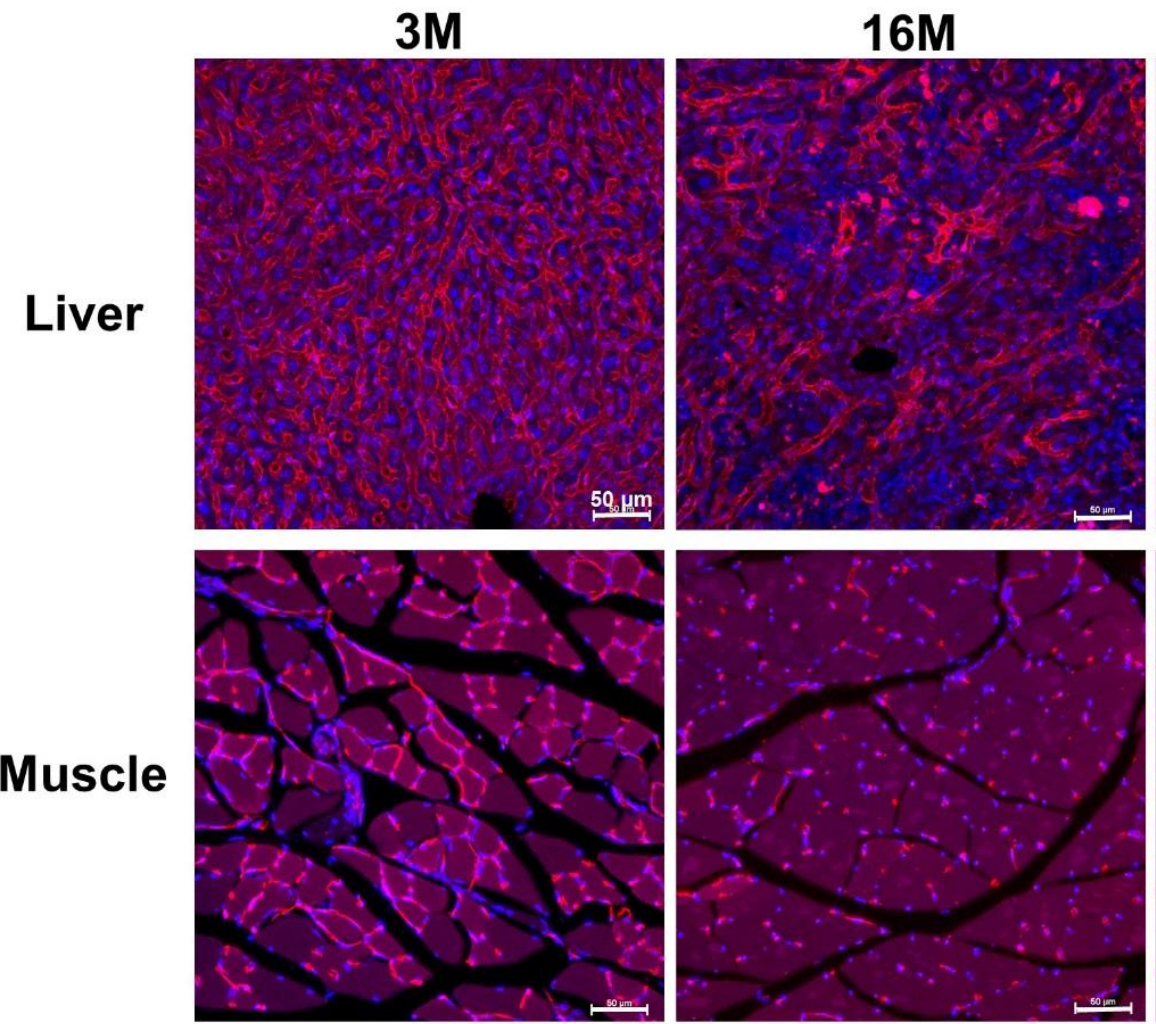

Muscle

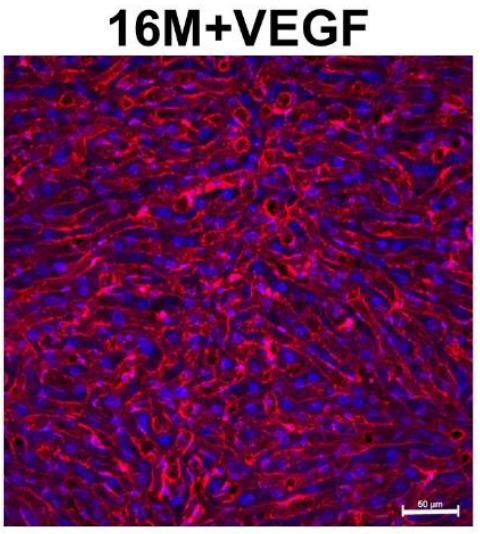

Fig. S6

Visualization of perfused vessels in liver and muscle. Representative images of tissue sections used for calculating the relative area occupied by perfused vessels presented in Fig. 1I. Perfused vessels are highlighted by red fluorescence and nuclei by DAPI staining (see Methods for details). 

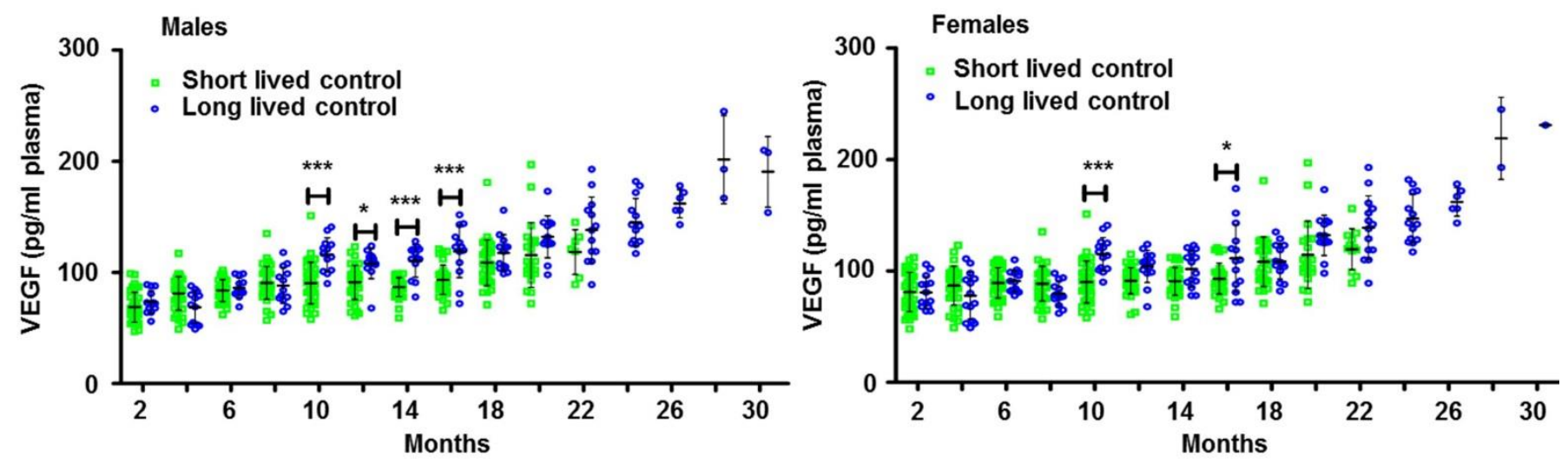

Fig. 57

Natural variability in systemic VEGF levels in 'short-lived' and 'long lived control mice. Control mice that have served for lifespan analysis (Fig. 2A) were retrospectively grouped as 'short-lived mice' (living up to $24 \mathrm{mo}$ ) and 'long lived mice (mice living > 24 mo) and VEGF levels recorded at the indicated earlier ages were separately complied. Average values and distribution ranges are shown. Short-lived mice $n=37$ for males, $n=36$ for females; Long-lived mice $n=13$ for males, $n=14$ for females.

Statistical analysis. Each dot represents a mouse. $\mathrm{p}$ values are derived from Two-way ANOVA with Bonferroni post-tests. Values are mean +/-SEM.

$\mathrm{p}$ values indicated as $*<0.05 ; * *<0.01 ; * * *<0.001 . \mathrm{p}$ values $>0.05$ are not indicated 


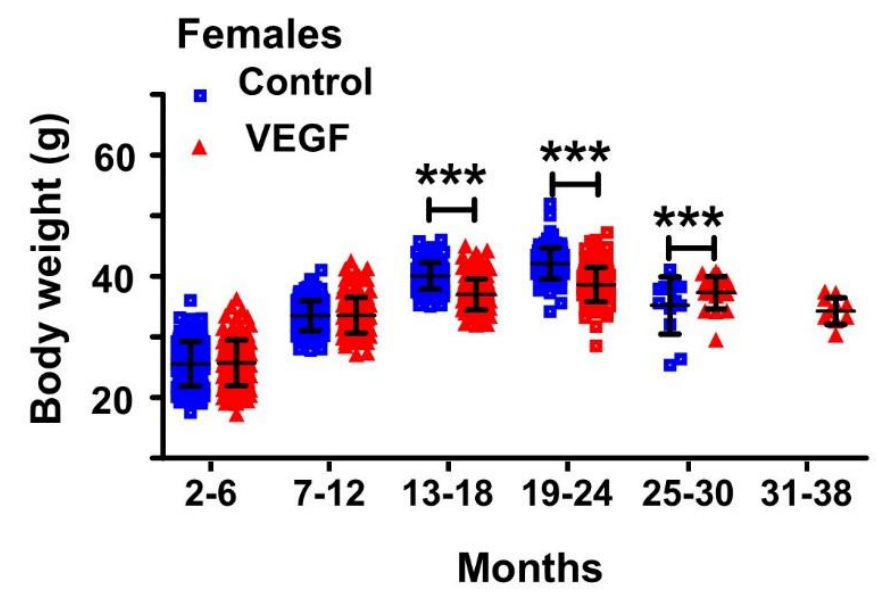

Fig. S8

Body weights of female mice. Mice weighed monthly were divided for presentation in age groups of 5 to 6 months each. $n>8$ per each age group.

Statistical analysis: Each dot represents a mouse. p values derived from two-tailed unpaired Student's $t$ test. Values are mean $+/$-SEM. $p$ values indicated as $*<0.05$;

$* *<0.01 ; * * *<0.001$. $\mathrm{p}$ values $>0.05$ are not indicated 

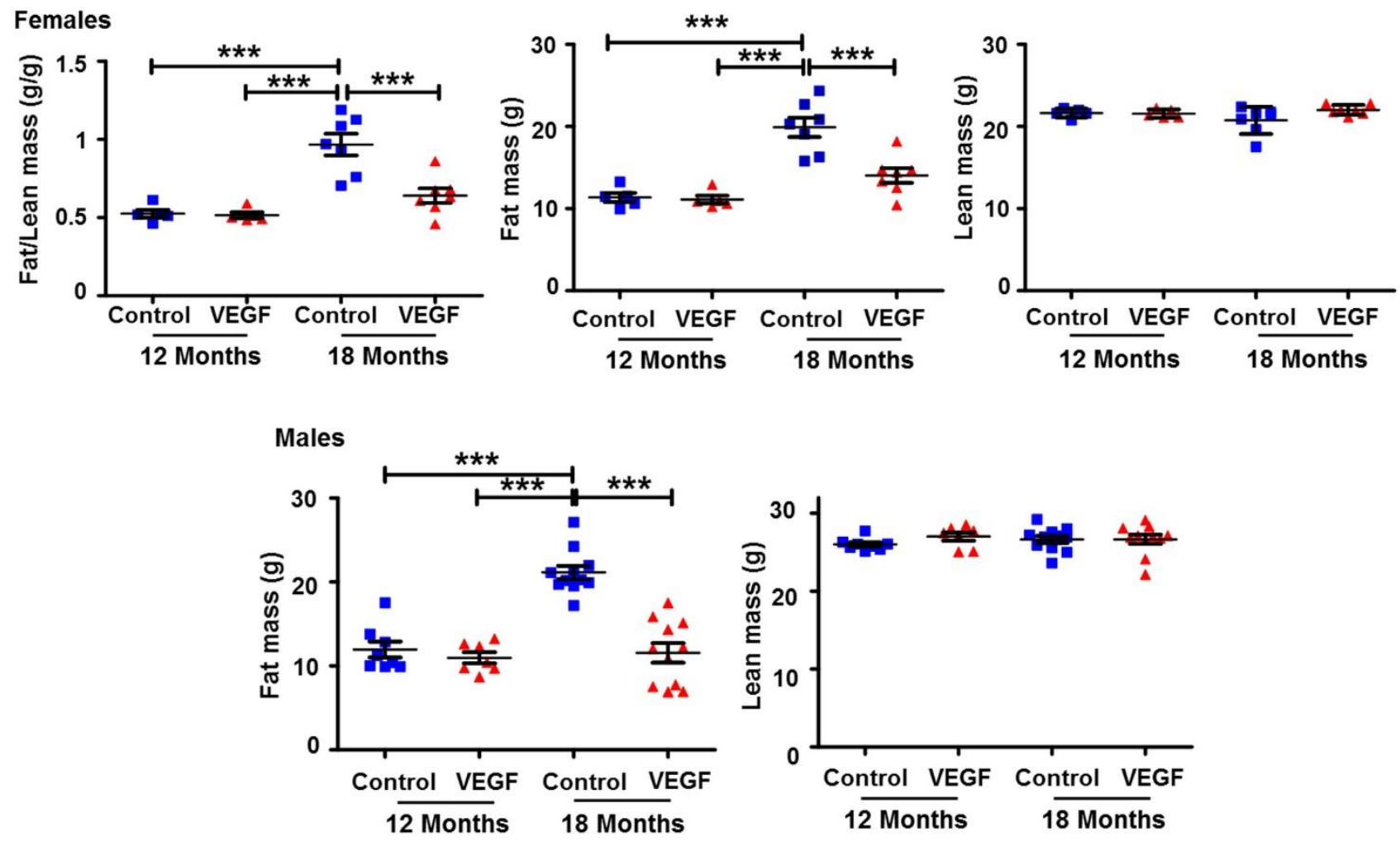

Fig. S9

\section{Fat and lean body masses}

Upper panel - Fat/lean body mass (left graph) of female control and VEGF mice was calculated at the indicated ages on the basis of Echo-MRI measurements. Fat and lean masses are detailed for each mouse in middle and right graphs respectively.

Lower panel - Fat and lean masses measured by Echo-MRI in control and VEGF male mice at the indicated ages.

Each dot represents the average of 2 measurements per mouse. $11>n>5$ mice per group.

Statistical analysis: Each dot represents a mouse. $p$ values are derived from One-way ANOVA with Tukey post-tests. Values are mean +/-SEM. $\mathrm{p}$ values indicated as $*<0.05 ; * *<0.01 ; * * *<0.001$. p values $>0.05$ are not indicated 


\section{Females}
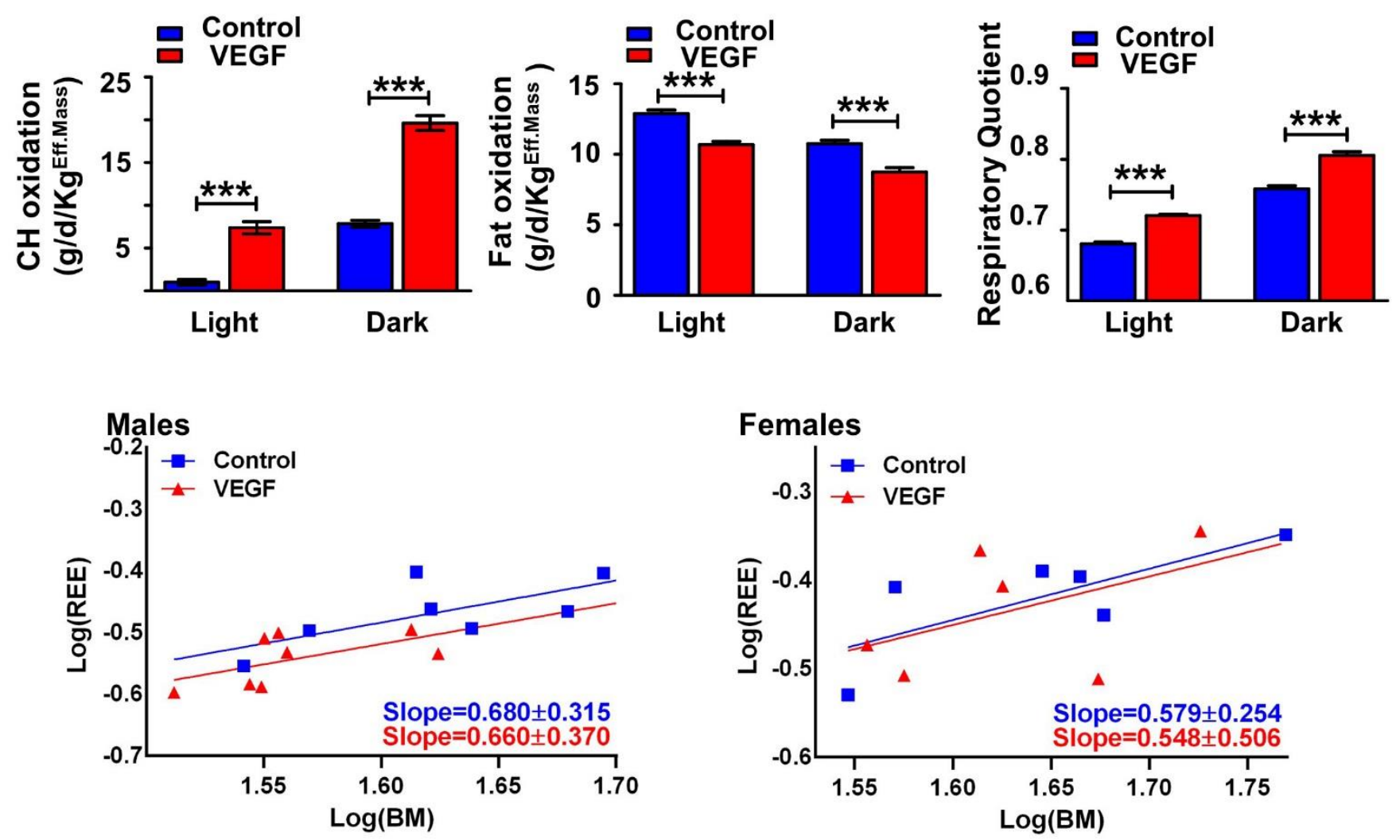

Fig. S10

Carbohydrate oxidation, fat oxidation and Respiratory Quotient in female mice upper panel:16 months old female mice were individually housed in metabolic cages and the indicated metabolic parameters were monitors in both light and dark phases lower panel: ANCOVA analysis- allometric regression graphs indicating no significant differences in slopes between control and VEGF mice ( $\mathrm{p}$ value for Males: 0.9686; $\mathrm{p}$ value for Females: 0.9556). $8>n>6$ for each group

\section{Statistical analysis:}

$\mathrm{p}$ values are derived from two-tailed unpaired Student's t test. Values are mean +/-SEM. $\mathrm{p}$ values indicated as $*<0.05 ; * *<0.01 ; * * *<0.001$. $\mathrm{p}$ values $>0.05$ are not indicated 


\section{Males}
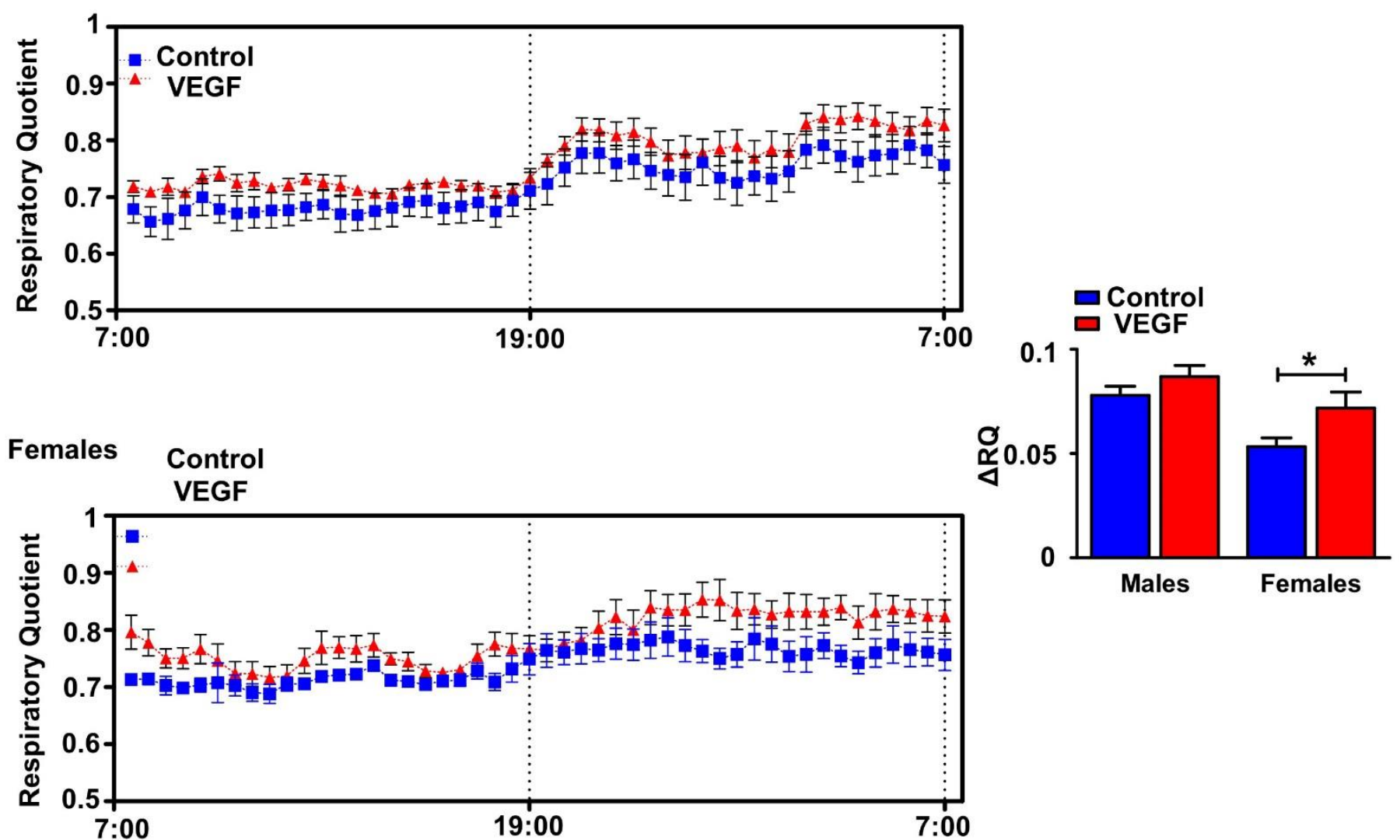

Fig. S11

Circadian dynamics of RQ changes in 16 months old control- and VEGF mice. Left: Half-hourly changes in RQ in the course of a $12 \mathrm{~h}$ light/12h dark cycle [mice used are those for which averaged RQ values for the respective light and dark periods were presented in Figures 2D (males) and S10 (females)].

Right: The extent by which RQ during the metabolically active dark period is higher in VEGF mice compared to control mice $(\triangle \mathrm{RQ})$, indicating a significant increase in female mice $(\mathrm{p}<0.05)$. $8>n>6$ for each group

Statistical analysis:

$\mathrm{p}$ values are derived from two-tailed unpaired Student's $t$ test. Values are mean +/-SEM. $\mathrm{p}$ values indicated as $*<0.05 ; * *<0.01 ; * * *<0.001 . \mathrm{p}$ values $>0.05$ are not indicated 


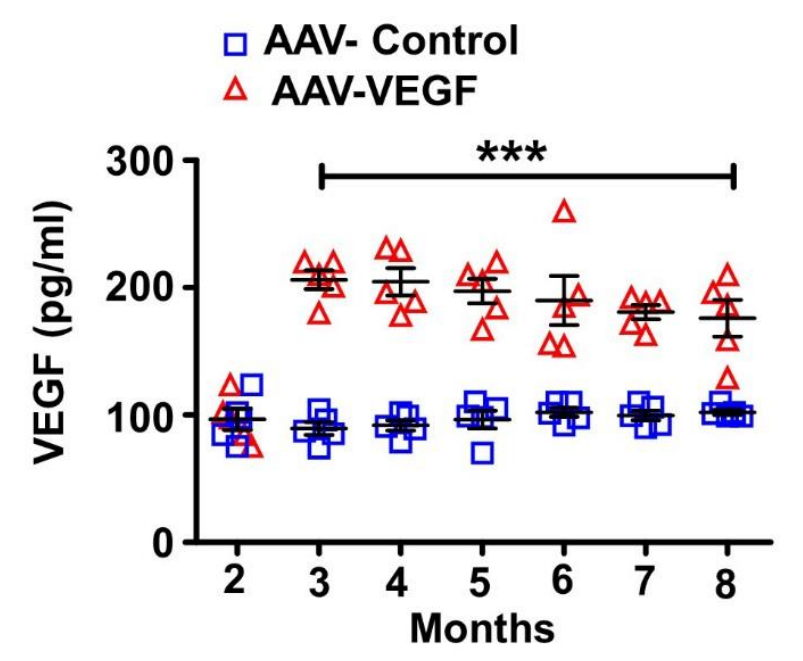

Fig. S12

Circulating VEGF levels after AAV-VEGF infection. Wild-type mice were infected with a low-titer AAV-VEGF165 virus (or with control virus) at the age of 2 months.

Plasma VEGF levels were measured monthly using a VEGF ELISA (mice with lower levels of VEGF were reinjected at 5 months). Significant higher levels at each time point are observed from 3 months and onward. $n=5$ mice per group

Statistical analysis: Each dot represents a mouse. $\mathrm{p}$ values are derived from Two-way ANOVA with Bonferroni post-tests. Values are mean +/-SEM. p values indicated as * $<0.05 ; * *<0.01 ; * * *<0.001$. p values $>0.05$ are not indicated 

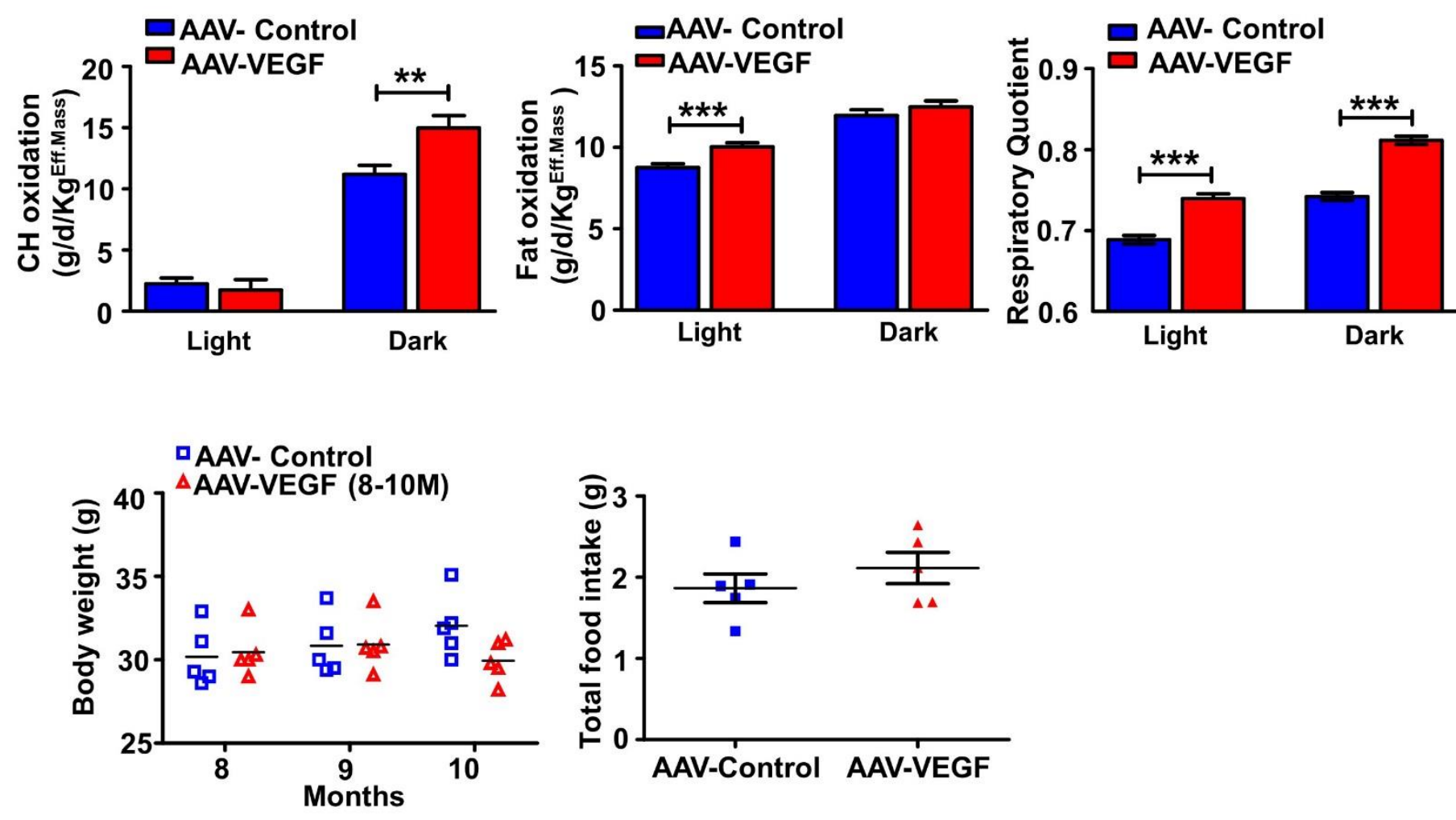

Fig. S13

Circadian changes in carbohydrate and fat oxidation and in RQ (upper panel): 8 months old mice were infected with a low titer of AAV-VEGF164 in parallel to control mice infected with the same titer of control AAV vector ( $n=5$ for each group of mice). Mice in metabolic cages were analyzed upon reaching the age of 10 months.

Body weight and total food intake (lower panel) were measured in the same mice used in metabolic cages analysis. Each dot represents a mouse.

Statistical analysis: $\mathrm{p}$ values are derived from two-tailed unpaired Student's t test. Values are mean $+/$-SEM. p values indicated as $*<0.05 ; * *<0.01 ; * * *<0.001$. p values $>$ 0.05 are not indicated 

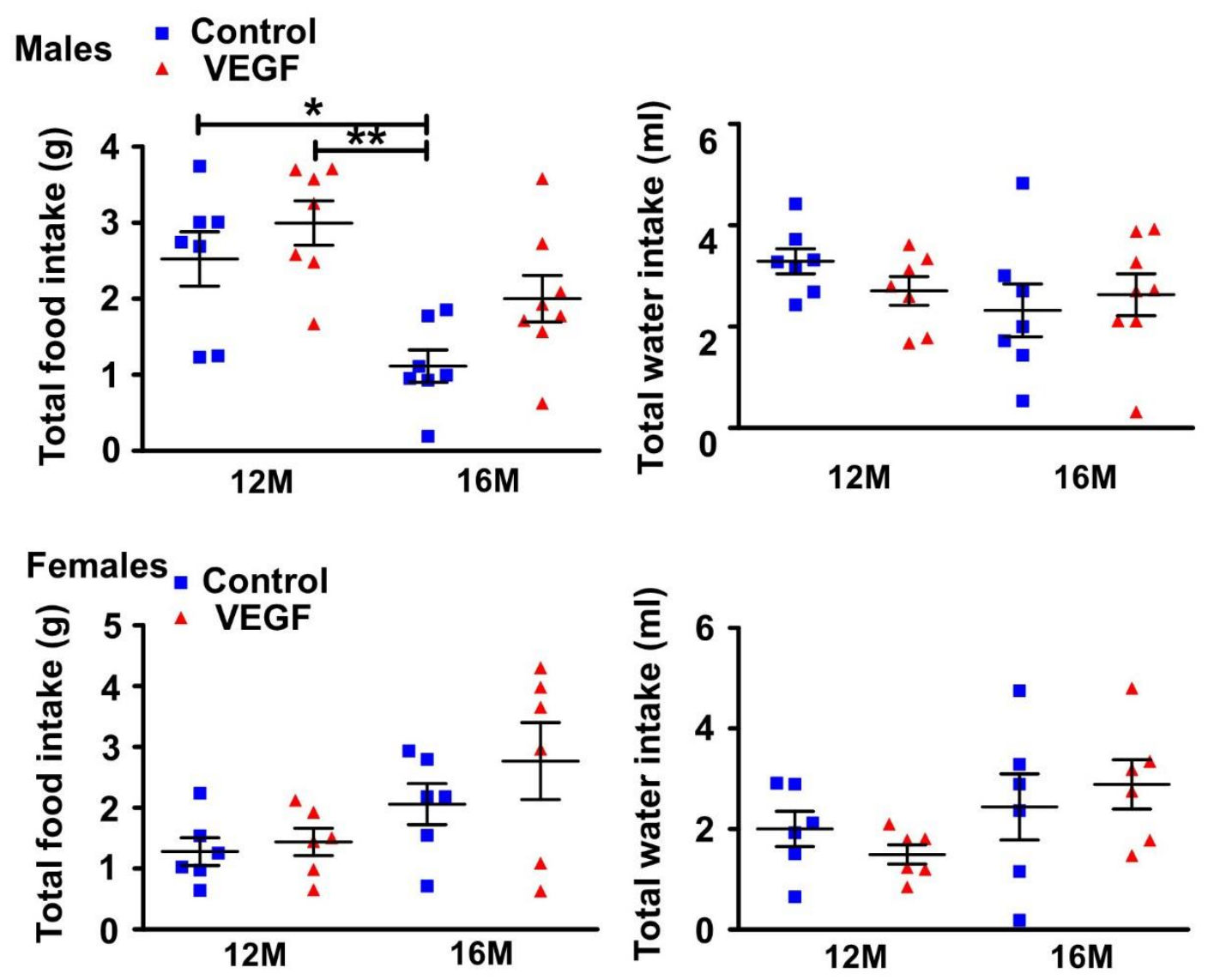

Fig. S14

Food and water intakes measured in 16 months old control and VEGF mice. Total food and water intakes and voluntary physical activity were measured as described under 'Methods' in 12 months old mice and in 16 months old mice used for measuring the metabolic parameters presented in Figures 2D, S10 and S11.

Statistical analysis: Each dot represents a mouse. $p$ values derived from one-way ANOVA non-parametric test (Kruskal-Wallis test and Dunn's Multiple Comparison post- Test). Values are mean +/-SEM. p values indicated as $*<0.05 ; * *<0.01 ; * * *<0.001$. p values $>0.05$ are not indicated 

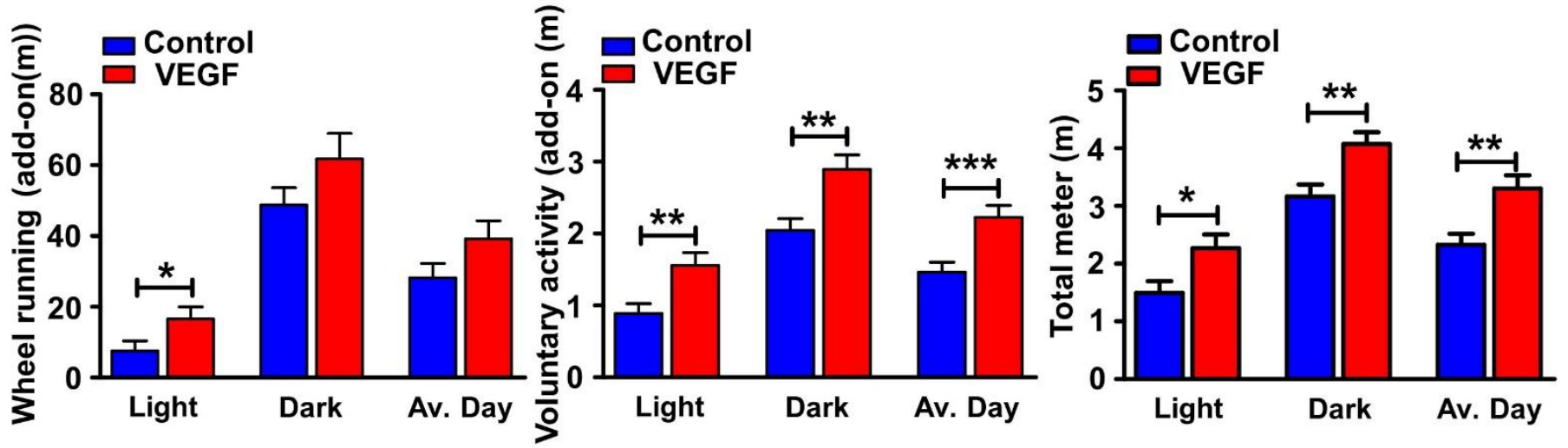

16M Females
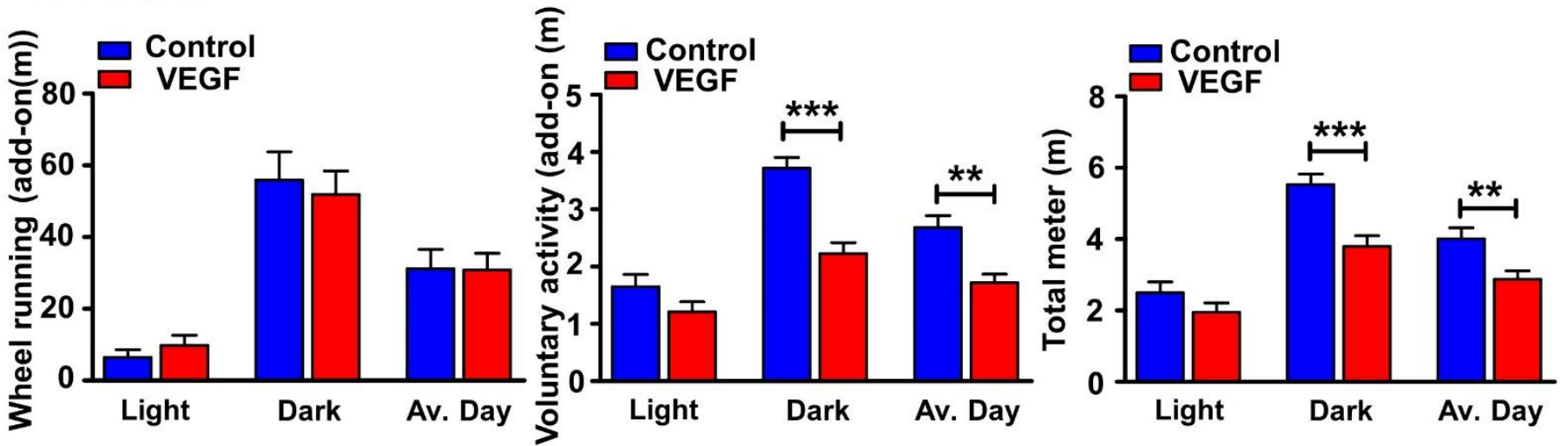

Fig. S15

Physical activity of 16M old male (upper panel) and female (lower panel) mice Wheel running, voluntary activity and total distance covered during active and resting periods were measured in a $24 \mathrm{hrs}$ cycle of stay in metabolic cages. $8>n>6$ mice per group

Statistical analysis: $p$ values are derived from two-tailed unpaired Student's $t$ test. Values are mean +/-SEM. p values indicated as $*<0.05 ; * *<0.01 ; * * *<0.001$. p values $>$ 0.05 are not indicated 


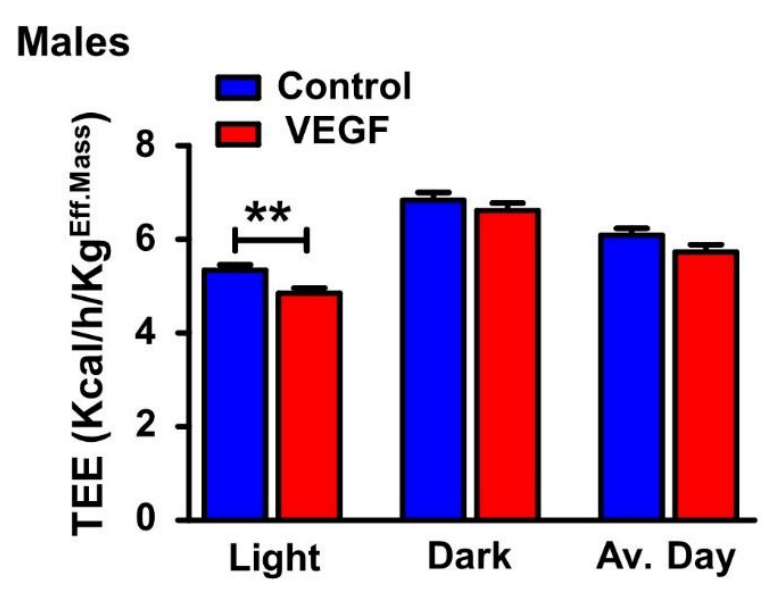

Fig. S16

Total energy expenditure (TEE) by 12M old control and VEGF male mice normalized to effective body mass) measured by indirect calorimetry. $n=7$ mice per group

Statistical analysis: $p$ values are derived from two-tailed unpaired Student's $t$ test. Values are mean +/-SEM. p values indicated as $*<0.05 ; * *<0.01 ; * * *<0.001$. p values $>$ 0.05 are not indicated. 
12M Females

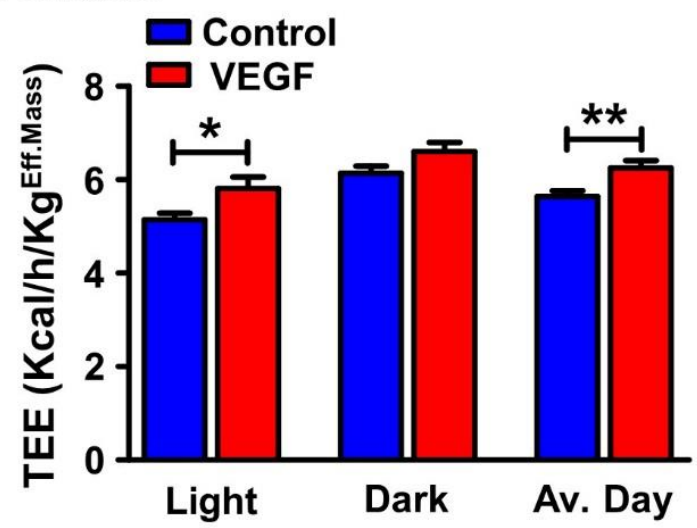

16M Females

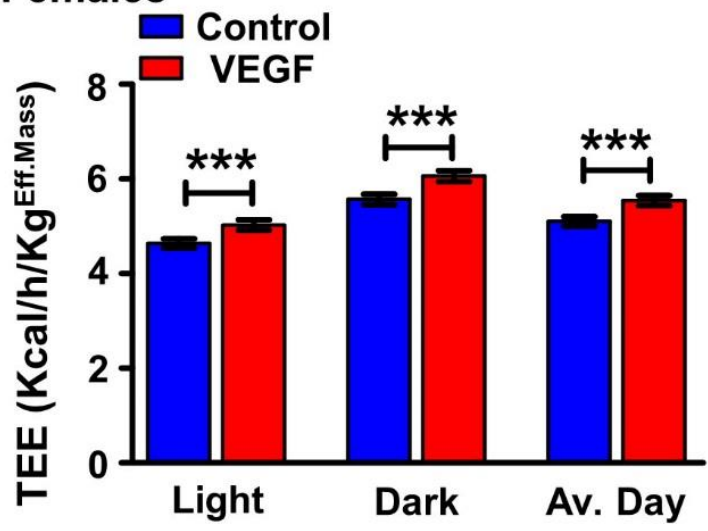

Fig. S17

Total energy expenditure (TEE) in12 and 16 months old female mice. TEE was measured by indirect calorimetry. Values shown were normalized to effective body mass. $n=6$ for each group

Statistical analysis: $p$ values derived from two-tailed unpaired Student's $t$ test. Values are mean +/-SEM. p values indicated as $*<0.05 ; * *<0.01 ; * * *<0.001$. p values $>0.05$ are not indicated 


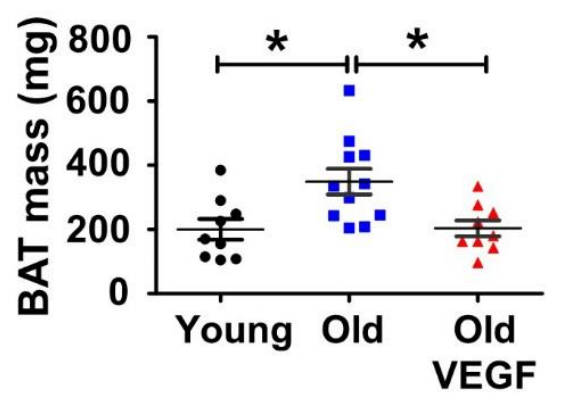

Fig. S18

BAT mass in young and old mice. Whole interscapular brown adipose tissue of young ( 3 mo) and old male and female mice (24 mo) was resected and weighted. $n>8$ in each group Statistical analysis: $\mathrm{p}$ values derived from One-way ANOVA with Tukey post-tests. Values are mean +/-SEM. p values indicated as $*<0.05 ; * *<0.01 ; * * *<0.001$. $\mathrm{p}$ values $>$ 0.05 are not indicated 
$24 \mathrm{M}$
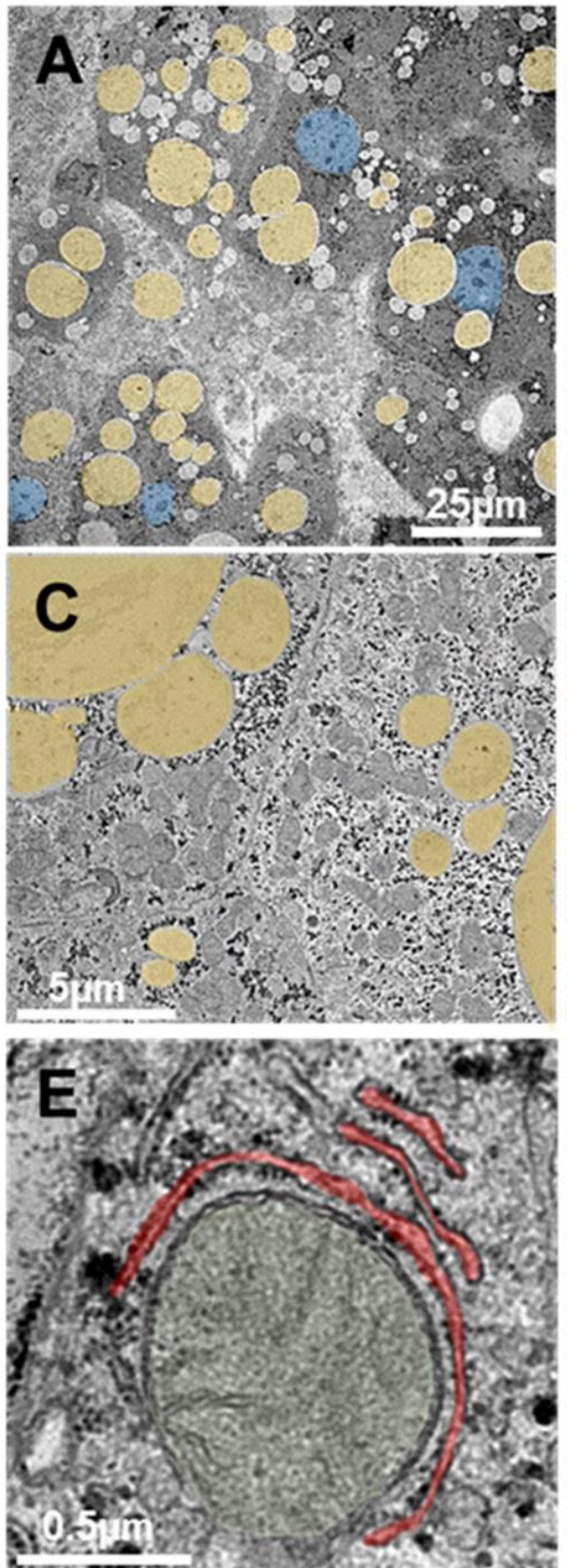

24M VEGF
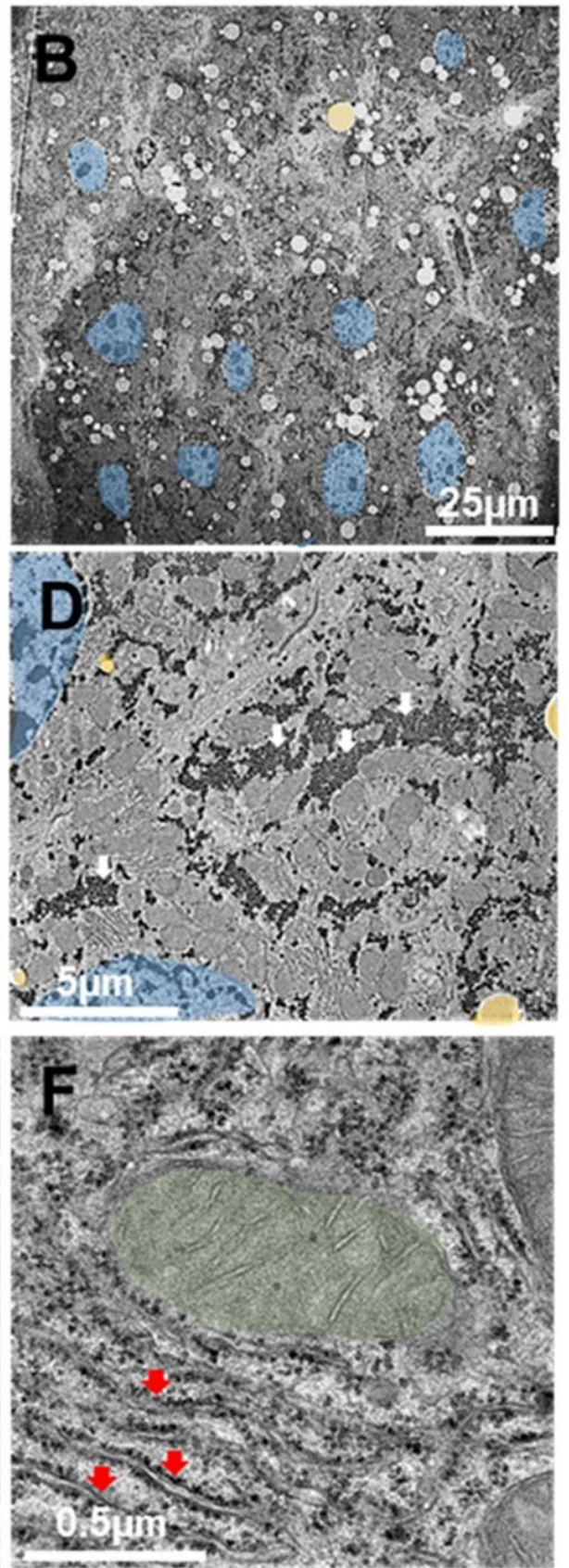

Fig. S19

Representative Electron microscopy images of liver sections from old control and VEGF mice. Pseudocolors highlight: (A, B) lipid droplets larger than $1 \mu \mathrm{m}$ (yellow), (A, B, D) hepatocytes nuclei (blue); (E) swollen and ribosomes-deprived endoplamic reticulum (red). Large mitochondria with disorganized cristae were observed in Old control mice (E, green). White arrows indicate glycogen deposition observed in Old VEGF mice (D). Red arrows indicate ribosomes-decorated endoplasmic reticulum observed in Old VEGF mice $(\mathrm{F})$. Bars are as indicated 

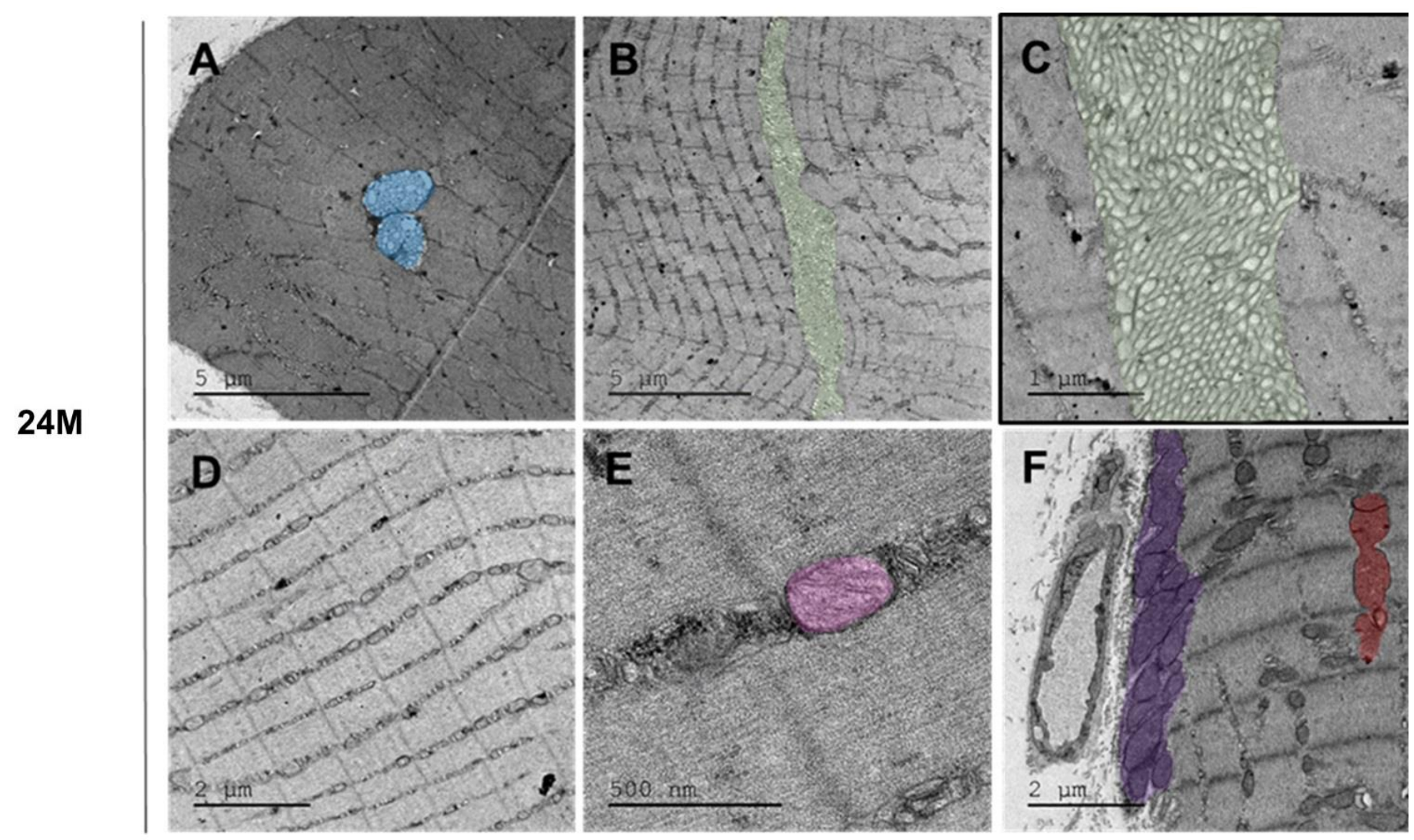

\section{M VEGF}
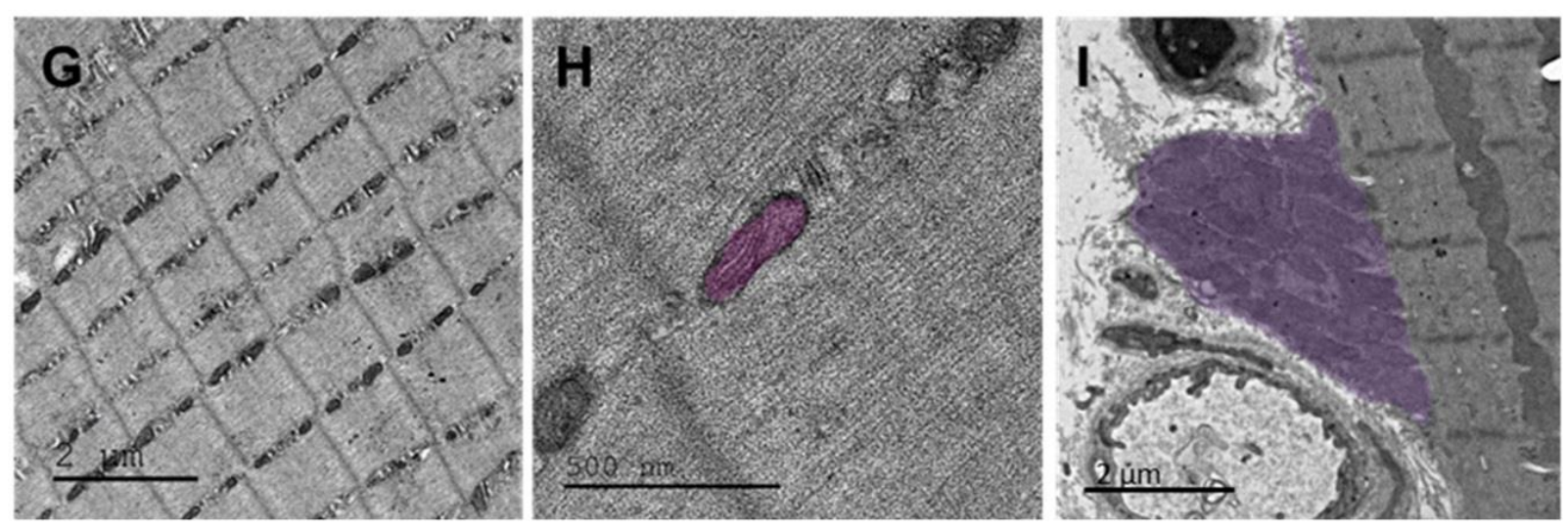

Fig. S20

Representative electron microscopy images of hind limb muscle sections from old control and VEGF mice (24 months old). Pseudocolors highlight: (A) ectopic multivesicular bodies (blue); (B, C) tubular aggregates in the sarcoplasmic reticulum (green); (E, H) interfibrillar mitochondria (pink) that appeared swollen in old control muscle; (G, I) sub-sarcollema mitochondria (violet) that were more numerous in Old VEGF mice. 
Table S1.

Genotype, lifespan and presence of tumors at the time of death for all female mice used in survival studies.

Horizontal red lines separate different litters.

Genotype: D- mice harboring only the driver transgene; R- mice harboring only the VEGF responder transgene; VEGF- double transgenic mice harboring both driver and responder transgenes.

Lifespan: Mice were euthanized when clinical signs suggested death within 24 hours or, in some cases, died naturally.

Censored mice (0): Reasons for censoring the indicated mice were - V1 and V5 suffered from malocclusion impairing normal weight gain; V3, V6, V21, V22, V23 and V19 presented ear/skin dermatitis resistant to antibiotics treatment; V10, V13, V4 and V20 presented severe fight injuries; V2 suffered from vaginal tissue prolapse. Otherwise, these mice did not present any clinical sign suggesting imminent death.

Tumors: presence of apparent neoplastic lesions at the time of sacrifice and the affected organs

\begin{tabular}{|c|c|c|c|c|c|c|c|}
\hline $\begin{array}{l}\text { Mouse } \\
\text { ID }\end{array}$ & Gene & $\begin{array}{l}\text { Date of } \\
\text { birth }\end{array}$ & $\begin{array}{l}\text { Date of } \\
\text { death }\end{array}$ & $\begin{array}{l}\text { Age at } \\
\text { death } \\
\text { (Days) }\end{array}$ & $\begin{array}{l}\text { Age at death } \\
\text { (Months) }\end{array}$ & $\begin{array}{l}\text { Censored (0) } \\
\text { Included (1) }\end{array}$ & $\begin{array}{l}\text { Neoplastic lesion in } \\
\text { indicated organ }\end{array}$ \\
\hline V1 & VEGF & $01 / 02 / 15$ & $04 / 11 / 15$ & 273 & 8.97 & 0 & 0 \\
\hline C1 & $\mathrm{D}$ & $01 / 02 / 15$ & $02 / 04 / 16$ & 421 & 13.84 & 1 & 0 \\
\hline $\mathrm{C2}$ & $\mathrm{R}$ & $01 / 02 / 15$ & $04 / 06 / 16$ & 483 & 15.88 & 1 & 0 \\
\hline V4 & VEGF & $01 / 02 / 15$ & $12 / 11 / 16$ & 641 & 21.07 & 0 & 0 \\
\hline V16 & VEGF & $01 / 02 / 15$ & $22 / 10 / 17$ & 981 & 32.25 & 1 & WAT \\
\hline $\mathrm{C4}$ & $\mathrm{R}$ & $02 / 02 / 15$ & $27 / 08 / 16$ & 565 & 18.57 & 1 & Liver, WAT \\
\hline C10 & $\mathrm{D}$ & $02 / 02 / 15$ & $07 / 01 / 17$ & 695 & 22.85 & 1 & Skin, Spleen \\
\hline C13 & $\mathrm{D}$ & $02 / 02 / 15$ & $13 / 02 / 17$ & 731 & 24.03 & 1 & Spleen, Liver \\
\hline V7 & VEGF & $02 / 02 / 15$ & $14 / 06 / 17$ & 852 & 28.01 & 1 & 0 \\
\hline V15 & VEGF & $02 / 02 / 15$ & $28 / 09 / 17$ & 956 & 31.43 & 1 & 0 \\
\hline$\overline{C 3}$ & $\mathrm{D}$ & $28 / 02 / 15$ & $06 / 08 / 16$ & 518 & 17.03 & 1 & Skin, Liver \\
\hline C7 & $\mathrm{R}$ & $28 / 02 / 15$ & $17 / 10 / 16$ & 589 & 19.36 & 1 & 0 \\
\hline C8 & $\mathrm{R}$ & $28 / 02 / 15$ & $11 / 12 / 16$ & 643 & 21.14 & 1 & 0 \\
\hline V6 & VEGF & $28 / 02 / 15$ & $10 / 04 / 17$ & 762 & 25.05 & 0 & 0 \\
\hline V17 & VEGF & $28 / 02 / 15$ & $05 / 11 / 17$ & 967 & 31.79 & 1 & 0 \\
\hline V3 & VEGF & $01 / 03 / 15$ & $01 / 08 / 16$ & 510 & 16.77 & 0 & 0 \\
\hline C5 & D & $01 / 03 / 15$ & $09 / 09 / 16$ & 548 & 18.01 & 1 & Skin \\
\hline C6 & $\mathrm{R}$ & $01 / 03 / 15$ & $04 / 10 / 16$ & 573 & 18.84 & 1 & 0 \\
\hline V9 & VEGF & $01 / 03 / 15$ & $18 / 06 / 17$ & 827 & 27.19 & 1 & WAT \\
\hline
\end{tabular}




\begin{tabular}{|c|c|c|c|c|c|c|c|}
\hline V18 & VEGF & $01 / 03 / 15$ & $09 / 12 / 17$ & 998 & 32.81 & 1 & 0 \\
\hline V2 & VEGF & $09 / 03 / 15$ & $19 / 06 / 16$ & 460 & 15.12 & 0 & Spleen \\
\hline C9 & $\mathrm{R}$ & $09 / 03 / 15$ & 05/01/17 & 656 & 21.56 & 1 & Skin \\
\hline V8 & VEGF & $09 / 03 / 15$ & $14 / 06 / 17$ & 815 & 26.79 & 1 & Liver \\
\hline V11 & VEGF & $09 / 03 / 15$ & $24 / 08 / 17$ & 885 & 29.09 & 1 & 0 \\
\hline V12 & VEGF & $09 / 03 / 15$ & 06/09/17 & 897 & 29.49 & 1 & WAT \\
\hline V14 & VEGF & $09 / 03 / 15$ & $22 / 09 / 17$ & 913 & 30.01 & 1 & Spleen \\
\hline $\mathrm{C} 12$ & $\mathrm{D}$ & $08 / 03 / 16$ & $21 / 01 / 17$ & 313 & 10.29 & 1 & 0 \\
\hline C18 & $\mathrm{D}$ & 08/03/16 & $27 / 10 / 17$ & 589 & 19.36 & 1 & 0 \\
\hline V19 & VEGF & $08 / 03 / 16$ & 03/01/18 & 655 & 21.53 & 0 & 0 \\
\hline $\mathrm{C} 23$ & $\mathrm{R}$ & 08/03/16 & 06/01/18 & 658 & 21.63 & 1 & 0 \\
\hline $\mathrm{C} 42$ & $\mathrm{D}$ & $08 / 03 / 16$ & $11 / 06 / 18$ & 813 & 26.73 & 1 & Skin, Spleen \\
\hline V31 & VEGF & 08/03/16 & $21 / 10 / 18$ & 943 & 31.00 & 1 & 0 \\
\hline V50 & VEGF & $08 / 03 / 16$ & 07/04/19 & 1109 & 36.46 & 1 & 0 \\
\hline C11 & $\mathrm{D}$ & $10 / 03 / 16$ & $16 / 01 / 17$ & 306 & 10.06 & 1 & Skin \\
\hline $\mathrm{C} 22$ & $\mathrm{D}$ & $10 / 03 / 16$ & $27 / 12 / 17$ & 647 & 21.27 & 1 & Skin \\
\hline $\mathrm{C26}$ & $\mathrm{R}$ & $10 / 03 / 16$ & $23 / 01 / 18$ & 673 & 22.12 & 1 & WAT, Skin \\
\hline V33 & VEGF & $10 / 03 / 16$ & $23 / 10 / 18$ & 943 & 31.00 & 1 & 0 \\
\hline V47 & VEGF & $10 / 03 / 16$ & $11 / 03 / 19$ & 1081 & 35.54 & 1 & 0 \\
\hline V49 & VEGF & $10 / 03 / 16$ & 03/04/19 & 1103 & 36.26 & 1 & 0 \\
\hline C14 & R & $15 / 03 / 16$ & $26 / 02 / 17$ & 341 & 11.21 & 1 & 0 \\
\hline C16 & $\mathrm{D}$ & $15 / 03 / 16$ & $01 / 06 / 17$ & 436 & 14.33 & 1 & 0 \\
\hline $\mathrm{C} 21$ & $\mathrm{D}$ & $15 / 03 / 16$ & $01 / 12 / 17$ & 616 & 20.25 & 1 & Spleen, Liver \\
\hline $\mathrm{C} 27$ & $\mathrm{R}$ & $15 / 03 / 16$ & $03 / 02 / 18$ & 678 & 22.29 & 1 & Liver, Lung, WAT \\
\hline \multirow[t]{2}{*}{ V20 } & VEGF & $15 / 03 / 16$ & $20 / 02 / 18$ & 695 & 22.85 & 0 & 0 \\
\hline & VEGF & $15 / 03 / 16$ & $28 / 10 / 18$ & 943 & 31.00 & 1 & Ovary \\
\hline V41 & VEGF & $15 / 03 / 16$ & 05/01/19 & 1010 & 33.20 & 1 & 0 \\
\hline $\mathrm{C15}$ & $\mathrm{R}$ & $18 / 03 / 16$ & $21 / 03 / 17$ & 363 & 11.93 & 1 & Spleen, Skin \\
\hline C19 & $\mathrm{D}$ & $18 / 03 / 16$ & $06 / 11 / 17$ & 588 & 19.33 & 1 & Spleen, Skin \\
\hline $\mathrm{C29}$ & $\mathrm{R}$ & $18 / 03 / 16$ & $28 / 02 / 18$ & 700 & 23.01 & 1 & Spleen, Liver, Lung \\
\hline C33 & $\mathrm{D}$ & $18 / 03 / 16$ & $28 / 03 / 18$ & 730 & 24.00 & 1 & Liver \\
\hline V24 & VEGF & $18 / 03 / 16$ & $21 / 08 / 18$ & 873 & 28.70 & 1 & 0 \\
\hline V32 & VEGF & $18 / 03 / 16$ & $22 / 10 / 18$ & 934 & 30.70 & 1 & Intestine \\
\hline V39 & VEGF & $18 / 03 / 16$ & $30 / 11 / 18$ & 972 & 31.95 & 1 & 0 \\
\hline V5 & VEGF & $20 / 03 / 16$ & $27 / 03 / 17$ & 367 & 12.06 & 0 & 0 \\
\hline
\end{tabular}




\begin{tabular}{|c|c|c|c|c|c|c|c|}
\hline C17 & $\mathrm{D}$ & $20 / 03 / 16$ & $30 / 06 / 17$ & 460 & 15.12 & 1 & Spleen, Liver \\
\hline $\mathrm{C20}$ & $\mathrm{D}$ & $20 / 03 / 16$ & $10 / 11 / 17$ & 590 & 19.40 & 1 & Spleen, Liver, BAT \\
\hline C30 & $\mathrm{R}$ & $20 / 03 / 16$ & 01/03/18 & 701 & 23.04 & 1 & Skin, WAT \\
\hline C34 & $\mathrm{R}$ & $20 / 03 / 16$ & 03/04/18 & 733 & 24.10 & 1 & Spleen, Liver, WAT \\
\hline C38 & $\mathrm{D}$ & $20 / 03 / 16$ & $30 / 04 / 18$ & 760 & 24.98 & 1 & Liver, Lung \\
\hline V26 & VEGF & $20 / 03 / 16$ & $04 / 10 / 18$ & 914 & 30.05 & 1 & Liver \\
\hline V43 & VEGF & $20 / 03 / 16$ & $04 / 02 / 19$ & 1034 & 33.99 & 1 & WAT, Liver \\
\hline V48 & VEGF & $20 / 03 / 16$ & $16 / 03 / 19$ & 1076 & 35.37 & 1 & 0 \\
\hline V10 & VEGF & $01 / 04 / 16$ & 02/07/17 & 451 & 14.83 & 0 & 0 \\
\hline $\mathrm{C} 24$ & $\mathrm{D}$ & 01/04/16 & 09/01/18 & 638 & 20.97 & 1 & 0 \\
\hline $\mathrm{C} 25$ & $\mathrm{D}$ & $01 / 04 / 16$ & $12 / 01 / 18$ & 641 & 21.07 & 1 & Liver, Lung \\
\hline C31 & $\mathrm{R}$ & $01 / 04 / 16$ & $12 / 03 / 18$ & 701 & 23.04 & 1 & 0 \\
\hline C41 & $\mathrm{R}$ & $01 / 04 / 16$ & $13 / 05 / 18$ & 762 & 25.05 & 1 & Liver, WAT, Ovary \\
\hline V27 & VEGF & $01 / 04 / 16$ & 07/10/18 & 906 & 29.78 & 1 & WAT \\
\hline $\mathrm{C43}$ & $\mathrm{R}$ & $03 / 04 / 16$ & $14 / 06 / 18$ & 791 & 26.00 & 1 & Liver \\
\hline C50 & $\mathrm{D}$ & 03/04/16 & $15 / 10 / 18$ & 912 & 29.98 & 1 & Lung, Liver \\
\hline V34 & VEGF & 03/04/16 & $27 / 10 / 18$ & 924 & 30.37 & 1 & Spleen \\
\hline V42 & VEGF & $03 / 04 / 16$ & $18 / 01 / 19$ & 1005 & 33.04 & 1 & 0 \\
\hline V44 & VEGF & $03 / 04 / 16$ & $24 / 02 / 19$ & 1041 & 34.22 & 1 & 0 \\
\hline $\mathrm{C28}$ & $\mathrm{D}$ & $05 / 04 / 16$ & $09 / 02 / 18$ & 664 & 21.83 & 1 & Kidney \\
\hline $\mathrm{C} 44$ & $\mathrm{D}$ & $05 / 04 / 16$ & $17 / 06 / 18$ & 792 & 26.04 & 1 & 0 \\
\hline $\mathrm{C} 49$ & $\mathrm{R}$ & $05 / 04 / 16$ & $22 / 09 / 18$ & 887 & 29.16 & 1 & 0 \\
\hline V28 & VEGF & 05/04/16 & 08/10/18 & 903 & 29.68 & 1 & 0 \\
\hline V30 & VEGF & $05 / 04 / 16$ & $18 / 10 / 18$ & 913 & 30.01 & 1 & Ovary, Liver \\
\hline V45 & VEGF & $05 / 04 / 16$ & $26 / 02 / 19$ & 1041 & 34.22 & 1 & 0 \\
\hline $\mathrm{C32}$ & $\mathrm{R}$ & $06 / 04 / 16$ & $17 / 03 / 18$ & 701 & 23.04 & 1 & 0 \\
\hline $\mathrm{C} 45$ & $\mathrm{R}$ & $06 / 04 / 16$ & $18 / 06 / 18$ & 792 & 26.04 & 1 & Spleen, Ovary, Liver \\
\hline V25 & VEGF & $06 / 04 / 16$ & $23 / 09 / 18$ & 887 & 29.16 & 1 & 0 \\
\hline V29 & VEGF & $06 / 04 / 16$ & 08/10/18 & 902 & 29.65 & 1 & 0 \\
\hline V40 & VEGF & 06/04/16 & $30 / 12 / 18$ & 984 & 32.35 & 1 & 0 \\
\hline V46 & VEGF & $06 / 04 / 16$ & 27/02/19 & 1041 & 34.22 & 1 & WAT \\
\hline V13 & VEGF & $10 / 05 / 16$ & $13 / 09 / 17$ & 483 & 15.88 & 0 & 0 \\
\hline $\mathrm{C} 46$ & $\mathrm{D}$ & $10 / 05 / 16$ & $19 / 06 / 18$ & 759 & 24.95 & 1 & Spleen, Skin \\
\hline $\mathrm{C} 47$ & VEGF & $10 / 05 / 16$ & $25 / 07 / 18$ & 795 & 26.13 & 1 & Spleen \\
\hline $\mathrm{C} 48$ & $\mathrm{R}$ & $10 / 05 / 16$ & $11 / 08 / 18$ & 811 & 26.66 & 1 & Liver \\
\hline
\end{tabular}




\begin{tabular}{|c|c|c|c|c|c|c|c|}
\hline V37 & VEGF & $10 / 05 / 16$ & $12 / 11 / 18$ & 902 & 29.65 & 1 & 0 \\
\hline \hline V21 & VEGF & $14 / 05 / 16$ & $28 / 03 / 18$ & 674 & 22.16 & 0 & 0 \\
\hline V22 & VEGF & $14 / 05 / 16$ & $28 / 03 / 18$ & 674 & 22.16 & 0 & 0 \\
\hline C35 & D & $14 / 05 / 16$ & $10 / 04 / 18$ & 686 & 22.55 & 1 & Spleen, Liver \\
\hline C36 & D & $14 / 05 / 16$ & $25 / 04 / 18$ & 701 & 23.04 & 1 & WAT, Liver \\
\hline C39 & R & $14 / 05 / 16$ & $30 / 04 / 18$ & 706 & 23.21 & 1 & Spleen, Liver \\
\hline C40 & D & $14 / 05 / 16$ & $06 / 05 / 18$ & 712 & 23.41 & 1 & Liver \\
\hline V36 & VEGF & $14 / 05 / 16$ & $08 / 11 / 18$ & 894 & 29.39 & 1 & Liver \\
\hline \hline V23 & VEGF & $17 / 05 / 16$ & $01 / 04 / 18$ & 674 & 22.16 & 0 & 0 \\
\hline C37 & D & $17 / 05 / 16$ & $27 / 04 / 18$ & 700 & 23.01 & 1 & Liver \\
\hline V38 & VEGF & $17 / 05 / 16$ & $19 / 11 / 18$ & 902 & 29.65 & 1 & 0 \\
\hline
\end{tabular}


Table S2.

Genotype, lifespan and presence of tumors at the time of death for all male mice used in survival studies.

Horizontal red lines separate different litters.

Genotype: D- mice harboring only the driver transgene; R- mice harboring only the VEGF responder transgene; VEGF- double transgenic mice harboring both driver and responder transgenes.

Lifespan: Mice were euthanized when clinical signs suggested death within 24 hours or, in some cases, died naturally.

Censored mice (0): Reasons for censoring the indicated mice were-C34, C35, C36, V29 and V41 suffered from ear/skin dermatitis resistant to antibiotics treatment. C29 and V23, V21 and V22, V7 and V8 presented severe fight injuries. V1, V2, V3, V4, V5 presented prolapsed penis due to cysts in the reproductive glands. V25 and V33 presented rectal prolapse. C26, C28, C33, V6, V15, V24 and V35 presented foot injury and self- mutilation.

Otherwise, these mice did not present any clinical sign suggesting imminent death. Tumors: presence of apparent neoplastic lesions at the time of sacrifice and the affected organs.

Tumors: presence of apparent neoplastic lesions at the time of sacrifice and the affected organs

\begin{tabular}{|c|c|c|c|c|c|c|c|}
\hline $\begin{array}{l}\text { Mouse } \\
\text { ID }\end{array}$ & Gene & $\begin{array}{l}\text { Date of } \\
\text { birth }\end{array}$ & $\begin{array}{l}\text { Date of } \\
\text { death }\end{array}$ & $\begin{array}{l}\text { Age at } \\
\text { death } \\
\text { (Days) }\end{array}$ & $\begin{array}{c}\text { Age at } \\
\text { death } \\
\text { (Months) }\end{array}$ & $\begin{array}{l}\text { Censored (0) } \\
\text { Included (1) }\end{array}$ & $\begin{array}{l}\text { Neoplastic lesion in } \\
\text { indicated organ }\end{array}$ \\
\hline $\mathrm{C4}$ & $\mathrm{R}$ & $05 / 12 / 14$ & $03 / 08 / 16$ & 598 & 19.66 & 1 & Spleen, WAT, Liver \\
\hline $\mathbf{V} 2$ & VEGF & $05 / 12 / 14$ & $18 / 08 / 16$ & 613 & 20.15 & 0 & 0 \\
\hline V11 & VEGF & $05 / 12 / 14$ & $04 / 05 / 17$ & 869 & 28.57 & 1 & 0 \\
\hline $\mathrm{V} 12$ & VEGF & $05 / 12 / 14$ & $10 / 05 / 17$ & 875 & 28.76 & 1 & 0 \\
\hline $\mathrm{C2}$ & $\mathrm{R}$ & $17 / 12 / 14$ & $06 / 07 / 16$ & 559 & 18.38 & 1 & 0 \\
\hline $\mathbf{C 3}$ & $\mathrm{D}$ & $17 / 12 / 14$ & $16 / 07 / 16$ & 569 & 18.70 & 1 & Skin \\
\hline C11 & D & $17 / 12 / 14$ & $19 / 11 / 16$ & 692 & 22.75 & 1 & Liver, Kidney \\
\hline V16 & VEGF & $17 / 12 / 14$ & $25 / 10 / 17$ & 1028 & 33.79 & 1 & 0 \\
\hline V26 & VEGF & $17 / 12 / 14$ & $15 / 01 / 18$ & 1108 & 36.42 & 1 & 0 \\
\hline C5 & $\mathrm{D}$ & $01 / 01 / 15$ & $29 / 08 / 16$ & 598 & 19.66 & 1 & Spleen, WAT \\
\hline V7 & VEGF & $01 / 01 / 15$ & $21 / 11 / 16$ & 680 & 22.35 & 0 & 0 \\
\hline V8 & VEGF & $01 / 01 / 15$ & $21 / 11 / 16$ & 680 & 22.35 & 0 & 0 \\
\hline C6 & $\mathrm{R}$ & $12 / 01 / 15$ & $14 / 09 / 16$ & 602 & 19.79 & 1 & 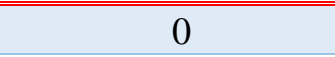 \\
\hline V4 & VEGF & $12 / 01 / 15$ & $10 / 11 / 16$ & 658 & 21.63 & 0 & 0 \\
\hline C14 & $\mathrm{R}$ & $12 / 01 / 15$ & $17 / 02 / 17$ & 755 & 24.82 & 1 & $\begin{array}{l}\text { Spleen, Skin, } \\
\text { Epididymis }\end{array}$ \\
\hline $\mathrm{V} 20$ & VEGF & $12 / 01 / 15$ & $25 / 12 / 17$ & 1063 & 34.94 & 1 & 0 \\
\hline V1 & VEGF & $15 / 01 / 15$ & $25 / 06 / 16$ & 520 & 17.09 & $\overline{0} 0$ & 0 \\
\hline C7 & $\mathrm{D}$ & $15 / 01 / 15$ & $28 / 09 / 16$ & 613 & 20.15 & 1 & 0 \\
\hline C17 & $\mathrm{R}$ & $15 / 01 / 15$ & $20 / 04 / 17$ & 815 & 26.79 & 1 & Spleen, Liver, Lung \\
\hline C19 & $\mathrm{D}$ & $15 / 01 / 15$ & $27 / 07 / 17$ & 912 & 29.98 & 1 & Spleen, WAT, Liver \\
\hline
\end{tabular}




\begin{tabular}{|c|c|c|c|c|c|c|c|}
\hline V17 & VEGF & $15 / 01 / 15$ & $30 / 10 / 17$ & 1005 & 33.04 & 1 & 0 \\
\hline V28 & VEGF & $15 / 01 / 15$ & $17 / 02 / 18$ & 1112 & 36.55 & 1 & 0 \\
\hline V3 & VEGF & $01 / 02 / 15$ & $25 / 08 / 16$ & 564 & 18.54 & 0 & 0 \\
\hline C10 & $\mathrm{D}$ & $01 / 02 / 15$ & $17 / 11 / 16$ & 646 & 21.24 & 1 & Spleen \\
\hline V10 & VEGF & $01 / 02 / 15$ & $20 / 03 / 17$ & 769 & 25.28 & 1 & Spleen, Liver, SG \\
\hline V27 & VEGF & $01 / 02 / 15$ & $18 / 01 / 18$ & 1067 & 35.08 & 1 & WAT \\
\hline C1 & $\mathrm{D}$ & $02 / 02 / 15$ & $30 / 03 / 16$ & 418 & 13.74 & 1 & 0 \\
\hline C8 & $\mathrm{D}$ & $02 / 02 / 15$ & $02 / 10 / 16$ & 600 & 19.72 & 1 & 0 \\
\hline V18 & VEGF & $02 / 02 / 15$ & $08 / 12 / 17$ & 1026 & 33.73 & 1 & 0 \\
\hline V30 & VEGF & $02 / 02 / 15$ & $22 / 02 / 18$ & 1100 & 36.16 & 1 & Spleen \\
\hline V5 & VEGF & $28 / 02 / 15$ & $11 / 11 / 16$ & 613 & 20.15 & 0 & 0 \\
\hline $\mathrm{C12}$ & $\mathrm{D}$ & $28 / 02 / 15$ & $26 / 12 / 16$ & 658 & 21.63 & 1 & Skin, Spleen, WAT \\
\hline V31 & VEGF & $28 / 02 / 15$ & $28 / 02 / 18$ & 1080 & 35.50 & 1 & 0 \\
\hline V32 & VEGF & $28 / 02 / 15$ & $06 / 03 / 18$ & 1088 & 35.77 & 1 & 0 \\
\hline C9 & $\mathrm{D}$ & $01 / 03 / 15$ & $12 / 10 / 16$ & 581 & 19.10 & 1 & 0 \\
\hline V6 & VEGF & $01 / 03 / 15$ & $14 / 11 / 16$ & 613 & 20.15 & 0 & 0 \\
\hline C13 & $\mathrm{D}$ & $01 / 03 / 15$ & $28 / 12 / 16$ & 657 & 21.60 & 1 & Liver, Spleen \\
\hline V34 & VEGF & $01 / 03 / 15$ & $25 / 04 / 18$ & 1134 & 37.28 & 1 & 0 \\
\hline V9 & VEGF & $09 / 03 / 15$ & $15 / 01 / 17$ & 666 & 21.89 & 1 & WAT, SG \\
\hline C15 & $\mathrm{D}$ & $09 / 03 / 15$ & $19 / 02 / 17$ & 700 & 23.01 & 1 & $\begin{array}{l}\text { WAT, Liver, Spleen, } \\
\text { Epididymis }\end{array}$ \\
\hline C16 & $\mathrm{D}$ & $09 / 03 / 15$ & $01 / 03 / 17$ & 712 & 23.41 & 1 & $\begin{array}{l}\text { WAT, Liver, Lung, } \\
\text { Epididymis }\end{array}$ \\
\hline V13 & VEGF & $09 / 03 / 15$ & $15 / 07 / 17$ & 846 & 27.81 & 1 & 0 \\
\hline V14 & VEGF & $09 / 03 / 15$ & $01 / 08 / 17$ & 862 & 28.34 & 1 & WAT \\
\hline $\mathrm{C20}$ & $\mathrm{R}$ & $08 / 03 / 16$ & $19 / 08 / 17$ & 521 & 17.13 & 1 & 0 \\
\hline $\mathrm{C24}$ & $\mathrm{R}$ & $08 / 03 / 16$ & $08 / 11 / 17$ & 600 & 19.72 & 1 & 0 \\
\hline V36 & VEGF & $08 / 03 / 16$ & $28 / 04 / 18$ & 770 & 25.31 & 1 & 0 \\
\hline $\mathrm{C26}$ & $\mathrm{R}$ & $10 / 03 / 16$ & $11 / 12 / 17$ & 631 & 20.74 & 0 & 0 \\
\hline V24 & VEGF & $10 / 03 / 16$ & $08 / 01 / 18$ & 658 & 21.63 & 0 & 0 \\
\hline C38 & $\mathrm{R}$ & $10 / 03 / 16$ & $20 / 03 / 18$ & 730 & 24.00 & 1 & $\begin{array}{l}\text { Liver, Spleen, WAT, } \\
\text { Epididymis }\end{array}$ \\
\hline V38 & VEGF & $10 / 03 / 16$ & $15 / 06 / 18$ & 815 & 26.79 & 1 & WAT, colon \\
\hline V49 & VEGF & $10 / 03 / 16$ & $14 / 05 / 19$ & 1144 & 37.61 & 1 & 0 \\
\hline V15 & VEGF & $15 / 03 / 16$ & $08 / 10 / 17$ & 563 & 18.51 & 0 & 0 \\
\hline $\mathrm{C} 21$ & $\mathrm{R}$ & $15 / 03 / 16$ & $09 / 10 / 17$ & 564 & 18.54 & 1 & 0 \\
\hline $\mathrm{C} 22$ & $\mathrm{D}$ & $15 / 03 / 16$ & $20 / 10 / 17$ & 575 & 18.90 & 1 & 0 \\
\hline $\mathrm{C23}$ & $\mathrm{D}$ & $15 / 03 / 16$ & $20 / 10 / 17$ & 575 & 18.90 & 1 & Liver, Lung, WAT \\
\hline V35 & VEGF & $15 / 03 / 16$ & $27 / 04 / 18$ & 762 & 25.05 & 0 & WAT, Spleen \\
\hline C31 & $\mathrm{D}$ & $18 / 03 / 16$ & $04 / 02 / 18$ & 676 & 22.22 & 1 & 0 \\
\hline $\mathrm{C44}$ & $\mathrm{R}$ & $18 / 03 / 16$ & $18 / 05 / 18$ & 780 & 25.64 & 1 & $\begin{array}{l}\text { Liver, Lung, Spleen, } \\
\text { Epididymis }\end{array}$ \\
\hline V37 & VEGF & $18 / 03 / 16$ & $23 / 05 / 18$ & 785 & 25.81 & 1 & WAT, Kidney \\
\hline V42 & VEGF & $18 / 03 / 16$ & $22 / 09 / 18$ & 904 & 29.72 & 1 & 0 \\
\hline
\end{tabular}




\begin{tabular}{|c|c|c|c|c|c|c|c|}
\hline C30 & $\mathrm{R}$ & $20 / 03 / 16$ & $12 / 01 / 18$ & 652 & 21.43 & 1 & 0 \\
\hline V25 & VEGF & $20 / 03 / 16$ & $12 / 01 / 18$ & 652 & 21.43 & 0 & 0 \\
\hline V33 & VEGF & $01 / 04 / 16$ & $11 / 04 / 18$ & 730 & 24.00 & 0 & 0 \\
\hline C41 & $\mathrm{D}$ & $01 / 04 / 16$ & $26 / 04 / 18$ & 745 & 24.49 & 1 & Liver, Spleen, SG \\
\hline $\mathrm{C} 43$ & $\mathrm{D}$ & $01 / 04 / 16$ & $14 / 05 / 18$ & 763 & 25.08 & 1 & 0 \\
\hline V40 & VEGF & $01 / 04 / 16$ & $24 / 07 / 18$ & 833 & 27.38 & 1 & 0 \\
\hline C49 & $\mathrm{R}$ & $01 / 04 / 16$ & $01 / 10 / 18$ & 900 & 29.59 & 1 & $\begin{array}{l}\text { Liver, WAT, Spleen, } \\
\text { Lung, Epididymis }\end{array}$ \\
\hline V48 & VEGF & $01 / 04 / 16$ & $28 / 04 / 19$ & 1107 & 36.39 & 1 & 0 \\
\hline $\mathrm{C27}$ & $\mathrm{R}$ & $03 / 04 / 16$ & $16 / 12 / 17$ & 613 & 20.15 & 1 & 0 \\
\hline $\mathrm{C} 28$ & $\mathrm{D}$ & $03 / 04 / 16$ & 01/01/18 & 628 & 20.64 & 0 & 0 \\
\hline C32 & $\mathrm{D}$ & $03 / 04 / 16$ & $05 / 02 / 18$ & 662 & 21.76 & 1 & 0 \\
\hline $\mathrm{V} 43$ & VEGF & $03 / 04 / 16$ & $06 / 10 / 18$ & 903 & 29.68 & 1 & 0 \\
\hline C18 & $\mathrm{R}$ & $05 / 04 / 16$ & $24 / 05 / 17$ & 409 & 13.45 & 1 & 0 \\
\hline V21 & VEGF & $05 / 04 / 16$ & 03/01/18 & 628 & 20.64 & 0 & 0 \\
\hline V22 & VEGF & $05 / 04 / 16$ & 06/01/18 & 631 & 20.74 & 0 & 0 \\
\hline C47 & $\mathrm{D}$ & $05 / 04 / 16$ & $21 / 06 / 18$ & 796 & 26.17 & 1 & Liver \\
\hline $\mathrm{C} 48$ & $\mathrm{R}$ & $05 / 04 / 16$ & $19 / 07 / 18$ & 824 & 27.09 & 1 & WAT, Spleen, Liver, SG \\
\hline V47 & VEGF & $05 / 04 / 16$ & $18 / 04 / 19$ & 1093 & 35.93 & 1 & 0 \\
\hline $\mathrm{C29}$ & $\mathrm{D}$ & $06 / 04 / 16$ & $07 / 01 / 18$ & 631 & 20.74 & 0 & 0 \\
\hline $\mathbf{V} 23$ & VEGF & $06 / 04 / 16$ & $07 / 01 / 18$ & 631 & 20.74 & 0 & 0 \\
\hline C39 & $\mathrm{D}$ & $06 / 04 / 16$ & $08 / 04 / 18$ & 722 & 23.73 & 1 & Liver, WAT \\
\hline $\mathrm{C40}$ & $\mathrm{D}$ & $06 / 04 / 16$ & $15 / 04 / 18$ & 729 & 23.96 & 1 & Liver, Spleen \\
\hline V45 & VEGF & $06 / 04 / 16$ & $18 / 01 / 19$ & 1002 & 32.94 & 1 & 0 \\
\hline $\mathrm{C25}$ & $\mathrm{D}$ & $10 / 05 / 16$ & $26 / 11 / 17$ & 556 & 18.28 & 1 & 0 \\
\hline $\mathrm{C} 45$ & $\mathrm{R}$ & $10 / 05 / 16$ & $01 / 06 / 18$ & 741 & 24.36 & 1 & 0 \\
\hline C46 & $\mathrm{R}$ & $10 / 05 / 16$ & $05 / 06 / 18$ & 745 & 24.49 & 1 & $\begin{array}{l}\text { WAT, Liver, Spleen, } \\
\text { Epididymis }\end{array}$ \\
\hline C50 & $\mathrm{D}$ & $10 / 05 / 16$ & 07/01/19 & 957 & 31.46 & 1 & $\begin{array}{l}\text { WAT, Spleen, Liver, } \\
\text { Lung }\end{array}$ \\
\hline V50 & VEGF & $10 / 05 / 16$ & $25 / 05 / 19$ & 1095 & 36.00 & 1 & WAT, Spleen \\
\hline C33 & $\mathrm{R}$ & $14 / 05 / 16$ & $14 / 02 / 18$ & 630 & 20.71 & 0 & 0 \\
\hline C37 & $\mathrm{R}$ & $14 / 05 / 16$ & $11 / 03 / 18$ & 657 & 21.60 & 1 & 0 \\
\hline V39 & VEGF & $14 / 05 / 16$ & $04 / 07 / 18$ & 770 & 25.31 & 1 & WAT \\
\hline V46 & VEGF & $14 / 05 / 16$ & 02/04/19 & 1038 & 34.12 & 1 & 0 \\
\hline V19 & VEGF & $17 / 05 / 16$ & $18 / 12 / 17$ & 571 & 18.77 & 1 & 0 \\
\hline C34 & $\mathrm{D}$ & $17 / 05 / 16$ & $18 / 02 / 18$ & 631 & 20.74 & 0 & 0 \\
\hline $\mathrm{C} 42$ & $\mathrm{R}$ & $17 / 05 / 16$ & $30 / 04 / 18$ & 703 & 23.11 & 1 & Spleen, Liver \\
\hline V44 & VEGF & $17 / 05 / 16$ & $30 / 11 / 18$ & 913 & 30.01 & 1 & 0 \\
\hline C35 & D & $20 / 05 / 16$ & $21 / 02 / 18$ & 631 & 20.74 & 0 & 0 \\
\hline C36 & $\mathrm{D}$ & $20 / 05 / 16$ & $21 / 02 / 18$ & 631 & 20.74 & 0 & 0 \\
\hline V29 & VEGF & $20 / 05 / 16$ & $21 / 02 / 18$ & 631 & 20.74 & 0 & 0 \\
\hline V41 & VEGF & $20 / 05 / 16$ & 03/09/18 & 823 & 27.05 & 0 & 0 \\
\hline
\end{tabular}


Table S3.

Levels of plasma VEGF (pg/ml) measured in all female mice used for lifespan studies.

VEGF levels in censored mice are indicated in bold.

\begin{tabular}{|c|c|c|c|c|c|c|c|c|c|c|c|c|c|c|c|c|c|c|}
\hline Months & 2 & 4 & 6 & 8 & 10 & 12 & 14 & 16 & 18 & 20 & 22 & 24 & 26 & 28 & 30 & 32 & 34 & 36 \\
\hline V1 & 90 & 87 & 94 & 101 & & & & & & & & & & & & & & \\
\hline C1 & 56 & 79 & 67 & 89 & 89 & 61 & 110 & & & & & & & & & & & \\
\hline C2 & 83 & 95 & 93 & 101 & 74 & 63 & 112 & 119 & & & & & & & & & & \\
\hline V4 & 95 & 79 & 95 & 96 & 108 & 182 & 167 & 187 & 174 & 150 & & & & & & & & \\
\hline V16 & 98 & 71 & 108 & 110 & 101 & 102 & 119 & 182 & 188 & 176 & 189 & 193 & 176 & 208 & 209 & 219 & & \\
\hline $\mathrm{C} 4$ & 70 & 100 & 107 & 76 & 98 & 99 & 92 & 89 & 107 & & & & & & & & & \\
\hline C10 & 87 & 57 & 94 & 135 & 85 & 82 & 101 & 119 & 181 & 99 & 99 & & & & & & & \\
\hline C13 & 96 & 55 & 99 & 78 & 122 & 68 & 92 & 72 & 82 & 128 & 152 & 128 & & & & & & \\
\hline V7 & 83 & 94 & 86 & 123 & 129 & 156 & 119 & 142 & 178 & 190 & 198 & 203 & 210 & 173 & & & & \\
\hline V15 & 82 & 90 & 94 & 136 & 176 & 193 & 172 & 156 & 176 & 194 & 183 & 195 & 198 & 224 & 217 & & & \\
\hline $\mathbf{C 3}$ & 77 & 76 & 102 & 99 & 73 & 87 & 94 & 121 & & & & & & & & & & \\
\hline C7 & 99 & 87 & 107 & 81 & 67 & 78 & 93 & 93 & 114 & & & & & & & & & \\
\hline C8 & 56 & 123 & 59 & 98 & 68 & 89 & 83 & 72 & 92 & 197 & & & & & & & & \\
\hline V6 & 86 & 92 & 91 & 90 & 122 & 173 & 182 & 192 & 172 & 197 & 187 & 192 & & & & & & \\
\hline V17 & 81 & 70 & 107 & 84 & 178 & 199 & 192 & 159 & 192 & 203 & 192 & 186 & 201 & 198 & 201 & & & \\
\hline V3 & 93 & 82 & 89 & 124 & 162 & 157 & 154 & 164 & & & & & & & & & & \\
\hline C5 & 90 & 99 & 110 & 85 & 91 & 93 & 89 & 92 & 118 & & & & & & & & & \\
\hline C6 & 112 & 92 & 85 & 93 & 73 & 81 & 89 & 78 & 125 & & & & & & & & & \\
\hline V9 & 85 & 76 & 114 & 97 & 186 & 164 & 152 & 123 & 162 & 192 & 186 & 143 & 201 & & & & & \\
\hline V18 & 84 & 84 & 90 & 113 & 114 & 116 & 183 & 192 & 176 & 147 & 209 & & 209 & & 200 & 254 & & \\
\hline V2 & 96 & 78 & 101 & 112 & 154 & 139 & 186 & & & & & & & & & & & \\
\hline C9 & 101 & 98 & 85 & 76 & 93 & 102 & 78 & 75 & 82 & 101 & & & & & & & & \\
\hline V8 & 91 & 78 & 90 & 131 & 167 & 182 & 162 & 176 & 198 & 193 & 175 & 189 & 190 & & & & & \\
\hline V11 & 76 & 75 & 122 & 83 & 132 & 148 & 135 & 172 & 195 & 154 & 186 & 165 & 172 & 189 & & & & \\
\hline V12 & 88 & 85 & 90 & 131 & 135 & 176 & 148 & 197 & 203 & 190 & 198 & 197 & 165 & 217 & & & & \\
\hline V14 & 84 & 89 & 84 & 121 & 128 & 193 & 162 & 195 & 202 & 178 & 184 & 182 & 194 & 218 & 190 & & & \\
\hline $\mathrm{C} 12$ & 86 & 92 & 99 & 78 & 110 & & & & & & & & & & & & & \\
\hline C18 & 61 & 59 & 110 & 107 & 58 & 87 & 85 & 82 & 119 & & & & & & & & & \\
\hline $\mathrm{C} 23$ & 110 & 99 & 96 & 65 & 95 & 93 & 85 & 66 & 91 & 99 & & & & & & & & \\
\hline $\mathrm{C42}$ & 73 & 111 & 83 & 69 & 114 & 114 & 121 & 152 & 129 & 173 & 142 & 151 & 156 & & & & & \\
\hline V19 & 90 & 91 & 89 & 113 & 135 & 153 & 182 & 192 & 192 & 167 & & & & & & & & \\
\hline V31 & 69 & 87 & 101 & 79 & 112 & 152 & 153 & 164 & 172 & 201 & 198 & 210 & 208 & 204 & 232 & & & \\
\hline V50 & 87 & 79 & 116 & 110 & 122 & 149 & 112 & 165 & 185 & 195 & 198 & 201 & 189 & 213 & 205 & 221 & 217 & 209 \\
\hline C11 & 80 & 87 & 90 & 89 & 111 & & & & & & & & & & & & & \\
\hline $\mathrm{C} 22$ & 104 & 93 & 75 & 99 & 83 & 87 & 99 & 88 & 90 & 127 & & & & & & & & \\
\hline C26 & 68 & 101 & 86 & 72 & 88 & 99 & 98 & 81 & 93 & 93 & 120 & & & & & & & \\
\hline V33 & 74 & 88 & 99 & 125 & 114 & 122 & 120 & 172 & 156 & 189 & 187 & 201 & 198 & 178 & 239 & & & \\
\hline V47 & 87 & 92 & 124 & 125 & 138 & 162 & 162 & 177 & 189 & 198 & 199 & 210 & & 221 & & 217 & 203 & \\
\hline V49 & 90 & 85 & 99 & 132 & 127 & 119 & 154 & 157 & 191 & 190 & 201 & 216 & & 234 & & 214 & 229 & 217 \\
\hline C14 & 74 & 76 & 108 & 82 & 93 & 108 & & & & & & & & & & & & \\
\hline C16 & 87 & 89 & 73 & 102 & 78 & 91 & 112 & & & & & & & & & & & \\
\hline C21 & 104 & 98 & 83 & 96 & 71 & 90 & 67 & 92 & 84 & 177 & & & & & & & & \\
\hline C27 & 94 & 117 & 102 & 94 & 105 & 84 & 59 & 83 & 101 & 82 & 118 & & & & & & & \\
\hline V20 & 73 & 49 & 89 & 110 & 98 & 93 & 87 & 92 & 82 & 102 & 123 & & & & & & & \\
\hline V35 & 78 & 92 & 91 & 96 & 182 & 186 & 128 & 164 & 178 & 195 & 179 & 198 & 201 & 231 & 271 & & & \\
\hline V41 & 79 & 83 & 98 & 124 & 93 & 126 & 146 & 167 & 174 & 193 & 199 & 203 & & 208 & & 210 & & \\
\hline C15 & 104 & 98 & 86 & 75 & 82 & 115 & & & & & & & & & & & & \\
\hline C19 & 48 & 84 & 93 & 101 & 82 & 82 & 98 & 85 & 128 & & & & & & & & & \\
\hline
\end{tabular}




\begin{tabular}{|c|c|c|c|c|c|c|c|c|c|c|c|c|c|c|c|c|c|c|}
\hline C29 & 95 & 55 & 72 & 108 & 103 & 98 & 83 & 99 & 102 & 110 & 134 & & & & & & & \\
\hline C33 & 68 & 68 & 101 & 62 & 103 & 83 & 90 & 88 & 109 & 132 & 145 & 171 & & & & & & \\
\hline V24 & 86 & 79 & 93 & 127 & 125 & 129 & 126 & 165 & 192 & 179 & 178 & 164 & 183 & 175 & & & & \\
\hline V32 & 93 & 85 & 92 & 145 & 190 & 143 & 201 & 124 & 182 & 198 & 199 & 187 & 193 & 159 & 176 & & & \\
\hline V39 & 78 & 82 & 110 & 99 & 102 & 121 & 162 & 190 & 192 & 182 & 198 & 210 & 195 & 224 & 196 & & & \\
\hline V5 & 76 & 92 & 94 & 98 & 102 & 148 & & & & & & & & & & & & \\
\hline C17 & 73 & 96 & 89 & 85 & 81 & 97 & 102 & & & & & & & & & & & \\
\hline C20 & 66 & 110 & 74 & 89 & 63 & 93 & 78 & 85 & 127 & & & & & & & & & \\
\hline C30 & 65 & 62 & 71 & 65 & 107 & 94 & 94 & 117 & 128 & 142 & 119 & & & & & & & \\
\hline C34 & 64 & 53 & 110 & 98 & 141 & 99 & 78 & 81 & 88 & 127 & 161 & 125 & & & & & & \\
\hline C38 & 89 & 71 & 91 & 86 & 126 & 104 & 78 & 72 & 89 & 98 & 89 & 178 & & & & & & \\
\hline V26 & 92 & 94 & 118 & 112 & 125 & 156 & 182 & 121 & 173 & 191 & 193 & 197 & 204 & 190 & 210 & & & \\
\hline V43 & 91 & 78 & 94 & 134 & 126 & 110 & 187 & 183 & 182 & 195 & 178 & 198 & & 204 & & 212 & 249 & \\
\hline V48 & 88 & 96 & 121 & 126 & 146 & 148 & 151 & 182 & 168 & 212 & 208 & 198 & & 210 & & 178 & 196 & \\
\hline V10 & 86 & 85 & 105 & 105 & 167 & 171 & 157 & & & & & & & & & & & \\
\hline C24 & 98 & 90 & 84 & 98 & 84 & 90 & 76 & 99 & 71 & 83 & & & & & & & & \\
\hline C25 & 62 & 102 & 86 & 69 & 63 & 104 & 87 & 99 & 128 & 110 & & & & & & & & \\
\hline C31 & 59 & 86 & 81 & 89 & 112 & 89 & 110 & 99 & 108 & 129 & 121 & & & & & & & \\
\hline C41 & 88 & 69 & 98 & 94 & 102 & 114 & 85 & 91 & 100 & 126 & 110 & 143 & & & & & & \\
\hline V27 & 76 & 79 & 108 & 90 & 172 & 187 & 132 & 178 & 189 & 204 & 175 & 203 & 189 & 169 & & & & \\
\hline C43 & 64 & 89 & 82 & 79 & 101 & 108 & 108 & 119 & 106 & 145 & 179 & 138 & & & & & & \\
\hline C50 & 88 & 53 & 78 & 84 & 121 & 109 & 112 & 109 & 104 & 126 & 119 & 172 & 178 & 193 & 231 & & & \\
\hline V34 & 95 & 86 & 99 & 108 & 117 & 176 & 199 & 132 & 165 & 173 & 201 & 200 & 97 & 199 & 198 & & & \\
\hline V42 & 86 & 96 & 99 & 118 & 99 & 182 & 142 & 194 & 190 & 187 & 190 & 201 & 211 & 198 & 219 & 189 & & \\
\hline V44 & 89 & 79 & 92 & 142 & 129 & 128 & 193 & 164 & 178 & 199 & 203 & 193 & & 203 & & 199 & 213 & \\
\hline C28 & 59 & 102 & 108 & 64 & 99 & 93 & 78 & 102 & 118 & 108 & & & & & & & & \\
\hline C44 & 106 & 92 & 82 & 75 & 90 & 108 & 112 & 120 & 123 & 145 & 110 & 117 & 143 & & & & & \\
\hline C49 & 81 & 98 & 81 & 65 & 117 & 107 & 120 & 143 & 108 & 125 & 156 & 182 & 172 & 245 & & & & \\
\hline V28 & 87 & 65 & 99 & 99 & 162 & 176 & 121 & 182 & 193 & 193 & 192 & 191 & 191 & 191 & & & & \\
\hline V30 & 89 & 92 & 86 & 131 & 124 & 176 & 152 & 192 & 210 & 185 & 194 & 174 & 184 & 199 & 202 & & & \\
\hline V45 & 84 & 69 & 99 & 127 & 131 & 103 & 165 & 152 & 187 & 201 & 207 & 201 & & 201 & & 201 & 253 & \\
\hline C32 & 100 & 84 & 79 & 97 & 151 & 77 & 89 & 97 & 119 & 129 & 128 & & & & & & & \\
\hline $\mathrm{C45}$ & 72 & 80 & 96 & 78 & 112 & 120 & 123 & 127 & 119 & 132 & 138 & 129 & 156 & & & & & \\
\hline V25 & 72 & 95 & 69 & 111 & 142 & 192 & 152 & 158 & 201 & 202 & 153 & 167 & 183 & 210 & & & & \\
\hline V29 & 75 & 83 & 83 & 89 & 133 & 134 & 139 & 123 & 176 & 210 & 128 & 185 & 208 & 198 & & & & \\
\hline V40 & 88 & 94 & 106 & 106 & 110 & 114 & 126 & 177 & 190 & 188 & 146 & 199 & 209 & 178 & 200 & 223 & & \\
\hline V46 & 86 & 90 & 118 & 139 & 142 & 151 & 173 & 169 & 198 & 201 & 204 & 189 & & 195 & & 200 & 216 & \\
\hline V13 & 67 & 88 & 94 & 90 & 116 & 142 & 192 & & & & & & & & & & & \\
\hline C46 & 71 & 49 & 90 & 76 & 138 & 98 & 91 & 101 & 135 & 106 & 119 & 156 & & & & & & \\
\hline C47 & 83 & 90 & 95 & 91 & 93 & 100 & 110 & 102 & 189 & 167 & 210 & 167 & 148 & & & & & \\
\hline C48 & 68 & 107 & 84 & 77 & 125 & 101 & 117 & 174 & 123 & 144 & 129 & 142 & 167 & & & & & \\
\hline V37 & 89 & 90 & 87 & 98 & 126 & 148 & 178 & 198 & 210 & 225 & 165 & 214 & 205 & 217 & & & & \\
\hline V21 & 94 & 117 & 102 & 94 & 105 & 84 & 59 & 83 & 101 & 82 & 118 & & & & & & & \\
\hline V22 & 67 & 83 & 93 & 89 & 112 & 86 & 99 & 89 & 92 & 72 & 156 & & & & & & & \\
\hline C35 & 67 & 83 & 93 & 89 & 112 & 86 & 99 & 89 & 92 & 72 & 156 & & & & & & & \\
\hline C36 & 87 & 67 & 72 & 89 & 87 & 108 & 88 & 90 & 98 & 102 & 89 & & & & & & & \\
\hline C39 & 71 & 76 & 106 & 86 & 117 & 99 & 101 & 97 & 125 & 106 & 95 & & & & & & & \\
\hline C40 & 93 & 66 & 102 & 57 & 99 & 107 & 89 & 99 & 99 & 121 & 132 & & & & & & & \\
\hline V36 & 78 & 99 & 91 & 109 & 164 & 156 & 155 & 143 & 199 & 187 & 203 & 210 & 186 & 205 & & & & \\
\hline $\mathrm{V} 23$ & 89 & 69 & 98 & 88 & 147 & 137 & 182 & 199 & 210 & 189 & 186 & & & & & & & \\
\hline V38 & 84 & 99 & 93 & 122 & 154 & 156 & 110 & 201 & 208 & 197 & 189 & 218 & 194 & 199 & & & & \\
\hline C37 & 95 & 55 & 72 & 108 & 103 & 98 & 83 & 99 & 102 & 110 & 134 & & & & & & & \\
\hline
\end{tabular}


Table S4.

Levels of plasma VEGF (pg/ml) measured in all male mice used for lifespan studies.

VEGF levels in censored mice are indicated in bold

\begin{tabular}{|c|c|c|c|c|c|c|c|c|c|c|c|c|c|c|c|c|c|c|}
\hline Months & 2 & 4 & 6 & 8 & 10 & 12 & 14 & 16 & 18 & 20 & 22 & 24 & 26 & 28 & 30 & 32 & 34 & 36 \\
\hline $\mathrm{C4}$ & 70 & 78 & 82 & 106 & 98 & 98 & 92 & 89 & 107 & & & & & & & & & \\
\hline V2 & 73 & 61 & 80 & 97 & 137 & 124 & 208 & 178 & 223 & 198 & & & & & & & & \\
\hline V11 & 77 & 97 & 69 & 97 & 165 & 141 & 181 & 111 & 167 & 181 & 197 & 202 & 210 & 187 & & & & \\
\hline V12 & 69 & 78 & 72 & 93 & 159 & 161 & 119 & 130 & 159 & 163 & 205 & 185 & 203 & 196 & & & & \\
\hline $\mathrm{C} 2$ & 56 & 79 & 67 & 89 & 89 & 61 & 90 & 87 & 92 & & & & & & & & & \\
\hline $\mathrm{C3}$ & 73 & 96 & 89 & 85 & 81 & 97 & 87 & 87 & 107 & & & & & & & & & \\
\hline C11 & 59 & 76 & 81 & 89 & 112 & 89 & 88 & 99 & 108 & 129 & 121 & & & & & & & \\
\hline V16 & 55 & 65 & 89 & 84 & 85 & 106 & 171 & 178 & 186 & 172 & 202 & 189 & 201 & 221 & 197 & 199 & & \\
\hline V26 & 70 & 82 & 73 & 82 & 102 & 125 & 123 & 170 & 157 & 146 & 168 & 169 & 136 & 187 & 175 & 196 & 192 & 196 \\
\hline C5 & 62 & 92 & 85 & 93 & 73 & 69 & 89 & 78 & 125 & & & & & & & & & \\
\hline V7 & 59 & 62 & 93 & 82 & 125 & 149 & 176 & 109 & 190 & 135 & 207 & & & & & & & \\
\hline V8 & 77 & 60 & 65 & 108 & 112 & 141 & 191 & 120 & 149 & 216 & 170 & & & & & & & \\
\hline C6 & 61 & 59 & 62 & 107 & 58 & 76 & 85 & 82 & 119 & & & & & & & & & \\
\hline V4 & 66 & 52 & 77 & 73 & 112 & 122 & 191 & 170 & 204 & 179 & & & & & & & & \\
\hline $\mathrm{C14}$ & 88 & 69 & 98 & 106 & 102 & 114 & 121 & 132 & 100 & 126 & 110 & 143 & & & & & & \\
\hline V20 & 61 & 67 & 69 & & 97 & 88 & 192 & 180 & 170 & 137 & 213 & 202 & 215 & & 201 & 249 & 229 & \\
\hline V1 & 67 & 70 & 73 & 86 & 118 & 105 & 125 & 181 & & & & & & & & & & \\
\hline C7 & 66 & 89 & 74 & 87 & 63 & 65 & 78 & 85 & 127 & 123 & & & & & & & & \\
\hline C17 & 72 & 80 & 84 & 78 & 112 & 120 & 123 & 127 & 119 & 132 & 138 & 129 & 156 & & & & & \\
\hline C19 & 81 & 88 & 81 & 65 & 117 & 107 & 120 & 143 & 108 & 125 & 134 & 182 & 172 & 245 & 210 & & & \\
\hline V17 & 59 & 73 & 73 & 121 & 108 & 178 & 191 & 144 & 172 & 184 & 187 & 174 & 204 & 221 & 218 & 203 & & \\
\hline V28 & 64 & 75 & 103 & 119 & 121 & 95 & 171 & 165 & 183 & 188 & 203 & 202 & & 218 & & 212 & 184 & 196 \\
\hline V3 & 63 & 68 & 84 & 90 & 150 & 156 & 166 & 187 & & & & & & & & & & \\
\hline $\mathrm{C} 10$ & 68 & 86 & 78 & 90 & 88 & 99 & 98 & 81 & 93 & 93 & & & & & & & & \\
\hline V10 & 78 & 49 & 48 & 96 & 125 & 177 & 184 & 160 & 192 & 192 & 157 & 159 & & & & & & \\
\hline V27 & 63 & 79 & 78 & 124 & 82 & 136 & 151 & 182 & 166 & 177 & 194 & 193 & 217 & 195 & 220 & 184 & 260 & \\
\hline $\mathrm{C} 1$ & 68 & 92 & 99 & 78 & 110 & 118 & & & & & & & & & & & & \\
\hline C8 & 48 & 94 & 83 & 101 & 82 & 98 & 98 & 85 & 128 & & & & & & & & & \\
\hline V18 & 58 & 53 & 86 & 69 & 100 & 184 & 201 & 147 & 186 & 193 & 196 & 166 & 207 & 195 & 202 & 211 & & \\
\hline V30 & 63 & 73 & 97 & 103 & 125 & 167 & 182 & 157 & 192 & 191 & 208 & 181 & & 192 & & 195 & 207 & 209 \\
\hline V5 & 44 & 71 & 73 & 75 & 99 & 127 & 191 & 203 & 212 & 208 & & & & & & & & \\
\hline $\mathrm{C} 12$ & 73 & 49 & 89 & 110 & 98 & 93 & 87 & 92 & 82 & 102 & & & & & & & & \\
\hline V31 & 56 & 66 & 77 & 111 & 76 & 133 & 155 & 155 & 150 & 183 & 203 & 195 & & 205 & & 205 & 195 & \\
\hline V32 & 68 & 61 & 73 & 110 & 109 & 147 & 196 & 171 & 172 & 185 & 182 & 190 & & 201 & & 207 & 216 & \\
\hline C9 & 90 & 99 & 83 & 85 & 91 & 96 & 89 & 92 & 118 & & & & & & & & & \\
\hline V6 & 70 & 65 & 68 & 109 & 130 & 142 & 171 & 152 & 178 & 198 & & & & & & & & \\
\hline $\mathrm{C13}$ & 67 & 83 & 93 & 89 & 112 & 86 & 99 & 89 & 92 & 72 & & & & & & & & \\
\hline V34 & 67 & 68 & 78 & 127 & 110 & 113 & 163 & 145 & 185 & 180 & 205 & 208 & & 231 & & 209 & 223 & 222 \\
\hline V9 & 61 & 68 & 69 & 116 & 118 & 167 & 163 & 180 & 180 & 181 & 196 & & & & & & & \\
\hline C15 & 56 & 74 & 79 & 97 & 151 & 77 & 89 & 97 & 119 & 129 & 128 & & & & & & & \\
\hline $\mathrm{C} 16$ & 71 & 76 & 86 & 86 & 117 & 99 & 93 & 97 & 125 & 106 & 95 & & & & & & & \\
\hline V13 & 62 & 87 & 53 & 75 & 173 & 172 & 162 & 186 & 183 & 194 & 179 & 190 & 195 & & & & & \\
\hline V14 & 72 & 63 & 61 & 106 & 95 & 178 & 129 & 180 & 196 & 168 & 188 & 187 & 200 & 215 & & & & \\
\hline C20 & 47 & 76 & 98 & 82 & 93 & 108 & 89 & 112 & & & & & & & & & & \\
\hline C24 & 99 & 87 & 87 & 81 & 67 & 99 & 93 & 93 & 114 & & & & & & & & & \\
\hline V36 & 82 & 55 & 70 & 94 & 147 & 141 & 207 & 131 & 171 & 177 & 207 & 202 & & & & & & \\
\hline
\end{tabular}




\begin{tabular}{|c|c|c|c|c|c|c|c|c|c|c|c|c|c|c|c|c|c|c|}
\hline C26 & 56 & 59 & 82 & 82 & 68 & 89 & 83 & 72 & 92 & 197 & & & & & & & & \\
\hline V24 & 60 & 84 & 65 & 95 & 145 & 141 & 195 & 166 & 195 & 180 & & & & & & & & \\
\hline C38 & 56 & 55 & 99 & 118 & 122 & 68 & 92 & 72 & 156 & 128 & 124 & 128 & & & & & & \\
\hline V38 & 73 & 66 & 66 & 83 & 109 & 133 & 195 & 162 & 204 & 215 & 169 & 206 & 211 & & & & & \\
\hline V49 & 64 & 62 & 95 & 112 & 105 & 134 & 121 & 153 & 179 & 185 & 202 & 193 & 195 & 210 & 206 & 216 & 220 & 210 \\
\hline V15 & 53 & 75 & 73 & 83 & 85 & 133 & 156 & 171 & & & & & & & & & & \\
\hline C21 & 87 & 89 & 73 & 102 & 78 & 91 & 92 & 99 & 102 & & & & & & & & & \\
\hline $\mathrm{C} 22$ & 83 & 95 & 93 & 101 & 74 & 63 & 88 & 119 & 108 & & & & & & & & & \\
\hline $\mathrm{C} 23$ & 77 & 76 & 102 & 99 & 73 & 89 & 94 & 121 & 116 & & & & & & & & & \\
\hline V35 & 58 & 53 & 101 & 68 & 115 & 133 & 173 & 152 & 189 & 144 & 178 & 186 & & & & & & \\
\hline C31 & 65 & 62 & 71 & 65 & 107 & 94 & 94 & 117 & 128 & 142 & 119 & & & & & & & \\
\hline C44 & 73 & 83 & 99 & 93 & 99 & 124 & 128 & 123 & 105 & 142 & 123 & 126 & & & & & & \\
\hline V37 & 66 & 62 & 52 & 74 & 116 & 119 & 214 & 180 & 170 & 200 & 132 & 177 & & & & & & \\
\hline V42 & 46 & 80 & 70 & 64 & 155 & 137 & 141 & 160 & 184 & 191 & 202 & 188 & 214 & 201 & & & & \\
\hline C30 & 54 & 117 & 73 & 94 & 105 & 84 & 59 & 83 & 101 & 82 & & & & & & & & \\
\hline V25 & 55 & 70 & 62 & 117 & 169 & 134 & 144 & 189 & 131 & 173 & & & & & & & & \\
\hline V33 & 62 & 63 & 72 & 112 & 108 & 114 & 181 & 112 & 191 & 169 & 189 & 192 & & & & & & \\
\hline C41 & 71 & 49 & 90 & 96 & 138 & 112 & 91 & 101 & 123 & 106 & 119 & 156 & & & & & & \\
\hline $\mathrm{C} 43$ & 64 & 79 & 82 & 79 & 101 & 108 & 108 & 119 & 106 & 145 & 179 & 138 & & & & & & \\
\hline V40 & 48 & 78 & 64 & 84 & 145 & 161 & 210 & 187 & 187 & 183 & 196 & 183 & 197 & & & & & \\
\hline C49 & 73 & 85 & 83 & 69 & 114 & 114 & 121 & 152 & 129 & 173 & 122 & 151 & 156 & 167 & 154 & & & \\
\hline V48 & 65 & 79 & 100 & 109 & 129 & 111 & 160 & 170 & 162 & 202 & 212 & 190 & & 207 & & 173 & 206 & 189 \\
\hline C27 & 54 & 98 & 83 & 113 & 71 & 64 & 67 & 92 & 84 & 177 & & & & & & & & \\
\hline $\mathrm{C} 28$ & 98 & 84 & 90 & 99 & 84 & 72 & 76 & 99 & 71 & 83 & & & & & & & & \\
\hline C32 & 75 & 55 & 72 & 108 & 103 & 98 & 83 & 99 & 102 & 110 & & & & & & & & \\
\hline V43 & 70 & 71 & 68 & 130 & 161 & 128 & 130 & 153 & 176 & 188 & 203 & 191 & 199 & 206 & & & & \\
\hline C18 & 67 & 87 & 90 & 89 & 111 & 123 & & & & & & & & & & & & \\
\hline V21 & 85 & 90 & 101 & 87 & 94 & 111 & 126 & 164 & 140 & 128 & & & & & & & & \\
\hline V22 & 72 & 62 & 74 & 81 & 170 & 167 & 161 & 196 & 168 & 140 & & & & & & & & \\
\hline C47 & 68 & 52 & 82 & 75 & 90 & 108 & 112 & 120 & 123 & 145 & 110 & 117 & 143 & & & & & \\
\hline $\mathrm{C} 48$ & 68 & 77 & 84 & 77 & 125 & 101 & 117 & 144 & 123 & 144 & 129 & 142 & 167 & & & & & \\
\hline V47 & 66 & 62 & 71 & 117 & 112 & 104 & 202 & 152 & 170 & 189 & 207 & 185 & & 200 & & 194 & 218 & \\
\hline C29 & 84 & 75 & 93 & 78 & 83 & 87 & 99 & 88 & 90 & 127 & & & & & & & & \\
\hline V23 & 67 & 74 & 68 & 98 & 105 & 138 & 128 & 188 & 186 & 157 & & & & & & & & \\
\hline C39 & 63 & 66 & 82 & 57 & 99 & 107 & 89 & 99 & 99 & 121 & 132 & & & & & & & \\
\hline C40 & 68 & 68 & 71 & 62 & 103 & 83 & 90 & 88 & 118 & 132 & 145 & & & & & & & \\
\hline V45 & 55 & 75 & 70 & 81 & 107 & 171 & 161 & 152 & 176 & 185 & 183 & 195 & 207 & 228 & 272 & 254 & & \\
\hline $\mathrm{C} 25$ & 54 & 98 & 86 & 75 & 82 & 115 & 89 & 98 & 132 & & & & & & & & & \\
\hline $\mathrm{C45}$ & 64 & 53 & 69 & 108 & 141 & 115 & 78 & 81 & 99 & 127 & 161 & 125 & & & & & & \\
\hline C46 & 89 & 71 & 91 & 99 & 126 & 104 & 112 & 123 & 134 & 98 & 82 & 178 & & & & & & \\
\hline C50 & 88 & 53 & 78 & 84 & 121 & 109 & 112 & 109 & 104 & 126 & 119 & 172 & 178 & 193 & 208 & & & \\
\hline V50 & 61 & 52 & 78 & 95 & 114 & 101 & 174 & 140 & 181 & 191 & 211 & 193 & & 198 & & 196 & 205 & 246 \\
\hline C33 & 62 & 86 & 79 & 81 & 63 & 104 & 87 & 99 & 128 & 110 & & & & & & & & \\
\hline C37 & 87 & 57 & 94 & 135 & 85 & 82 & 78 & 119 & 181 & 99 & & & & & & & & \\
\hline V39 & 68 & 65 & 69 & 116 & 118 & 161 & 202 & 185 & 214 & 180 & 202 & 189 & & & & & & \\
\hline V46 & 65 & 77 & 85 & 91 & 93 & 99 & 135 & 165 & 184 & 178 & 150 & 179 & 215 & 175 & 201 & 218 & 225 & \\
\hline V19 & 70 & 67 & 87 & 100 & 124 & 137 & 128 & 154 & 157 & & & & & & & & & \\
\hline C34 & 56 & 85 & 98 & 87 & 93 & 102 & 78 & 75 & 82 & 101 & & & & & & & & \\
\hline C42 & 87 & 67 & 72 & 89 & 87 & 108 & 88 & 90 & 98 & 102 & 89 & & & & & & & \\
\hline V44 & 51 & 78 & 71 & 110 & 111 & 107 & 171 & 146 & 168 & 179 & 191 & 193 & 204 & 175 & 240 & & & \\
\hline C35 & 78 & 96 & 99 & 93 & 95 & 93 & 85 & 66 & 91 & 99 & & & & & & & & \\
\hline C36 & 59 & 98 & 81 & 90 & 99 & 93 & 78 & 102 & 118 & 108 & & & & & & & & \\
\hline V29 & 64 & 66 & 66 & 92 & 150 & 132 & 135 & 166 & 140 & 124 & & & & & & & & \\
\hline V41 & 82 & 72 & 61 & 107 & 137 & 141 & 208 & 124 & 202 & 187 & 193 & 210 & 200 & & & & & \\
\hline
\end{tabular}

